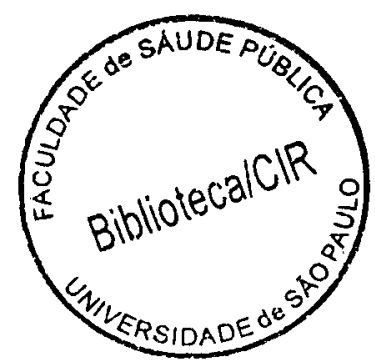

\title{
CONSUMO ENERGÉTICO E AUMENTO PONDERAL DURANTE A GESTAÇÃO
}

\author{
ROSEMARIE ANDREAZZA
}

Tese de doutorado apresentada ao Departamento de Nutrição da Faculdade de Saúde Pública da Universidade de São Paulo para obtenção do Grau de Doutor.

Área de concentração:

Nutrição

ORIENTADORA: PROFA. DRA. MARIA HELENA D' AQUINO BENÍCIO

São Paulo

2000 
"(...) Sabido é que todo efeito tem sua causa, e esta é uma universal verdade, porém, não é possivel evitar alguns erros de juízo, ou de simples identificação, pois acontece considerarmos que este efeito provém daquela causa, quando afinal ela foi outra, muito fora do alcance do entendimento que temos e da ciência que julgávamos ter $(. . .)^{n}$

José Saramago - A Jangada de Pedra, 1988 
(...), nós somos demasiado ignorantes individualmente, cada um de nós, para poder elaborar toda uma teoria sólida. (...)Menos ainda nestes momentos do mundo."

Che Guevara

\section{Obrigada,}

Maria Helena D'Aquino Benício (minha orientadora nesse trabalho); Wladimir Taborda, Vera, Maria do Carmo e Rose - do "Amparo Maternal" (sem vocês esse trabalho não teria sido realizado); Mônica - a primeira -, Ana Paula, Ana

Cristina, Tamara, Flávia e Maria José (que fizeram acontecer o "campo"); Marrisol, Juliana e Caroline (pela paciência no minucioso e cuidadoso trabalho de cálculo dos inquéritos alimentares); Fernanda e Renata (que se somaram à equipe no momento em que quase já não havia mais tempo, vocês ajudaram a fazer o impossivel!); Anita e Mary (amigas de muito tempo, pelas discussões e pelo resumo em inglês); Myrian e Ana Lúcia (amigas e companheiras .....sempre, não importa onde, por tudo); Peninha/ José Eduardo Moncau (orientador dos meus trabalhos); Flory Cabral Senna (amiga, antes de tudo, mas também pela "delicada e carinhosa" revisão do português); Sandra, Nicanor, Pasca e Lacaz (que hoje fazem parte do meu dia- a-dia, e que dias!); Maria (pela "paz" trazida ao lar e pelos cafés, bolinhos..!); meus companheiros do movimento docente, em especial, os amigos da diretoria da Associação dos Docentes da Escola Paulista de

Medicina - ADEPM (com quem divido e aprendo todo dia o significado de ser Professor, compartilhando o desafio de construir uma Universidade mais democrática e socialmente referenciada).

À minha grande pequena família, meu pai, Nelson (que me ensinou a questionar os fatos) e a irmã, Jeane (minha amiga de sempre, não importa a razão).

Finalmente, às minhas duas estrelas:

Dora, minha doce e vibrante mãe, que me deu à luz e Eliete, a amiga, que sempre compartilhou a sua luz (pelo exemplo de luta, solidariedade, carinho, amor enfim de vida). 


\section{ÍNDICE}

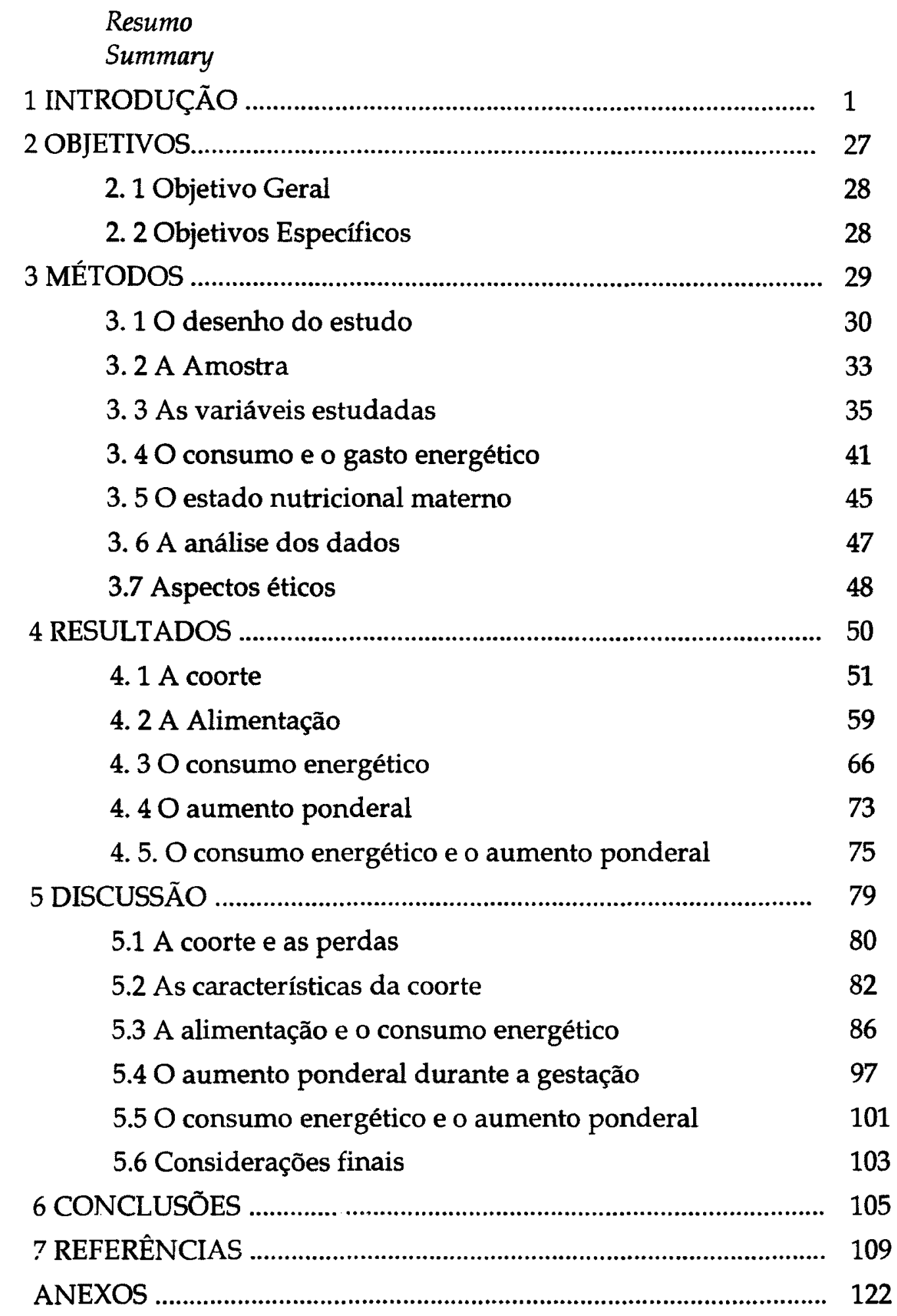




\section{RESUMO}

Andreazza, R. O consumo energético e o aumento ponderal durante a gestação. São Paulo; 1999. [Tese de Doutorado - Faculdade de Saúde Pública da USP].

Objetivo: Verificar a influência do consumo energético no ganho de peso durante a gestação em mulheres de baixa renda, atendidas em serviço de pré-natal. Métodos: Estudou-se uma coorte de gestantes, que inciaram a assistência pré-natal de março de 1997 a março de 1998 no serviço "Amparo Maternal", São Paulo, apresentando na primeira entrevista idade gestacional inferior a 17 semanas. Foram incluídas na coorte 261 mulheres, observandose uma perda de $45(19,8 \%)$ gestantes. Para se estimar o consumo energético aplicou-se o questionário de freqüência de consumo de alimentos em 3 momentos durante a gestação. Visando a verificar a adequação deste consumo energético, aplicou-se nos momentos, referidos anteriormente, um questionário de frequuência de atividades físicas diárias. $O$ gasto energético destes períodos foi calculado a partir da taxa de metabolismo basal (TMB), estimado segundo as equações propostas pela OMS,1985, acrescidas de um valor energético conforme o trimestre de gestação. $\grave{A}$ TMB total foi acrescentado, como múltiplos desta taxa, o gasto energético para o desenvolvimento de grupo de atividades físicas (RDA,1899). As gestantes foram categorizadas, segundo o estado nutricional inicial, obtido pelo Índice de massa corpórea (IMC). Calculou-se o ganho de peso total e por semana de gestação nos três períodos: analisados segundo o estado nutricional inicial. Resultados: A mediana de consumo de energia aumentou de forma progressiva, 2.344, 2.403 e $2.508 \mathrm{kcal}$, no primeiro, segundo e terceiro períodos da gravidez. Verificou-se que as mulheres com baixo peso e eutrofia apresentaram uma ingestão energética maior do que aquela observada entre as gestantes com sobrepeso e obesidade. O consumo de calorias foi superior, 
ou muito próximo, ao gasto energético nas mulheres da coorte, a não ser nas gestantes com obesidade inicial, onde o gasto foi sempre superior ao consumo de energia, e nas com sobrepeso inicial, que no terceiro intervalo, também, apresentaram o mesmo comportamento. As gestantes eutróficas e com baixo peso inicial apresentaram uma aumento ponderal maior em relação às com sobrepeso e obesidade. A partir da análise da regressão linear múltipla entre o consumo energético sobre o desempenho de ganho de peso ao longo da gestação, os modelos foram construídos para cada intervalo, controlando-se o tempo entre as observações, o peso inicial do período, a estatura, a idade e a paridade. O consumo de energia associou-se, positivamente, com o aumento ponderal no início e no segundo período de gestação. Conclusão: A associação entre o consumo de energia e o ganho de peso durante a gestação foi positiva durante o primeiro e o segundo trimestres de gestação, portanto, em um momento da gravidez, em que é possível a realização de intervenções nutricionais/alimentares, visando um aumento ponderal suficiente para garantir, não só um ótimo crescimento fetal, mas também um acúmulo adequado de gordura nos tecidos maternos.

Descritores: Gestação; Consumo energético; Ganho de peso 


\section{SUMMARY}

Andreazza, R. $O$ consumo energético e o aumento ponderal durante a gestação. [Energy intake and weight gain during pregnancy] São Paulo (BR); 1999. [Tese de Doutorado - Faculdade de Saúde Pública da USP].

Objective. To Verify the influence of energy intake on weight gain during pregnancy. Methods. A longitudinal cohort of pregnant women who began pre-natal care in March 1997 at "Amparo Maternal"- São Paulo, Brazil and who presented on the first interview a gestational age bellow to 17 weeks was studied. The cohort started with 261 women of which $45(19.8 \%)$ were lost. The following characteristics were examined in order to describe the sample: age, schooling, parity, interval between deliveries, and smoking habits. In order to determine the energy intake a food frequency questionnaire was administered at 3 different moments during gestation; first trimester and beginning of the second (first period), in the middle of the second trimester (second), and finally during the third trimester (third). With the aim of checking the adequacy of the energy intake a physical daily activity questionnaire was also administered at the same moments referred above. The energy cost for these periods was obtained from metabolic basal rate (BMR), using the WHO,1985 equations, adding an energy value according to the gestational trimester. The energy cost was calculated according to what was suggested by RDA, 1989. The subjects were put into categories according to their nutritional status obtained from the body mass index (BMI), weight and gestational age when joining the cohort. The total and gestational week weight gain were calculated at three different moments taking into account the initial nutritional status. Results. The median energy intake increased progressively, 2,344, 2,403 and 2,508 kcal, in the first, second and third periods of the gestation. It was observed that the underweight and normal subjects before pregnancy had a higher energy intake than that of the overweight or obese subjects. The calorie consumption was above or very 
close to the energy cost for the subjects of the cohort, except for the women who were obese at the beginning, for whom the cost was always above the energy intake and for the overweight ones who also showed the behavior described above for obese subjects in the third period. The normal and underweight subjects had a higher weight gain than that of the overweight and obese. Conclusions. The association between energy intake and weight gain during the gestation was positive during the first and second trimesters. Therefore, at a gestational moment in which it is possible to give nutritional counseling in order to guarantee enough weight gain not only for an excellent fetal development, but also to have an adequate fat store in the maternal tissues and to prevent and or control the development of postpartum obesity.

Descriptors: pregnancy, energy intake, weight gain 
INTRODUÇÃO 


\section{INTRODUÇÃO}

\section{O PROBLEMA}

Promover uma nutrição adequada durante a gestação, não só garantindo um aporte suficiente de energia e de nutrientes ao feto como também a manutenção da saúde materna, tem sido, há muito, objeto de investigações e de recomendações alimentares. $\mathrm{O}$ aumento ponderal durante a gestação é reconhecido como um dos fatores que pode influenciar de forma direta o crescimento fetal, sendo, assim, foco de várias normatizações tanto clínicas, quanto de saúde pública. Essas têm variado ao longo do tempo, passando de indicações que restringiam o aumento ponderal a menos de 9 $\mathrm{kg}$, com o objetivo de prevenir os quadros de toxemia gravídica e complicações no parto por distócia fetal, nas décadas de 40 e 50, a uma liberação desse ganho na década de 60 . Essa mudança de orientação foi resultado dos estudos que evidenciavam a associação entre o ganhı de peso materno e o peso de nascimento, e a mortalidade perinatal. Já a partir dos anos 70, as recomendações indicavam um aumento ponderal diferenciado, 
segundo o estado nutricional pré-gestacional (Naeye, 1979; Brown et al.,1986; Abrams \& Laros, 1986; Brown, 1988; Institute of Medicine -USA, 1990a ).

Frente a essas recomendações - alimentares e de aumento ponderal foram elaborados diversos instrumentos de monitoramento do ganho de peso durante a gestação, visando a detectar o risco de retardo de crescimento intra-uterino e, assim, propor ou encaminhar as mulheres para ações do tipo suplementação alimentar e/ou orientações nutricionais específicas (Gueri et al., 1982; Lechtig, 1988; Rosso, 1985; Krasovec, 1991).

Em meados da década de 90, a Organização Mundial de Saúde (OMS) publica extensa revisão acerca de aspectos metodológicos, ligados à avaliação antropométrica durante a gestação (World Health Organization - WHO, 1995 a). Os resultados do WHO Collaborative Study, 1995 - estudo de metaanálise de 25 investigações de seguimento de gestantes - contribuíram para a discussão da utilização de curvas de monitoração do aumento ponderal, durante a gravidez, com o objetivo de discriminar a ocorrência não só de baixo peso ao nascer, mas também de retardo de crescimento intra-uterino (RCIU) e, ainda, de nascimentos prematuros.

Os resultados do estudo colaborativo da OMS e de outras pesquisas indicam que a utilização das curvas de monitoração do aumento ponderal na gravidez é ainda um campo em aberto e merece maior número de estudos que visem discutir como, através do estado nutricional materno, avaliado pela antropometria, pode-se prever o crescimento fetal. E, ainda, como estes instrumentos de monitoração do ganho de peso durante a gestação podem auxiliar e até mesmo apontar a orientação alimentar mais adequada à gestante, objetivando um aumento ponderal condizente com a manutenção do estado de saúde da mulher (WHO, 1995a; WHO Collaborative Study, 1995; Andreazza et al., 1995; Atalah et al., 1997).

O papel da dieta durante a gestação e a sua relação com o ganho de peso e, consequientemente, com o peso do recém-nascido, tem merecido 
maior atenção nos últimos anos, não só com referência à saúde da criança, mas também, em relação ao estado nutricional materno. O aumento do tecido adiposo materno e o efeito deste na sua saúde, principalmente na ocorrência da obesidade, que hoje é altamente prevalente tanto em países desenvolvidos como em regiões menos desenvolvidas, tem sido foco de várias investigações (Lederman, 1993; Boardley et al., 1995; Monteiro et al., 1995; Lederman et al., 1997; Coitinho, 1998).

As gestações consecutivas têm sido destacadas como um dos fatores responsáveis pelo aumento de peso entre as mulheres (Manson et al., 1994). Apesar da crença comum, e até mesmo popular, de que o ganho ponderal durante a gestação não é totalmente perdido após o parto, e que, sendo assim, gravidezes sucessivas levariam ao sobrepeso e à obesidade, nem sempre essa associação tem sido demostrada. Em sociedades subdesenvolvidas, tem-se encontrado, inclusive, associação entre a perda de peso nas mulheres e o número de gestações, com intervalos interpartais pequenos (WHO, 1997; Coitinho, 1998).

Várias investigações, em diferentes sociedades e etnias, foram realizadas nos últimos anos com o objetivo central de elucidar a relação entre obesidade e gravidez. Nesses trabalhos, a principal conclusão é de que o ganho de peso excessivo, durante sucessivas gestações, associado a mudanças no estilo de vida após o parto, pode estar contribuindo de forma importante para o aumento de peso da população feminina, alguns estudos demostram, inclusive, uma modificação da relação cintura/quadril, já após a primeira gravidez (Öhlin \& Rössner, 1990; Parham et al., 1990; Rodin et al. 1990; Tonkelaar et al., 1990; Rössner, 1992; Lederman, 1993; Smith et al., 1994; Boardley et al., 1995).

Assim, a gestação não necessariamente levará à óbesiudade, entretanto, parece que um incremento ponderal excessivo nesse periodo, associado a outros fatores podem contribuir, para o desenvolvimento desta doença. Pela 
associação da obesidade com o aparecimento e/ou agravamento de outros problemas de saúde na vida adulta, pela dificuldade e mesmo pelo fracasso de tratamento, a implementação de ações visando à sua prevenção são urgentes e, talvez, a única maneira de diminuir essa patologia que atinge parcelas consideráveis da população, em especial as mulheres, seja em países desenvolvidos, seja em sociedades menos desenvolvidas. Portanto, as ações de nutrição durante o pré-natal devem, necessariamente, incorporar essa preocupação, agindo, também, no sentido da promoção de saúde das mulheres (Manson, et al., 1994; WHO, 1997; Coitinho, 1998; Sichieri, 1998).

Merchant \& Martorell (1988) em artigo de revisão, comentam, a partir de alguns diagramas, os mecanismos fundamentais na manutenção do balanço energético, durante o ciclo reprodutivo da mulher. Reafirmam que a energia proveniente da ingestão dietética transforma-se na energia disponível. Esta vai ser utilizada, de forma esquemática, na realização do trabalho, incluindo aí todas as atividades físicas diárias, na manutenção e recuperação dos diferentes tecidos maternos e, finalmente, no depósito de proteínas e gorduras nos tecidos do feto e na manutenção da placenta. Esses autores reforçam a hipótese de que, durante a gestação, as reservas de tecido adiposo desempenham papel fundamental no balanço de energia e, portanto, a forma de ganho de tecido gorduroso ao longo da gestação - velocidade e localização da deposição - influencia o crescimento fetal.

Uma das recomendações desses autores, já em 1988, é a elaboração de estudos longitudinais que descrevam, além das medidas antropométricas durante a gestação, também o consumo alimentar e o padrão de atividade física, incluindo aí o trabalho materno.

Susser (1991) discute a possível seqüência causal entre nutrição materna, ganho de peso durante a gestação e o peso do recém-nascido. Para o autor, existem evidências mais do que suficientes na literatura que descrevem essa relação em situação extrema de fome, na qual a desnutrição 
materna ocorre de forma severa. No entanto, essa associação não aparece de forma tão linear em situações intermediárias, ou mesmo quando o problema com o acesso aos alimentos já foi superado. Nessas situações, o ganho de peso durante a gestação, como medida indireta da nutrição materna, influencia, quando o faz, de forma muito modesta, o peso do recém-nascido, criando, talvez, a falsa impressão de que, na verdade, estes fatores, e principalmente o estado nutricional, não estão relacionados com o peso do recém-nascido. Dessa forma, o autor recomenda a realização de pesquisas onde o foco central seja o entendimento do papel da dieta e do estado nutricional materno no crescimento fetal. Aponta a necessidade de se levar em conta, nestes estudos, a heterogeneidade fisiológica, o metabolismo de gorduras e de energia e o gasto energético. Os efeitos do estado nutricional pré-gestacional, da composição da alimentação e, mais, o acompanhamento durante esse período das modificações do padrão alimentar, associados às alterações das medidas antropométricas, principalmente o peso, podem ser fundamentais para um entendimento mais definitivo das relações entre nutrição materna e o peso do recém-nascido e, entre o ganho de peso durante gestação e a ocorrência da obesidade.

O questionamento, hoje, até da prática de pesagem sistemática das gestantes nos serviços de pré-natal, baseia-se na baixa acurácia dos instrumentos existentes para monitorar, a partir da antropometria, o estado nutricional materno e mais, na incapacidade destes em prever o risco de retardo de crescimento intra-uterino (Dawes, et al., 1992; Garner et al., 1992; Yu \& Jackson, 1995). Assim, mesmo amplamente difundida, a antropometria materna necessita, para melhor interpretação de seus resultados, não ser avaliada isoladamente, mas outros fatores relacionados com a mulher e com a sua vida devem ser incorporados à análise.

Na Figura 1, adaptada do livro "Nutrition during pregnancy" (Institute of Medicine - USA, 1990a), é possível visualizar de forma esquemática as 
diferentes variáveis que influenciam, durante a gestação, a saúde da mulher e da criança.

Figura 1: Esquema sumarizado dos determinantes do ganho de peso durante a gestação e possíveis consequiências na saúde materna e infantil A

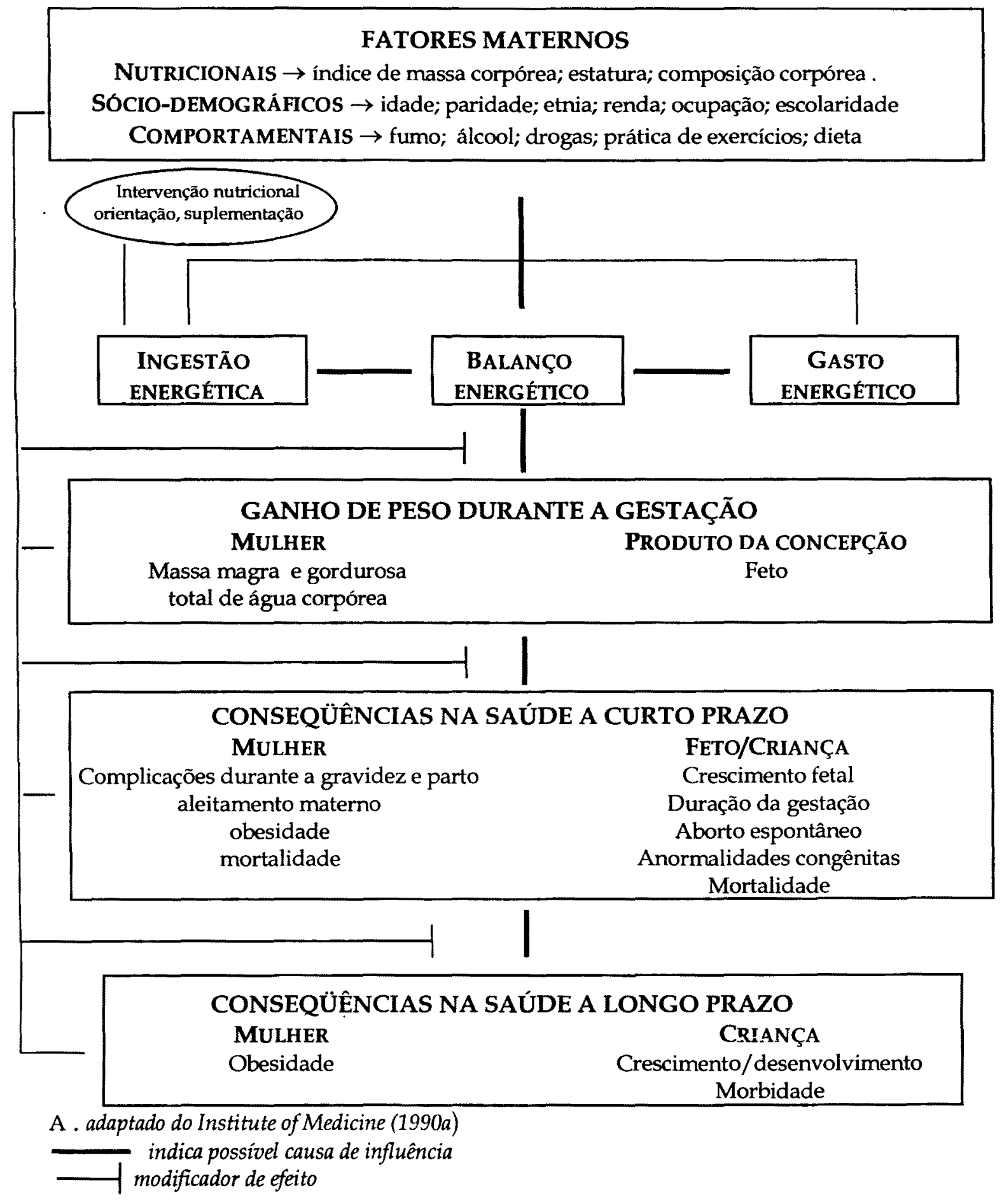


Por este esquema, fica claro que a ingestão e o gasto energético são aspectos que podem interferir no ganho de peso durante a gestação, influenciando o peso do recém-nascido, e o estado nutricional no pósparto. Segundo essa publicação, é essencial considerar quais os fatores determinantes do aumento ponderal neste período, pois, nestes será possível intervir, garantindo-se, assim, uma orientação mais adequada durante o pré-natal e, também, um direcionamento das políticas públicas de alimentação/nutrição e saúde durante a gestação, com o intuito de prevenir retardo de crescimento intra-uterino e a obesidade materna.

Dessa forma, verificar a influência do consumo energético no ganho de peso durante a gestação, reconhecendo-se o papel da dieta nesta associação, poderá melhorar a interpretação dos resultados obtidos a partir da avaliação antropométrica. E, ainda, possibilitará uma orientação nutricional/alimentar que considere, não só o crescimento fetal, mas também a saúde materna, prevenindo-se o ganho excessivo de peso, durante a gestação, e a retenção desse peso no pós-parto, uma das causas de obesidade feminina.

\section{O CONSUMO E O GASTO ENERGÉTICO}

Durante a gestação, é necessário um aumento da quantidade de energia para o crescimento e manutenção do feto, da placenta e dos tecidos maternos. O metabolismo basal das mulheres grávidas é maior devido ao incremento de massa dos tecidos metabolicamente ativos, à intensificação do trabalho cardiovascular, renal e respiratório e à síntese de novos tecidos. $\mathrm{O}$ requerimento energético parece ser maior entre a $10^{a}$ e $30^{a}$ semanas de gestação, quando o depósito de tecido adiposo materno é mais intenso. Provavelmente, em relação aos componentes dietéticos, a energia proveniente da alimentação possa ser o principal determinante do ganho de peso materno, relacionando-se assim, diretamente com um ótimo 
crescimento fetal e com a manutenção do estado de saúde materno. Entretanto, não está complemente clara a real necessidade energética durante este período e o real gasto energético decorrente da gestação. Um balanço energético positivo durante a gravidez pode ser obtido a partir de um aumento na ingestão calórica, ou de uma diminuição do gasto energético, ou, ainda, do aumento da eficiência metabólica de utilização da energia na síntese de novos tecidos, ou possivelmente da combinação destes fatores. Nesse sentido, ainda não se sabe de que forma a alteração e/ou modificação na alimentação da gestante é essencial para um ganho adequado de tecidos tanto para a gestante, quanto para o feto (Merchant \& Martorell, 1988; Institute of Medicine - USA, 1990b e c).

Teoricamente, o gasto energético durante a gestação é de aproximadamente $85.000 \mathrm{kcal}$ para um aumento ponderal de $12,5 \mathrm{~kg}$, o que corresponde a um gasto de 6,4 kcal por cada grama de acréscimo de peso (Hytten, 1980). No estudo coordenado por Durnin (1987), com objetivo de verificar o gasto energético durante a gestação em diferentes países (Escócia, Holanda, Gambia, Tailândia e Filipinas -"Five Nation Study"), observou-se, a partir de medidas diretas do custo energético durante a gravidez, um gasto menor que o teórico, de $55.000 \mathrm{kcal}$ para um ganho de peso de $11,8 \mathrm{~kg}$, ou 4,7 $\mathrm{kcal} / \mathrm{g}$ de aumento ponderal. É importante verificar que os valores encontrados - 6,4 kcal (teórico) e 4,7 kcal (observacional) - são inferiores a 8,0 $\mathrm{kcal} / \mathrm{g}$, que é o valor observado para o aumento de peso em adultos, homens e mulheres não grávidas (Forbes, 1988; Institute of Medicine - USA, 1990b). Pode ser que a menor necessidade calórica para o ganho de peso, durante a gestação, reflita um maior conteúdo de água no tecido magro, depositado neste período. $O$ ajuste hormonal durante a gravidez pode alterar, pussivelmente, a utilização da energia, reduzindo o gasto energético na síntese de gorduras e proteínas (Institute of Medicine - USA, 1990c). 
Os componentes básicos do gasto energético são o metabolismo basal, a atividade física e a termogênese dos alimentos.

Medidas longitudinais do metabolismo basal ou de repouso têm sido realizadas, visando a avaliar o seu grau de acréscimo durante a gestação. Várias investigações indicam um aumento no metabolismo basal ou de repouso durante a gravidez, porém a magnitude desta elevação varia de forma importante entre as populações. $O$ aumento parece ser maior nas mulheres grávidas dos países desenvolvidos (27\%) do que aquele observado entre as gestantes de países subdesenvolvidos (15\%). Esse menor acréscimo no metabolismo de repouso, nas mulheres de países em desenvolvimento, menor inclusive do que a recomendação teórica, pode ser não só devido, em parte, ao seu menor tamanho corpóreo (menor estatura, menor peso), mas também, possivelmente, ao resultado de uma adaptação metabólica (Institute of Medicine - USA, 1990b).

O custo energético da termogênese, pela digestão, absorção, transporte, e armazenamento dos alimentos é de aproximadamente $10 \%$ da ingestão calórica; este valor tende a diminuir durante a gravidez, conservando, assim, energia (Institute of Medicine - USA, 1990b).

O aumento do gasto energético durante a gestação pode ser compensado por uma diminuição nas atividades físicas. Esse pressuposto foi durante algum tempo aceito, e dessa forma, não se incluía nas recomendações de energia o custo energético associado à realização de atividades físicas (Hytten, 1980). Algumas investigações, entretanto, demostraram que essa premissa nem sempre é verdadeira, e que a redução das atividades não ocorre de forma linear em todas as sociedades (Blackburn \& Calloway, 1976a e b; Durnin et al., 1986; Van Raaij et al., 1987). O custo energético para realização de uma dada atividade não parece diferir entre as mulheres grávidas ou não, desde que esses valores sejam corrigidos pelo peso corpóreo. O impacto das atividades físicas no cálculo das necessidades 
energéticas durante a gestação depende da proporção de tempo gasto na realização das mesmas (Institute of Medicine - USA, 1990b).

No já mencionado estudo de Durnin (1987), com realidades distintas de desenvolvimento econômico e social, observou-se que o requerimento energético na gestação está, na maioria dos países estudados, superestimado. Ressalta, ainda, a grande variabilidade encontrada, tanto em relação ao gasto e ingestão energética, quanto ao ganho de tecido adiposo entre as mulheres estudadas. Demonstrou, também que, nas gestantes de países desenvolvidos, pequenos aumentos na ingestão energética são suficientes para atingir as recomendações de energia, devido ao gasto energético observado; nos países em desenvolvimento, os dados não foram tão homogêneos, refletindo diferenças entre as regiões, principalmente em relação à ingestão energética e à taxa de metabolismo de repouso, durante a gestação.

Em estudo longitudinal, realizado em 57 mulheres holandesas, Van Raaij et al. (1989), calculando o gasto energético durante toda a gestação, a partir de um acompanhamento que incluía os períodos pré-gestacional e pós-parto, concluem que o custo energético está muito próximo daquele calculado teoricamente por Hytten (1980). Ressaltam, porém, que a variação da composição corporal materna, anterior à gestação e, também, outros fatores não estudados nesta pesquisa, como o gasto energético para atividade física, sugerem que o requerimento energético em toda a gestação pode ser mais variável do que se acreditava. Recomendam, assim, outros estudos, em diferentes populações que levem em conta os fatores descritos.

Em investigação realizada em 18 casos (gestantes) e 18 controles (mulheres não grávidas) com adequado estado nutricional, na Índia, objetivando verificar o gasto e o consumo energético durante a gestação, constatou-se um gasto energético de aproximadamente $72145 \mathrm{kcal}$, valor muito próximo daquele recomendado pela OMS (1985), comparável, 
também, a valores observados em sociedades ocidentais de países desenvolvidos (Piers et al., 1995)

A Tabela 1, apresenta quadro resumo extraído da última publicação do Institute of Medicine - USA (1990b), com estudos realizados nas décadas de 70 e 80 , com objetivo de analisar o papel do consumo de energia no incremento ponderal e, também, no peso do recém nascido.

Outros estudos realizados na década de 90 demostraram uma associação entre o consumo de energia e o ganho de peso durante a gestação. Scholl \& Hediger (1995), a partir da análise dos resultados do estudo de "Camden", realizado com gestantes adolescentes e adultas, encontraram nos dois grupos que a diminuição da ingestão energética associava-se a um menor incremento ponderal durante a gestação. Bergmann et al. (1997), investigaram 156 gestantes saudáveis da Alemanha e concluíram que o incremento de peso líquido durante a gestação foi influenciado, tanto pelo diagnóstico nutricional pré-gestacional (categorias de IMC), quanto pelo consumo de calorias.

Essa associação também é mediada pela atividade física e pelo tamanho corpóreo e, portanto, se estas variáveis não forem controladas e/ou investigadas, a relação entre o consumo energético e o aumento ponderal durante a gestação poderá ser confundida pelo efeito daqueles fatores. $O$ aumento ou a perda de peso durante a gestação é determinada pelo balanço de energia, e, assim, o impacto da ingestão energética no ganho ponderal requer informação ou controle do gasto energético. A medição desse gasto de forma acurada pela calorimetria, durante este período é tecnicamente difícil; o método de água duplamente marcada poderá melhorar essa estimativa, porém esta é uma técnica, até o momento, cuslosa e, portanto. pouco factívei em estudos populacionais. 
Tabela1: Estudos relacionandoà ingestãoe o ganho de peso durante a gestação em países desenvolvidos eem desenvolvimento $\mathrm{A}$

\begin{tabular}{|c|c|c|c|c|c|}
\hline País e Referência & População & $\begin{array}{l}\text { Ingestão Energética (kcaVdia) media } \pm \text { vPP } \\
\text { variação } \\
\text { Período de Gestação (PG) } \\
\text { Número de Individuos (N) } \\
\end{array}$ & $\begin{array}{l}\text { Ganho de Peso } \mathrm{kg} \\
(\text { média } \pm D P) / \text { período } \\
\text { de gestação }\end{array}$ & \begin{tabular}{|l|} 
Peso ao \\
nascer $_{\mathrm{g}}$ \\
$($ média de $\pm D P)$
\end{tabular} & $\begin{array}{l}\text { Correlação ou nivel de } \\
\text { significância }\end{array}$ \\
\hline $\begin{array}{l}\text { Escócia } \\
\text { Thomson, } 1959\end{array}$ & $\begin{array}{l}\text { Grávidas normais incluindo } \\
\text { pré-eclâmpsia toxemia } \\
\text { hipertensão }\end{array}$ & $\begin{array}{l}<1800 \\
P G=2^{\circ} \text { e } 3^{\circ} \text { trimestres } N=38 \\
1800-2200 \\
P G=2^{\circ} \text { e } 3^{\circ} \text { trimestres } N=94 \\
2200-2600 \\
P G=2^{\circ} \text { e } 3^{\circ} \text { trimestres } N=131 \\
2600-3000 \\
P G=2^{\circ} \text { e } 3^{\circ} \text { trimestres } N=93 \\
>3000 \\
P G=2^{\circ} \text { e } 3^{\circ} \text { trimestres } N=56\end{array}$ & $\begin{array}{l}0,35 / \text { semana } \\
P G=20-36 \text { semanas } \\
0,43 / \text { semana } \\
P G=20-36 \text { semanas } \\
0,45 \text { 'semana } \\
P G=20-36 \text { semanas } \\
0,49 / \text { semana } \\
P G=20-36 \text { semanas } \\
0,56 / \text { semana } \\
P G=20-36 \text { semanas }\end{array}$ & $\begin{array}{l}3090, \text { ambos } \\
\text { os sexos } \\
3190, \text { ambos } \\
\text { os sexos } \\
3210, \text { ambos } \\
\text { os sexos } \\
3210, \text { ambos } \\
\text { os sexos } \\
3330, \text { ambos } \\
\text { os sexos }\end{array}$ & $\begin{array}{l}\text { IE* X ganho de peso** }, R=0,30 \\
\text { IE X peso ao nascer, } R=0,05\end{array}$ \\
\hline $\begin{array}{l}\text { Estados Unidos } \\
\text { Beal, } 1971\end{array}$ & $\begin{array}{l}\text { Pacientes particulares, } \\
\text { média de peso e altura de } 54 \\
\mathrm{~kg} \text { e } 164,5 \mathrm{~cm} \\
\text { respectivamente }\end{array}$ & $\begin{array}{l}1887 \\
P G=\text { inteiro } \\
N=95\end{array}$ & $\begin{array}{l}10,7 \\
P G=\text { inteiro }\end{array}$ & $\begin{array}{l}3260, \text { mas. } \\
3230 \text {, fem. }\end{array}$ & $\begin{array}{l}\text { IE X ganho de peso: } R=0,29, p<0.01 \\
\left(2^{\circ} \text { trimestre); } R=0.20, N S \text { (gestação }\right. \\
\text { inteira) } \\
\text { IE X peso ao nascer, NS } \\
\text { Ganho de peso } X \text { peso ao nascer: } \\
r=0,20 \text {, masc., } N S ; r=0,37 \text {, fem., } \\
p<0,05\end{array}$ \\
\hline $\begin{array}{l}\text { Estados Unidos } \\
\text { Ancri et al., } 1977\end{array}$ & $\begin{array}{l}18-19 \text { anos } \\
20-24 \text { anos } \\
25-32 \text { anos }\end{array}$ & $\begin{array}{l}2254 \pm 637 \\
P G=3^{\circ} \text { trimestre } \mathrm{N}=22 \\
1922 \pm 380 \\
\mathrm{PG}=3^{\circ} \text { trimestre } \mathrm{N}=24 \\
2007 \pm 552 \\
\mathrm{PG}=3^{\circ} \text { trimestre } \mathrm{N}=26 \\
\end{array}$ & $\begin{array}{l}12,4 \pm 3,8 \\
P G=\text { inteiro } \\
11,2 \pm 1,8 \\
P G=\text { inteiro } \\
10,7 \pm 2,0 \\
P G=\text { inteiro } \\
\end{array}$ & $\begin{array}{l}2986 \pm 602 \\
3381 \pm 525 \\
3473 \pm 477\end{array}$ & $\begin{array}{l}\text { Ganho de peso com peso ao nascer, } \\
\text { NS }\end{array}$ \\
\hline $\begin{array}{l}\text { Canadá } \\
\text { Haworth et al., } 1980\end{array}$ & $\begin{array}{l}\text { Pacientes particulares, não } \\
\text { fumantes } \\
\text { Pacientes particulares, } \\
\text { fumantes }\end{array}$ & $\begin{array}{l}421 \pm 701 \\
P G=3^{\circ} \text { trimestre } N=175 \\
2587 \pm 736 \\
P G=3^{\circ} \text { trimestre } N=208\end{array}$ & Medida não relatada & NR & $\begin{array}{l}\text { IE } X \text { ganho de peso, } r=0,16, p<0,01 \\
\text { Ganho de peso } X \text { peso ao nascer, } \\
r=0,19, p<0,01\end{array}$ \\
\hline $\begin{array}{l}\text { Estados Unidos } \\
\text { Picone et al., 1982b }\end{array}$ & $\begin{array}{l}\text { Baixo ganho de peso, não } \\
\text { fumantes } \\
\text { Média de ganho de peso, } \\
\text { Não fumantes } \\
\end{array}$ & $\begin{array}{l}1617 \pm 459 \\
P G=2^{\circ} \text { e } 3^{\circ} \text { trimestre } N=10 \\
1905 \pm 322 \\
P G=2^{\circ} \text { e } 3^{\circ} \text { trimestre } N=18\end{array}$ & $\begin{array}{l}2,4 \pm 3,2 \\
P G=\text { inteiro } \\
14,9 \pm 3,2 \\
P G=\text { inteiro } \\
\end{array}$ & $\begin{array}{l}3060 \pm 502 \\
\text { ambos os } \\
\text { sexos, ambos } \\
\text { os grupos } \\
\end{array}$ & $\begin{array}{l}\text { IE } X \text { ganho de peso, } R=0,44, p<0,02 \\
\text { Ganho de peso } X \text { peso ao nascer, } \\
r=0,57, p<0,001 \\
\text { IE X peso ao nascer, } r=0,34, p<0,05\end{array}$ \\
\hline $\begin{array}{l}\text { França } \\
\text { Papoz et al., } 1982\end{array}$ & $\begin{array}{l}\text { Nunca fumaram } \\
\text { Ex-fumantes } \\
\text { Fumantes }\end{array}$ & $\begin{array}{l}2151 \\
P G=1^{\circ} \text { trimestre } N=334 \\
2189 \\
P G=1^{\circ} \text { trimestre } N=97 \\
2242 \\
P G=1^{\circ} \text { trimestre } \mathrm{N}=103\end{array}$ & & $\begin{array}{l}3260 \pm 457 \\
3270 \pm 404, \\
3190 \pm 355 \\
\text { ambos os } \\
\text { sexos }\end{array}$ & $\begin{array}{l}\text { IE X ganho de peso, NS } \\
\text { Ganho de peso } X \text { peso ao nascer, } \\
r=0,25, p<0,001\end{array}$ \\
\hline
\end{tabular}


Tabela 1: continuação

\begin{tabular}{|c|c|c|c|c|c|}
\hline País e Referência & População & $\begin{array}{l}\text { Ingestão Energética (kcaVdia média } \pm \text { DP) } \\
\text { Período de Gestação (PG) } \\
\text { Número de Indivíduos }\end{array}$ & $\begin{array}{l}\text { Ganho de Peso } \mathrm{kg} \\
(\text { média } \pm D P) / p e r i o d o \\
\text { de gestação }\end{array}$ & $\begin{array}{l}\text { Peso ao } \\
\text { nascer }_{\mathrm{g}} \\
\text { (média de } \pm D P)^{\text {ma }}\end{array}$ & $\begin{array}{l}\text { Correlação ou nível de } \\
\text { significância }\end{array}$ \\
\hline $\begin{array}{l}\text { Inglaterra } \\
\text { Abraham et al., } 1985\end{array}$ & $\begin{array}{l}\text { Harrow Asians } \\
\text { Europeus }\end{array}$ & $\begin{array}{l}2010 \pm 532 \\
\mathrm{PG}=2^{\circ} \text { trimestreN }=813 \\
2013 \pm 636 \\
\mathrm{PG}=2^{\circ} \text { trimestreN }=54\end{array}$ & $\begin{array}{l}0,462 / \text { semana } \\
\mathrm{PG}=\text { inteiro } \\
0,458 / \text { semana } \\
\text { PG inteiro }\end{array}$ & $\begin{array}{l}\text { NR } \\
\text { NR }\end{array}$ & NR \\
\hline $\begin{array}{l}\text { Estados Unidos } \\
\text { Endres et al., } 1985\end{array}$ & Adult WIC participants & $\begin{array}{l}1904 \pm 806 \\
P G=2^{\circ} \text { trimestreN }=204\end{array}$ & $\begin{array}{l}11,0 \\
\mathrm{PG}=\text { inteiro }\end{array}$ & NR & NR \\
\hline $\begin{array}{l}\text { Inglaterra } \\
\text { Anderson e Lean, } 1986\end{array}$ & Mulheres saudáveis & $\begin{array}{l}2065 \pm 441 \\
P G=3^{\circ} \text { trimestre } N=49\end{array}$ & $11,2 \mathrm{PG}=$ inteiro & NR & $\begin{array}{l}\text { Ganho de peso } \leq 8 \mathrm{~kg} \text {; IE média de } 1770 \\
\pm 452 \mathrm{kcal} ; \text { Ganho de peso }>8 \mathrm{~kg} \text {; } \\
\text { IE média de } 2115 \pm 425 \mathrm{kcal}\end{array}$ \\
\hline $\begin{array}{l}\text { Escócia } \\
\text { Durnin, 1987; } \\
\text { Durnin et al., } 1986\end{array}$ & $\begin{array}{l}\text { Mulheres saudáveis, média } \\
\text { de peso e altura, } 57 \pm 8 \mathrm{~kg} \\
162 \pm 6 \mathrm{~cm}\end{array}$ & $\begin{array}{l}2250 \\
\mathrm{PG}=3^{\circ} \text { trimestre } \\
2120 \pm 334 \\
\mathrm{PG}=1^{\circ} \text { trimestre } \mathrm{N}=\mathbf{8 8}\end{array}$ & $\begin{array}{l}11,7 \pm 3,2 \\
P G=\text { inteiro }\end{array}$ & $3,370 \pm 404$ & $\mathrm{NR}$ \\
\hline $\begin{array}{l}\text { Suécia } \\
\text { Langhoff-Roos et al., } 1987\end{array}$ & Mulheres saudáveis & $\begin{array}{l}2201 \pm 399 \mathrm{PG}=2^{\circ} \text { trimestre } \\
2266 \pm 406 \\
\mathrm{PG}=3^{\circ} \text { trimestre } \mathrm{N}=56\end{array}$ & Medidas não relatadas & NR & $\begin{array}{l}\text { Ingestão calórica X ganho de peso, NS } \\
\text { Ingestão calórica } X \text { peso ao nascer, NS }\end{array}$ \\
\hline $\begin{array}{l}\text { Holanda } \\
\text { Van Raaij et al., } \\
\text { 1986,1987 }\end{array}$ & $\begin{array}{l}\text { Mulheres saudáveis, média } \\
\text { peso e altura, } 62 \pm 8 \mathrm{~kg} \mathrm{e} \\
169 \pm 7 \mathrm{~cm}\end{array}$ & $\begin{array}{l}2140 \pm 461 \mathrm{PG}=1^{\circ} \text { trimestre } \\
2119 \pm 392 \mathrm{PG}=2^{\circ} \text { trimestre } \\
2187 \pm 426 \mathrm{PG}=3^{\circ} \text { trimestre } \\
2140 \pm 461 \mathrm{PG}=\text { inteiro }\end{array}$ & $\begin{array}{l}11,6 \\
P G=\text { inteiro }\end{array}$ & $3458 \pm 527$ & NR \\
\hline $\begin{array}{l}\text { Austrália } \\
\text { Truswell et al., } 1988\end{array}$ & \begin{tabular}{|l|} 
Mulheres saudáveis, média \\
peso e altura, $57 \pm 7 \mathrm{~kg} \mathrm{e}$ \\
$164 \pm 6,4 \mathrm{~cm}$ \\
\end{tabular} & $\begin{array}{l}2113 \pm 483 \mathrm{PG}=1^{\circ} \text { trimestre } \\
2127 \pm 434 \mathrm{PG}=2^{\circ} \text { trimestre } \\
2127 \pm 532 \mathrm{PG}=3^{\circ} \text { trimestre } \mathrm{N}=49\end{array}$ & $\begin{array}{l}12,4 \pm 3,7 \\
P G=\text { inteiro }\end{array}$ & $3540 \pm 473$ & NR \\
\hline $\begin{array}{l}\text { Jamaica } \\
\text { De Benoist et al., } 1985\end{array}$ & $\begin{array}{l}\text { Saudáveis, classe média, } \\
\text { mulheres primingestas }\end{array}$ & $\begin{array}{l}1864 \pm 264 \mathrm{PG}=1^{\circ} \text { trimestre } \mathrm{N}=6 \\
2271 \pm 527 \mathrm{PG}=2^{\circ} \text { trimestre } \mathrm{N}=6 \\
2366 \pm 235 \mathrm{PG}=3^{\circ} \text { trimestre } \mathrm{N}=6\end{array}$ & $\begin{array}{l}10,0 \pm 2,2 \mathrm{PG}=\text { inteiro } \\
11,2 \pm 2,9 \mathrm{PG}=\text { inteiro } \\
13,7 \pm 2,9 \mathrm{PG}=\text { inteiro }\end{array}$ & $\begin{array}{l}3200 \pm 490 \\
3200 \pm 245 \\
3500 \pm 490\end{array}$ & NR \\
\hline $\begin{array}{l}\text { Tailândia } \\
\text { Thongprasert e Valaysevi, } \\
\text { 1986; Thongprasert et al., } \\
\text { 1987 }\end{array}$ & $\begin{array}{l}\text { Mulheres saudáveis de } 12 \\
\text { vilarejos rurais; engajadas em } \\
\text { trabalhos leves } \\
\text { Peso gestacional inicial < } 49 \mathrm{~kg} \\
\text { Ptsogesacmal incal } 49 \mathrm{a} 58 \mathrm{~kg} \\
\text { Peso gestacional inicial }>58 \mathrm{~kg}\end{array}$ & $\begin{array}{l}1932 \pm 358 \mathrm{PG}=1^{\circ} \text { trimestre } \\
2279 \pm 380 \mathrm{PG}=2^{\circ} \text { trimestre } \\
2201 \pm 350 \mathrm{PG}=3^{\circ} \text { trimestre } \mathrm{N}=44 \\
1641 \pm 367 \mathrm{PG}=2^{\circ} \text { e } 3^{\circ} \text { trimestre } \mathrm{N}=66\end{array}$ & $\begin{array}{l}8,9 \pm 2,9 \mathrm{PG}=\text { inteiro } \\
10,1 \mathrm{PG}=\text { inteiro } \\
9,2 \mathrm{PG}=\text { inteiro } \\
8,5 \mathrm{PG}=\text { inteiro }\end{array}$ & $\begin{array}{l}2980 \pm 358 \\
3300 \pm 386 \\
3198 \pm 361 \\
3345 \pm 419\end{array}$ & NR \\
\hline $\begin{array}{l}\text { Filipinas } \\
\text { Tuazon et al., 1986,1987 }\end{array}$ & $\begin{array}{l}\text { Mulheres da zona rural, } \\
\text { peso e altura, } 44 \pm 6 \mathrm{~kg} \mathrm{e} \\
151 \pm 5 \mathrm{~cm}\end{array}$ & $\begin{array}{l}1760 \pm 347 \mathrm{PG}=1^{\circ} \text { trimestre } \\
1773 \pm 412 \mathrm{PG}=2^{\circ} \text { trimestre } \\
1680 \pm 382 \mathrm{PG}=3^{\circ} \text { trimestre } \\
1750 \pm 352 \mathrm{PG}=\text { inteiro } \mathrm{N}=51\end{array}$ & $8,4 \pm 2,4 \mathrm{PG}=$ inteiro & $2885 \pm 395$ & NR \\
\hline $\begin{array}{l}\text { Mexico } \\
\text { Hunt et al., } 1987\end{array}$ & \begin{tabular}{|l|} 
Mulheres atendidas \\
posoealura $56 \pm 10 \mathrm{kge} 155 \pm 5 \mathrm{om}$
\end{tabular} & $\begin{array}{l}1831 \pm 623 \mathrm{PG}=2^{\circ} \text { trimestre } \\
1750 \pm 481 \mathrm{PG}=3^{\circ} \text { trimestre } \mathrm{N}=44\end{array}$ & $\begin{array}{l}0,4 \pm 0,2 \mathrm{~kg} / \text { semana } \\
\mathrm{PG}=19 \text { a } 35 \text { semanas }\end{array}$ & $3381 \pm 456$ & NR \\
\hline
\end{tabular}

A: adaptado do Institute of Medicine (1990 a) *IE = ingestão energética *\# Ganho de peso = ganho de peso durante a gestaçấo 
Embora, nem sempre, a associação entre a ingestão energética e o ganho de peso durante a gestação tenha sido revelada com significância estatística, como se observa nos dados da Tabela 1, o ganho de peso durante esse período é consequiência direta do balanço energético, isto é, da diferença entre a ingestão e o gasto energético. A ausência dessa associação, em vários estudos, pode ser explicada pela grande variação da ingestão energética entre os indivíduos, pelos desenhos das investigações - estudos transversais , pelo tamanho da amostra estudada e, finalmente, pela dificuldade de se estimar a ingestão energética, a partir das metodologias de inquérito de consumo de alimentos.

\section{AS DIFICULDADES}

Segundo o Institute of Medicine - USA (1990a), apenas estudos longitudinais foram capazes de detectar um aumento, mesmo que pequeno, no consumo energético de gestantes, devido talvez à dificuldade de se estimar com precisão a ingestão de alimentos. Nessa mesma publicação, é evidenciado o número restrito de dados em relação ao efeito da atividade física e/ou trabalho fora de casa durante a gestação, no ganho de peso materno, além da ausência de informações a respeito do padrão de alteração dessas atividades no período gestacional. Durnin (1982), reafirma a necessidade metodológica da realização de estudos longitudinais que se proponham a investigar o requerimento energético durante a gestação.

\section{ESTIMATIVA DA INGESTÁO ENERGÉTICA}

$O$ método de frequêencia de consumo de alimentos tem sido amplamente utilizado em estudos epidemiológicos, pela sua praticidade e validade, e vem sendo usado para se estimar a ingestão de alimentos, podendo ser aplicado em grande número de indivíduos, sem um aumento dos custos da investigação. Entretanto, o método necessita de um cuidado especial por parte dos investigadores, quando da construção do mesmo - 
lista de alimentos representativa da ingestão habitual da população a ser estudada - e, também, da definição precisa dos objetivos a serem alcançados a partir desses dados (Haraldsdottir \& Van Staveren, 1988; Gibson,1990; Willet, 1990a).

Esse método parece ser a forma mais adequada de se avaliar a alimentação em estudos epidemiológicos. Entretanto, ainda é uma questão crucial saber qual a acurácia apresentada por essas metodologias para medir a verdadeira ingestão de alimentos. Essa tem sido uma pergunta com que todos os investigadores da área de alimentação têm se deparado, desde os primeiros trabalhos que utilizaram uma lista de freqüência de consumo de alimentos, como na investigação realizada por Burke, 1947. Nos últimos anos, foram desenvolvidas várias análises, visando a validar os estudos dietéticos, principalmente os questionários de freqüência de consumo de alimentos, buscando-se estratégias, para se conhecer e avaliar os erros inerentes à avaliação dietética, desde a estruturação da base de dados (coleta, armazenamento e cálculo) até a elaboração de métodos estatísticos visando à análise destes (Willett, 1994; Beaton et al., 1997; Thompson et al., 1997, Willett, 1990a).

Observa-se que a diferença na ingestão energética, verificada entre os indivíduos, é determinada, fundamentalmente, pela atividade física, pelo tamanho corpóreo e pela eficiência metabólica. Os estudos epidemiológicos, onde se relaciona a ingestão energética com algum fator de risco, para o desenvolvimento de um evento, apresentam dificuldade ou mesmo impossibilidade de interpretar esses resultados. Essa impossibilidade pode ser devida, provavelmente, aos seguintes pontos: à dificuldade de se estimar a ingestão energética a partir de questionários; à metodologia disponível para se verificar o grau de ativiuadé física neste tipo de estudo e, finalmente, à total ausência de formas de medir a eficiência metabólica em estudos populacionais (Willett, 1990c; Willett et al.,1997). 
Talvez uma das maneiras mais adequada de se apreender a validade e o grau de precisão da ingestão energética seja a utilização do peso e da estatura, com medidas do tamanho corpóreo. Essas são simples, confiáveis e reproduzíveis e devem ser coletadas sempre que se quiser estimar a ingestão calórica, pois podem representar o resultado de um balanço energético positivo - aumento de peso - ou negativo - perda de peso (Willett, 1990c).

Outra maneira de se analisar o instrumento utilizado para se estimar a ingestão energética, que vem sendo empregada em estudos epidemiológicos, tem sido o cálculo da razão entre a ingestão energética e a taxa estimada de metabolismo basal. Quando a razão é superior 0,9 indica que o método utilizado está adequado para estimar essa ingestão (Briefel et al., 1997). No $3^{\circ}$ inquérito de nutrição dos Estados Unidos (NHANES III), esta razão variou de 1,2 a 1,4, demonstrando que, apesar de um sub-registro de alimentos, o instrumento utilizado foi adequado. Observou-se, também, no Estudo Multicêntrico sobre Consumo Alimentar em 5 cidades brasileiras, uma razão superior a 1,5, mostrando a validade do inquérito de freqüência de consumo utilizado nessa investigação (Galeazzi et al., 1997; Sichieri, 1998).

$O$ método de inquérito de freqüência de consumo de alimentos também tem sido empregado em estudos que objetivam não só verificar alterações dietéticas no decorrer da gestação, como também avaliar o consumo de nutrientes durante este período. Brown et al. (1996), estudando uma amostra de gestantes brancas americanas concluíram que este método de inquérito alimentar é adequado para identificar as modificações de consumo, de energia, de proteínas, de carboidratos, de gorduras, de cálcio, de ferro e de vitamina $C$. Com o objetivo de comparar o consumo de nutrientes avaliados pelo inquérito de frequêencia de consumo de alimentos e pelo método de diário alimentar (4 dias de registro), Robinisisor et al. (1996) investigaram 603 gestantes, concluindo que o questionário de freqüência 
estima de forma precisa esse consumo, possibilitando distribuir os indivíduos em diferentes graus de ingestão de nutrientes.

\section{ESTIMATIVA DO GASTO ENERGÉTICO}

Define-se necessidade energética como a quantidade de energia ingerida proveniente da alimentação que compensa a gasta, para manter o estado de saúde, o crescimento e a recuperação de tecidos e um grau de atividade física; todos estes fatores estão relacionados com o tamanho corpóreo, com o gênero e com a idade. Nas crianças, gestantes e nutrizes, as necessidades energéticas incluem, ainda, aquelas associadas com a formação de novos tecidos e a produção de leite, para a manutenção de uma boa saúde (OMS, 1985).

A partir dessa definição, é impossível estipular um único valor de necessidade de energia em um determinado grupo, pois a variação individual não só em relação às dimensões corpóreas, mas também, em relação ao tipo, grau e quantidade de atividade física, impõe a determinação do gasto energético como forma de se chegar ao cálculo dessas necessidades. Nesse sentido, a Organização Mundial da Saúde (OMS, 1985), em seu documento a respeito das necessidades energéticas e de proteínas, propõe equações para se estimar o gasto energético, considerando no cálculo todos os componentes do gasto energético total como múltiplos da taxa de metabolismo basal (TMB). Essa taxa representa o maior componente do gasto energético, podendo ser medida com exatidão em condições normais. Em qualquer indivíduo a TMB depende, principalmente, do tamanho, da composição corpórea e da idade, sendo maior nas crianças e menor nos idosos.

As equações propostas pela OMS, (1985), baseiam-se na medição direta dc 11.000 indivíduos de ambos os sexos e de todas as idades em hom estado de saúde, e foram consideradas pelo comitê responsável por esta publicação as melhores estimativas disponíveis, para se obter a TMB de pessoas 
saudáveis de qualquer população, quando não for possível a medição direta do gasto energético. As atividades físicas diárias representam, também, um importante componente do gasto energético e, portanto, devem ser consideradas, quando do seu cálculo. Dessa maneira, é imprescindível identificar o tipo de atividade física realizada habitualmente pelos indivíduos e o tempo gasto na execução das mesmas. Existem hoje várias tabelas onde se encontra o gasto energético, como múltiplos da TMB, para a realização de diferentes atividades; estas estimativas podem ser utilizadas no cálculo das necessidades energéticas, considerando-se o tempo gasto em minutos na realização das mesmas.

Encontra-se, atualmente, dificuldade na obtenção de questionários previamente validados, com o objetivo de avaliar as atividades físicas diárias e caracterizar e quantificar o número de horas gasto na realização de uma série de tarefas executadas em casa ou no trabalho (Sallis et al., 1985; Blair et al., 1985; Washburn \& Montoye, 1986). Observou-se na literatura um maior número de estudos analisando a atividade física como prática desportiva.

A medida de atividade física diária, usualmente realizada pelos indivíduos, tem sido objeto de alguns estudos epidemiológicos, a partir do desenvolvimento de instrumentos simples, mas capazes de mensurar estas variáveis em estudos populacionais. $O$ interesse por essa área advém da necessidade de se conhecerem, principalmente, as associações entre a execução de atividades físicas diárias, desenvolvidas usualmente pela população, e a ocorrência de doenças crônicas não-transmissíveis, principalmente as doenças do coração, além do estudo da relação entre estas práticas e a qualidade de vida/saúde, fundamentalmente em população idosa. (Yasin et. al., 1967; Baecke et al., 1982; Jacobs et al.,1989; Osler et al., 1991). 


\section{o ganho de peso durante a gestação}

A alteração de peso durante a gestação pode variar desde perda até aumento superior a $30 \mathrm{~kg}$. Essa grande variação é atribuida, entre mulheres saudáveis, a diversos fatores fisiológicos e ambientais. As mudanças hormonais que ocorrem durante esse período, além de outros ajustes fisiológicos afetam, indubitavelmente, a utilização da energia e, portanto, o aumento ponderal nesse momento do ciclo reprodutivo da mulher (Institute of Medicine - USA, 1990c; WHO, 1995a).

Os componentes do ganho de peso podem ser divididos em dois - os produtos da concepção e o aumento dos tecidos maternos. Compreendem os produtos da concepção: o feto, a placenta e o líquido amniótico, que são responsáveis por, aproximadamente, $36 \%$ do aumento ponderal em gestações a termo. $O$ acréscimo de tecidos maternos representa quase $2 / 3$ do ganho ponderal total durante a gravidez. Além da expansão dos tecidos uterino e mamário, observa-se, também, um aumento do volume sangüíneo, do líquido extracelular e do tecido adiposo entre outros.

As mulheres, normalmente, acumulam tecido gorduroso neste período. Estima-se que para um ganho de peso de $12,5 \mathrm{~kg}$, sem edema, $3,5 \mathrm{~kg}$ derivam do aumento deste tecido (Hytten, 1980). A razão desse acréscimo não está totalmente clara; provavelmente, este represente uma reserva de energia na gestação e lactação (Institute of Medicine - USA, 1990c).

Segundo as estimativas realizadas por Hytten (1980), em média, a contribuição do aumento do tecido adiposo é da ordem de $30 \%$ em relação ao ganho de peso total durante a gestação. $\mathrm{O}$ acúmulo de água contribui em torno de $60 \%$ e o aumento de tecido magro $8 \%$ do acréscimo ponderal na gravidez. Entretanto, existe uma grande variação nestes valores. Em relação ao acréscimo do tecido adiposo, $90 \%$ é depositadn nos tecidos maternos (Institute of Medicine - USA, 1990c). 
Entre os fatores que se associam com o ganho de peso durante a gestação destacam-se, além do consumo de energia, a paridade, a idade, a etnia, o hábito de fumar e o peso e/ou o índice de massa corpórea prégestacional (Abrams \& Parker, 1990; Dawes \& Grudzinskas, 1991).

O estado nutricional pré-gestacional, medido a partir das relações entre o peso pré-gestacional e a estatura, reflete as reservas maternas antes da gestação. Um índice de massa corpórea (IMC) compatível com baixo peso pode estar indicando uma reserva marginal de tecido adiposo. Já uma gestante com IMC maior poderá ter uma alta reserva desse tecido. Alguns trabalhos têm mostrado uma diferenciação no aumento ponderal, durante a gestação, segundo o estado nutricional pré-gestacional (Abrams \& Laros, 1986; Kramer, 1987; Krasovec, 1991; Krasovec \& Anderson, 1991; Andreazza, 1993; Perry et al., 1995; Bergmann et al., 1997). A deposição de tecido adiposo pode diferir entre os grupos e, assim, o maior ou o menor ganho de peso e/ou de tecido adiposo durante a gestação pode-se associar de maneiras diferentes com o crescimento fetal, e, também com o desenvolvimento da obesidade.

A última recomendação de ganho de peso durante a gestação incorpora a avaliação nutricional pré-gestacional a partir do IMC, propondo incrementos de peso diferenciados, segundo esse diagnóstico (Institute of Medicine, 1990c; WHO, 1995a). Parker \& Abrams (1992), visando a verificar a adequação das recomendações de ganho de peso propostas por esse Instituto e o efeito do aumento ponderal, na ocorrência de recém-nascidos pequenos e grandes para a idade gestacional e à freqüência de cesáreas, a partir de registros hospitalares, concluíram que essas recomendações são válidas, pois observaram uma redução no risco de ocorrência dos três eventos analisados, entre as gestantes que tiveram um acréscimo ponderal dentro do recomendado. 
Johnson et al. (1992), preocupados com a liberação do ganho de peso durante a gestação, a partir da publicação das recomendações do Institute of Medicine (1990c), que tem como base a diminuição do risco de ocorrência de baixo peso ao nascer, e o aumento do peso pré-gestacional e também a ocorrência de obesidade entre as mulheres nos Estados Unidos da América estudaram, retrospectivamente, 7.407 gestantes que deram à luz a termo, entre os anos de 1987 e 1989. Os autores evidenciaram que um aumento ponderal maior na gravidez associou-se de forma positiva com a macrosomia fetal, o que ocasionou, por sua vez, um aumento das taxas de cesáreas, além de outras complicações maternas e fetais. Portanto, os autores apontam para a necessidade de revisão cuidadosa das atuais recomendações de aumento ponderal durante esse período do ciclo vital.

Alguns pesquisadores verificaram a pertinência das recomendações de ganho de peso, durante a gestação proposta pelo Institute of Medicine, 1990. Essas prevêem um aumento ponderal um pouco superior às recomendações anteriores. Observaram, entretanto, que as recomendações parecem não aumentar o risco de desenvolvimento de obesidade, principalmente nas mulheres brancas e nas com baixo peso e eutrofia prégestacional. Nas gestantes com sobrepeso e obesidade antes da gestação, sugerem a realização de mais avaliações (Keppel \& Taffel, 1993; Schieve et al., 1998). Johnson \& Yancey (1996), fazem uma crítica a essas recomendações de aumento ponderal, considerando que existem poucas evidências para sustentar uma elevação das taxas de ganho de peso durante a gestação, levando-se em conta, principalmente, o aumento do peso pré-gestacional observado, nos últimos anos, na população feminina.

Lederman et al. (1997), no entanto, afirmam que as atuais recomendações de ganho de peso na gravidez não aumentam o risco do desenvolvimento de obesidade em qualquer nível de peso pré-gestacional. Segundo os pesquisadores, após comparar o acréscimo de tecido adiposo, 
obtido a partir do modelo dos quatros componentes corpóreos, com as categorias de recomendação de aumento ponderal, propostas pelo Institute of Medicine, as mulheres com baixo peso normalizaram o seu peso e as obesas tiveram um pequeno ou nenhum acréscimo de tecido adiposo, quando aumentaram os seus pesos dentro dos limites preconizados por este Instituto.

Foram realizadas várias investigações, em especial, a partir dos anos 90, com o objetivo de verificar qual o ganho de peso durante a gestação e o acréscimo de tecido adiposo nesse período, que não se associe com o posterior aumento de peso das mulheres e ao mesmo tempo otimize o crescimento fetal. Esses estudos propõem e realizam diferentes medidas antropométricas, utilizando, ainda, diferentes métodos para se obter a composição corpórea durante a gestação (Viegas et al, 1987; . Lawrence et al., 1991).

Villar et al. (1992) investigaram prospectivamente 105 gestantes saudáveis da Guatemala, que deram à luz a termo, com o objetivo de descrever o padrão e a localização da deposição de tecido adiposo e de tecido livre de gordura durante a gestação e avaliar o efeito dessa deposição no crescimento fetal. Os dois indicadores que se associaram de forma mais intensa com o crescimento fetal foram o estado nutricional pré-gestacional e o aumento de tecido adiposo no início da gestação. Os autores concluem que, pelas evidências dessa investigação, as intervenções nutricionais devem ocorrer o mais precocemente possível. E que, talvez, a lacuna na explicação do efeito das ações de nutrição durante o pré-natal no peso do recémnascido, ocorra porque as ações acontecem muito tardiamente. Além disso propõem algumas fórmulas obtidas a partir de medidas antropométricas (pregas cutâneas) e da bioinpedância, para se estimar de forma operacional a composição corpórea (tecido adiposo e tecido livre de gordura) das gestantes. 
A utilização do método de bioimpedância, entre as gestantes, vem sendo apontada como uma técnica prática e adequada, para se estimar a quantidade de água corpórea. Contribuindo, desta forma, para determinação da composição corpórea durante a gestação (Lukaski et al., 1994; JaqueFortunato et al., 1996).

Paxton et al., em 1998, estudando 200 gestantes, concluem que as equações antropométricas, tradicionalmente utilizadas para se calcular o tecido adiposo e que já foram previamente testadas e validadas em adultos, são inadequadas para predizer o tecido gorduroso em gestantes, pois superestimam esse tecido. Dessa forma, propõem e validam, na mesma amostra, duas equações com o objetivo de estimar o acréscimo final de tecido adiposo na gestação e determinar a quantidade total deste tecido nas mulheres nesse momento do ciclo vital. Essas fórmulas, segundo os autores, podem ser utilizadas em gestantes com diferentes pesos pré-gestacionais e incrementos de peso durante a gestação e, ainda, em diferentes etnias e níveis sócio-econômicos.

Assim, a antropometria durante a gestação, baseada no peso, na estatura e no ganho de peso, tem sido amplamente utilizada, para se avaliar o risco de retardo de crescimento intra-uterino e, desta forma, encaminhar essa população para programas de intervenção nutricional. Atualmente, com a alta prevalência de obesidade observada, tanto em sociedades desenvolvidas, quanto em regiões subdesenvolvidas, principalmente nas mulheres, as medidas das dimensões corpóreas durante a gestação deveriam considerar, também, a saúde materna, prevenindo o desenvolvimento do sobrepeso e da obesidade. 
AS AÇōes

De forma resumida e amplamente aceita, os objetivos do pré-natal são: orientar os hábitos de vida da gestante (dieta alimentar, atividade física etc.), fornecer assistência psicológica e educacional, preparar a gestante para o parto, fazer o diagnóstico e tratar as doenças preexistentes que podem gerar riscos na gravidez e parto, orientar e preparar a mulher para o aleitamento materno e, finalmente, acompanhar sequiencialmente o processo de gestação (Nogueira, 1994). Assim, a assistência pré-natal pode representar um espaço único e privilegiado de ações educativas e, portanto, de promoção de saúde tanto da mulher quanto da criança, pois o período perinatal tem conseqüências diretas para ambos.

No Brasil, as intervenções nutricionais durante esse período ganham um contorno especial, pois ainda são necessárias ações visando à diminuição da ocorrência de baixo peso ao nascer, mas também impõem-se a realização de estratégias para prevenir a obesidade entre as mulheres. Assim, não é possível apenas uma orientação única e geral a respeito da alimentação nesse período, mas sim, orientações específicas e direcionadas para as gestantes, considerando-se o seu estado nutricional pré-gestacional, o acesso à alimentação, os hábitos alimentares e, entre outros aspectos, a estimativa de aumento ponderal durante esse período

Tem-se observado no País, nas últimas décadas, fortes evidências de estabilidade ou mesmo elevação da ocorrência de baixo peso ao nascer. Esse comportamento pode ser observado em estudo realizado por Monteiro et al., (1999), a partir das informações do Sistema de Declaração de Nascidos Vivos - SINASC/Fundação SEADE, e do inquérito realizado em amostra, representativa, dos partos hospitalares em 1976, registrando incidências de baixo peso ao nascer, praticamente constantes no período entre 1993 a 1998, respectivamente, $9,4 \%$ e $8,9 \%$. 
Em outras regiões do País, verifica-se, também, essa tendência. Resultados recentes de um estudo com duas coortes, de base populacional, realizados na cidade de Pelotas - RS, em 1982 e em 1993, mostraram incidências de baixo peso ao nascer iguais a 9,0 e 9,8\%, respectivamente. Quando os autores consideraram os dois processos que podem ocasionar elevação do baixo peso - retardo do crescimento intra-uterino (RCIU) e prematuridade -, observaram um aumento de 15,0\% para 17,5\% de nascimentos com RCIU e uma elevação de 5,6\% para 7,5\% de partos prematuros (Horta et al., 1996).

Dessa forma, o peso de nascimento ainda constitui um problema de saúde pública em nosso meio, pois, além das evidências relatadas anteriormente, as prevalências constatadas no país, em torno de $10 \%$ de baixo peso ao nascer, representam o dobro da média verificada em países desenvolvidos.

Por outro lado, a Pesquisa Nacional de Saúde e Nutrição (PNSN,1989) revelou uma prevalência em torno de $27 \%$ de obesidade entre as mulheres, valor superior a este foi evidenciado na região Sudeste (29\%). Esses achados apontam que a obesidade, em especial nos adultos do sexo feminino, representa, atualmente, um problema de nutrição em saúde pública em nosso meio (Souza, 1999; Monteiro et al.,1995; Sichieri, 1998).

Verificar a influência do consumo energético no ganho de peso durante a gestação poderá contribuir na construção de orientações nutricionais/alimentares mais específicas nesse período do ciclo vital. Essas intervenções devem ter como objetivos não só a prevenção do retardo de crescimento intra-uterino de etiologia nutricional, mas também, a promoção da :jaúde da mulher, reforçando, desta forma, as estratégias para o controle e prevenção da obesidade na população adulta brasileira. 
OBJETIVOS 


\section{OBJETIVOS}

\subsection{GERAL}

- Verificar a influência do consumo energético no ganho de peso durante a gestação em mulheres de baixa renda, atendidas em serviço de pré-natal

\section{2 ESPECÍficos}

- Descrever o consumo energético e a sua adequação nos diferentes trimestres de gestação segundo o estado nutricional inicial.

- Descrever o ganho de peso total e por semana durante a gestação segundo o estado nutricional inicial.

- Estudar a assuciação entre o consumo energético e o ganho de peso nos diferentes trimestres de gestação. 
MÉTODOS 


\section{MÉTOdOS}

\subsection{O DESENHO DO ESTUDO}

Esse trabalho faz parte de um projeto de pesquisa maior intitulado "Eficiência de indicadores antropométricos maternos na predição do baixo peso ao nascer" que tem como objetivo principal estudar, em uma população de gestantes de baixa renda, a eficiência de indicadores antropométricos na predição do baixo peso ao nascer, a partir de avaliação antropométrica e da monitoração das alterações da composição corpórea, durante o período gestacional.

Delineou-se um estudo de coorte com gestantes que iniciaram o atendimento pré-natal, ainda no primeiro trimestre de gestação, sendo realizado no serviço df: pré-natal do "Amparo Maternal", após discussões com a equipe deste serviço e, também, com a Disciplina de Obstetrícia do Departamento de Tocoginecologia da Universidade Federal de São Paulo/Escola Paulista de Medicina - Unifesp/EPM, que coordena o serviço 
de pré-natal daquela Instituição. A viabilidade da execução dessa investigação, foi avaliada a partir de um levantamento com uma sub-amostra de 111 gestantes atendidas, no primeiro semestre de 1995.

A partir deste levantamento, delimitou-se a entrada das gestantes na coorte até a $17^{\text {a }}$ semana de gestação, pois das 111 mulheres estudadas, 13,5\% iniciaram o pré-natal até essa semana e apenas $7,2 \%$ até a $14^{\text {a }}$ semana - final do primeiro trimestre. Observou-se ainda que $60 \%$ delas deram à luz na maternidade dessa Instituição. Em relação ao número de gestantes que procuram esse serviço, verificou-se uma média de 18,5 de consultas novas, variando de 9 a 34 mulheres por mês. Essa oscilação ocorre principalmente por este serviço servir de campo de estágio para escolas de enfermagem da Unifesp e da Universidade de São Paulo - USP e, para os médicos residentes da Disciplina de Obstetrícia da Unifesp/EPM, o que acarreta uma variação do número de profissionais envolvidos no atendimento pré-natal.

Visando ampliar a entrada de gestantes na coorte implantou-se, em conjunto com a equipe do serviço, uma estratégia de captação precoce de mulheres para o atendimento pré-natal. Dessa maneira, todas as gestantes que procuravam o serviço eram argüidas a respeito da data da última menstruação (DUM) e, com essa informação, calculava-se a idade gestacional. Se esta fosse menor do que 17 semanas, as gestantes eram encaminhadas para as entrevistadoras que, após o treinamento realizado pelos médicos responsáveis pelo atendimento de pré-natal, obtinham a história obstétrica, coletavam as medidas antropométricas e solicitavam os exames de rotina, agendando o exame de ultrasonografia e a primeira consulta médica. Se a mulher apresentasse qualquer queixa relevante era encaminhada para o serviço de emergência do "Amparo Maternal". Assim foi possível aumentar a média de consultas novas.

Dada a complexidade e o número de informações coletadas, foram elaborados diferentes questionários e fichas de resumo de informações. Com 
o objetivo de garantir uma homogeneização dos tempos para a obtenção de alguns dados, elaborou-se um fluxo de aplicação dos questionários, conforme verifica-se na Figura 2.

Tendo em vista um maior controle das perdas de seguimento, elaboraram-se alguns instrumentos de contato entre a gestante e o serviço, de tal forma que qualquer falta, mudança e outras alterações que explicassem a interrupção do acompanhamento, fossem monitoradas.

Figura 2: Fluxorama de coleta de dados

\begin{tabular}{|c|c|c|}
\hline $\begin{array}{l}\text { Idade gestacional } \\
\text { semanas de gestação }\end{array}$ & $\begin{array}{l}\text { Questionário } \\
\text { aplicado }\end{array}$ & Informações coletadas \\
\hline 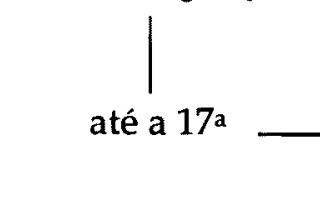 & $\begin{array}{r}1 \\
-\quad \mathrm{Q} 1+\end{array}$ & $\begin{array}{l}\text { Identificação } \\
\text { A mulher } \\
\text { Os antecedentes obstétricos e morbidade } \\
\text { A antropometria }\end{array}$ \\
\hline até a 22a & $-\mathrm{Q} 2$ & $\begin{array}{l}\text { A alimentação } \\
\text { A atividade física } \\
\text { O trabalho } \\
\text { A antropometria }\end{array}$ \\
\hline até a $24^{\mathrm{a}}$ & —Q3 & $\begin{array}{l}\text { A família e a renda } \\
\text { O cigarro e outras drogas } \\
\text { A antropometria }\end{array}$ \\
\hline Entre a $17^{a}$ e $28^{a}$ & _ Q4 & $\begin{array}{l}\text { A alimentação } \\
\text { A atividade física B } \\
\text { A antropometria }\end{array}$ \\
\hline $30^{\mathrm{a}} \pm 1 \mathrm{sem}$ & $-\mathrm{A} 30-$ & A antropometria \\
\hline a partir da $32^{a}$ & - Q5 & $\begin{array}{l}\text { A alimentação } \\
\text { A atividade física B } \\
\text { A antropometria }\end{array}$ \\
\hline Após o nascimento & QRN - & $\begin{array}{l}\text { Peso ao nascer } \\
\text { Idade gestacional }\end{array}$ \\
\hline
\end{tabular}




\subsection{Amostra}

Foi estudada uma coorte de gestantes que iniciaram a assistência prénatal de março de 1997 a março de 1998 no serviço "Amparo Maternal", apresentando na primeira entrevista idade gestacional igual $\mathrm{e} / \mathrm{ou}$ inferior a 17 semanas e que deram à luz a uma única criança viva.

A idade gestacional foi calculada a partir da data da última menstruação (DUM), e depois confirmada pelo exame de ultra-som. Excluíram-se da coorte as mulheres nas quais não ocorreu a confirmação da idade gestacional até a $17^{\text {a }}$ semana de gestação.

Visando, já neste momento, controlar algumas variáveis que sabidamente influenciam o aumento ponderal durante a gestação, foram determinados alguns critérios para seleção da coorte. Foram incluídas gestantes com idade igual ou superior a 18 anos, afastando-se, assim, aquelas que ainda podem estar na fase de crescimento. Foram excluídas as portadoras de doenças como: diabetes mellitus, cardiopatias, nefropatias, entre outras. Também não integraram a coorte as mulheres com gestação múltipla e as que deram à luz a criança portadora de anomalia congênita, detectável ao nascer..

Na Figura 3, vê-se o número final de gestantes incluídas na coorte, o número mulheres perdidas e as razões dessas perdas. Foi estudada uma coorte de 227 gestantes, notando-se uma perda de 19\% (45 perdas) das gestantes incluídas. Observaram-se 5 mulheres com informações incompletas em relação às medidas antropométricas (177) e 16 gestantes nas quais não foi realizado o último questionário a respeito da alimentação e da atividade física (166). Dessa forma, nas análises que relacionam as medidas antropométricas com a ingestão energética, trabalhou-se com 161 gestantes. 
Constataram-se, ainda, 9 gestantes que tiveram parto prematuro e, portanto, não realizaram o Q5.

Figura 3: Gestantes incluídas na coorte, número de mulheres perdidas e razão das perdas.

ENTRADA

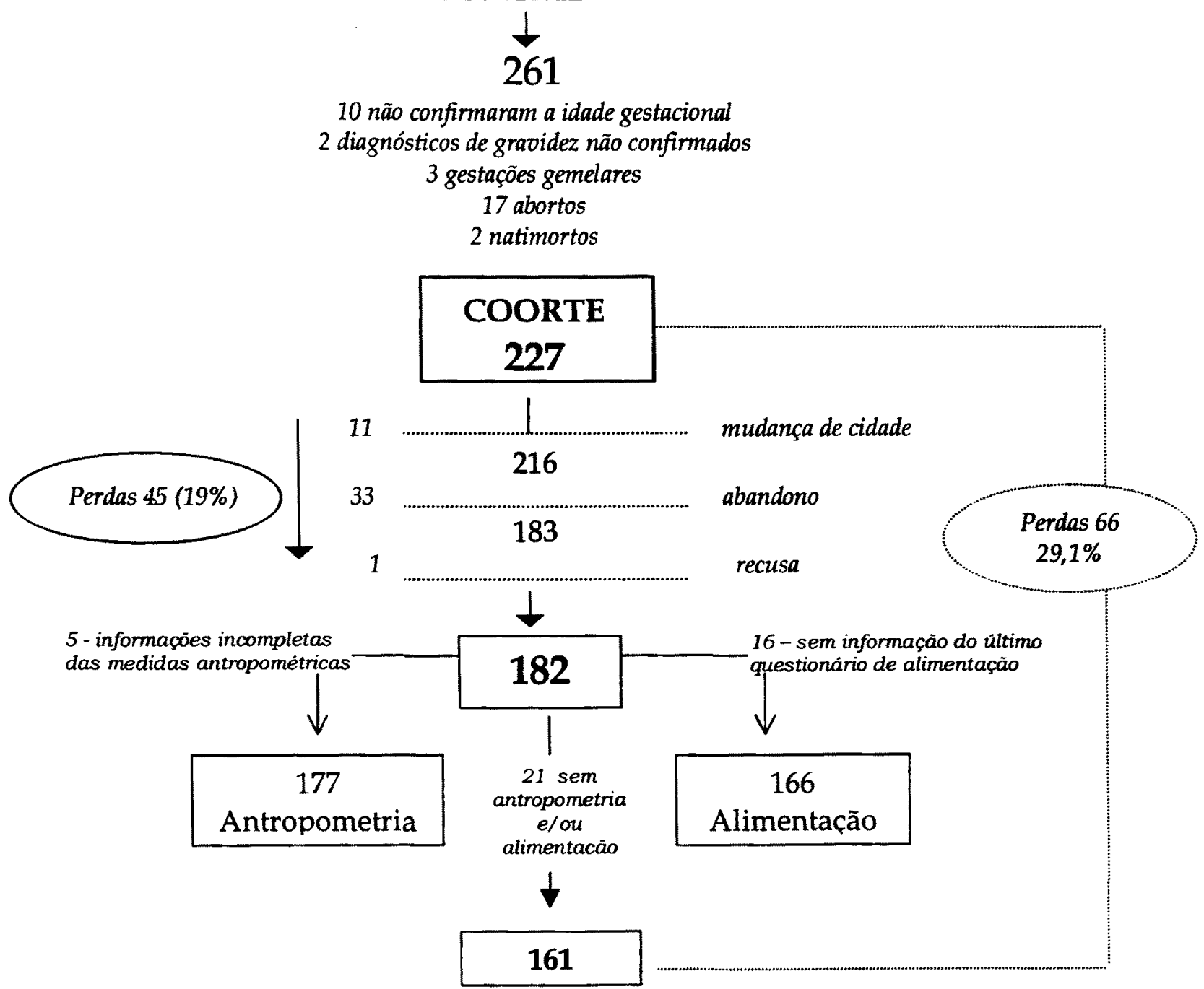




\subsection{AS VARIÁVEIS ESTUDADAS}

Levantaram-se informações a respeito da mulher, incluindo-se aí, além da identificação, a escolaridade, a alimentação, o trabalho e a atividade física. Questionou-se a gestante, também, quanto ao uso de álcool, drogas e o hábito de fumar. Em relação à família, verificou-se a composição e a renda familiar. Para caracterizar o estado nutricional materno, realizaram-se, durante todo o ciclo gravídico, medidas antropométricas que incluíram o peso e a estatura, as circunferências e pregas cutâneas. As informações ligadas aos antecedentes obstétricos e à morbidade materna foram levantadas, a partir do prontuário clínico - ficha de acompanhamento prénatal da Disciplina de Obstetrícia do Departamento de Tocoginecologia da Unifesp/EPM.

As gestantes foram entrevistadas durante o período gestacional por uma equipe composta, inicialmente, por cinco entrevistadoras, sendo duas "antropometristas", devidamente treinadas. As entrevistas foram realizadas a partir de questionários pré-testados. Para garantir a qualidade dos dados e também o controle da obtenção das informações, que foram coletadas em diferentes momentos da gestação, conforme já relatado anteriormente Figura 2 - ,contou-se com uma supervisão de campo que, além de supervisionar periodicamente os questionários, controlava o agendamento e as faltas, buscando também as informações das mulheres que interrompiam o seguimento de pré-natal.

Na Figura 4, observa-se o diagrama das variáveis estudadas, segundo o esquema proposto pelo Institute of Medicine - USA (1990a), dos determinantes do ganho de peso durante a gestação. 
Figura 4: Resumo esquemático das variáveis estudadas

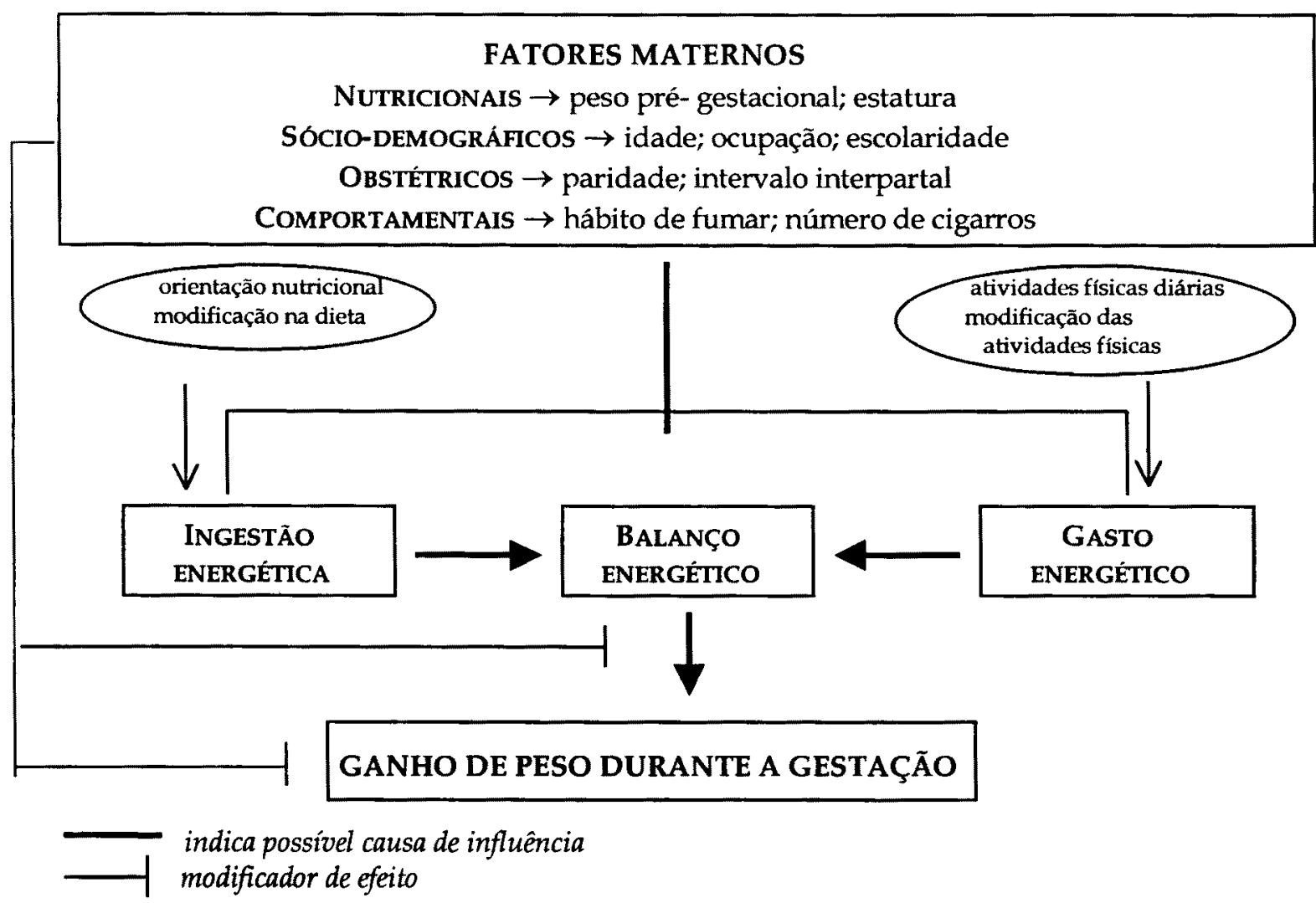

\subsubsection{A MULHER}

Essas informações foram coletadas no primeiro contato com a gestante, a partir de questionário próprio - PARTE 2: A MULHER -, que integra o conjunto de dados obtidos no que se denominou Q1 (anexo 1). Esse instrumento foi aplicado uma única vez, até a $17^{\text {a }}$ semana de gestação.

A idade foi questionada diretamente e, também, a data de nascimento. Nesse estudo, foi considerada a idade em anos, calculada a partir da diferença entre a data de nascimento e a data de aplicação deste questionário.

A escolaridade foi considerada em anos completos de estudo. As gestantes com menos de 4 anos de estudo foram interrogadas a propósito da capacidade de ler e escrever. Essa variável será utilizada como um marcador do nível socioeconômico, empregando-se para caracterizar a coorte estudada. 


\subsubsection{OS ANTECEDENTES OBSTÉTRICOS}

Essas informações foram obtidas no primeiro contato da gestante com o serviço, sendo transcritas, posteriormente, para o questionário próprio (PARTE 3: OS ANTECEDENTES OBSTÉTRICOS E MORBIDADE - anexo 2) que também integra o que se denominou Q1, aplicado uma única vez.

Coletaram-se informações a respeito da paridade e do intervalo interpartal (Kramer, 1987; Perry et al., 1995; Cogswell \& Yip, 1995).

\subsubsection{O TRABALHO}

As informações a respeito do trabalho materno foram levantadas em três momentos durante a gravidez (Q2, Q4 e Q5 - Figura 2). Primeiro, até a 22a semana de gestação (PARTE 6: O TRABALHO - anexo 3), no segundo entre a $17^{\mathrm{a}}$ e $28^{\mathrm{a}}$ semanas de gestação (PARTE 7: A ATIVIDADE FÍSICA B anexo 4) e, finalmente, entre a $32^{\mathrm{a}}$ e a $40^{\mathrm{a}}$ semanas de gestação.

A realização deste questionário, em três ocasiões permitiu verificar as alterações no trabalho materno ao longo da gestação. Possibilitando, assim, monitorar as modificações da atividade física relacionada com o trabalho fora de casa.

Com o objetivo de mensurar a atividade física no trabalho, a gestante foi argüida em relação a quantos dias trabalha na semana e também ao número de horas por dia. Nos outros questionários, verificaram-se as alterações do tipo e na quantidade de dias e horas gastas no trabalho.

\subsubsection{A ATIVIDAdE FísicA}

Elaborou-se um questionário específico, visando mensurar o tipo, a quantidade e a intensidade de atividades físicas diárias, realizadas pelas gestantes. Esse instrumento foi testado previamente, em uma amostra semelhante e foi aplicado em três momentos diferentes durante a gestação, objetivando acompanhar as modificações no padrão diário de atividades. As 
gestantes foram entrevistadas em relação a esses aspectos até a $22^{\mathrm{a}}$ semana de gestação (PARTE 7: A ATIVIDADE FÍSICA - anexo 5). Anotou-se, também a percepção das mesmas em relação à modificação de suas atividades, desde o início da gravidez. O mesmo formulário, incorporando-se as informações a respeito do trabalho materno, foi aplicado entre a $17^{\mathrm{a}}$ e a $28^{\mathrm{a}}$ semanas e entre a $32^{\mathrm{a}}$ e a $40^{\mathrm{a}}$ semanas de gestação. Estes formulários integram, respectivamente o $\mathrm{Q} 2$, o $\mathrm{Q} 4$ e o $\mathrm{Q} 5$.

O questionário de freqüência de atividades físicas diárias (QAFD) foi construído a partir de uma lista de atividades ligadas ao trabalho doméstico, ao trabalho fora de casa, ao lazer e ao exercício físico, como caminhar. Perguntava-se à gestante com que freqüência realizava cada uma das atividades na última semana, categorizando-as em nunca, de 1 a 2, de 3 a 4 e de 5 a 7 vezes por semana. Registrava-se, ainda, o tempo gasto na execução de cada uma das tarefas listadas, além da verificação da intensidade de algumas destas atividades, como andar lentamente, em velocidade normal ou rapidamente em terreno plano, descida ou subida. A gestante era argüida em relação às horas diárias de sono.

Com o QFDA estabeleceu-se o gasto energético específico para cada gestante, conforme apresentado no item 3. 4 "o consumo e o gasto energético".

\subsubsection{O CIGARRO}

Na PARTE 10: O CIGARRO E OUTRAS DROGAS - anexo 6, a mulher foi questionada em relação ao hábito de fumar durante a gestação e o número de cigarros fumados por dia. Esse formulário foi aplicado uma única vez até a $20^{\mathrm{a}}$ semana de gestação e integra o Q3.

Controlou-se essa variável nas análises pela relação que a mesma pode apresentar com a ingestão dietética e mesmo com o ganho de peso durante a 
gestação. Podendo representar uma variável de confusão na associação entre a ingestão dietética e o ganho de peso materno.

\subsubsection{A ANTROPOMETRIA}

Realizaram-se várias medidas das dimensões corpóreas da gestante durante todo o seguimento. As mensurações permitiram estimar o ganho de peso durante o período gravídico.

$O$ peso foi coletado em todos os atendimentos realizados à gestante no serviço de pré-natal. Visando garantir que todas as gestantes apresentassem essas medidas em pontos homogêneos do período gestacional, os momentos de coleta foram preestabelecidos, conforme Figura 2. Estipulou-se a variação de mais ou menos uma semana na tomada das medidas antropométricas nestes momentos.

A estatura da mulher e o peso pré-gestacional referido foram obtidos uma única vez, quando da realização da primeira entrevista.

$\mathrm{Na}$ definição do conjunto de medidas antropométricas realizadas neste estudo, foram utilizadas as recomendações sugeridas pela WHO, 1995b. Levou-se em conta, ainda, nessa definição, o grau de dificuldade na obtenção das mesmas, verificando-se a variação intra e inter-observadores.

As mulheres foram pesadas, sem sapatos e com pouca roupa, em balança digital eletrônica portátil da marca "Soehnle", com capacidade máxima de $150 \mathrm{~kg}$ e escala com divisões de 100 gramas.. A estatura foi medida, também sem sapatos, com estadiômetro.

As técnicas de tomada das medidas antropométricas foram padronizadas, utilizando-se as recomendações de Lohman et al.,1988 e Jellife \& Jellife,1989. As "antropometristas" foram treinadas em dois momentos. No primeiro, eram-lhes apresentadas as técnicas e os equipamentos de medições, estabelecendo-se os principais cuidados a serem realizados no momento da coleta dessas medidas. No segundo momento de treinamento, realizou-se a 
padronização das medidas antropométricas, comparando-se as aferições do entrevistador com as do treinador (medida padrão), segundo a recomendação da UN,1986.

\subsubsection{A ALIMENTAÇÃo}

Visando caracterizar a alimentação e estimar a ingestão calórica da gestante durante o período gravídico, foi elaborado um questionário específico - PARTE 8: A ALIMENTAÇÃO -anexo 7, no qual ela era argüida em relação à modificação alimentar desde o início da gravidez, à orientação dietética recebida, ao número de refeições realizadas e aos alimentos/bebidas consumidos na última semana. Esse instrumento foi prétestado em uma sub-amostra e as entrevistadoras foram devidamente treinadas para a sua aplicação.

O questionário de alimentação foi aplicado na mesma gestante em 3 ocasiões, até a $22^{\mathrm{a}}$ semana e entre a $17^{\mathrm{a}}$ e a $28^{\mathrm{a}}$ e finalmente entre a $32^{\mathrm{a}}$ e a $40^{\mathrm{a}}$ semanas de gestação, correspondendo ao Q2, Q4 e Q5. Verificaram-se, assim, as modificações no perfil de consumo dietético e da ingestão energética. A aplicação do questionário de alimentação ocorreu concomitantemente ao questionário de atividade física, permitindo a comparação entre o gasto e a ingestão calórica.

Para caracterizar a ingestão alimentar das gestantes, utilizou-se o método de inquérito de freqüência de consumo alimentar (QFA). Optou-se por este método, sob o formato de entrevista, para a obtenção qualitativa e quantitativa de consumo alimentar. Dessa maneira foi possível estimar o consumo energético das gestantes.

Os alimentos incluídos no questionário correspondem aos mais comumente consumidos pela população de adultos em área urbana, no município de São Paulo (Departamento Intersindical de Estatísticas e Estudos sócio-econômicos - DIEESE, 1987). Foi construída uma lista com 41 
alimentos e/ou bebidas, esta foi testada em uma sub-amostra de 10 gestantes, antes do início da pesquisa visando a estabelecer se este conjunto de alimentos/bebidas faziam parte do consumo habitual dessas mulheres. Incluíram-se, também, no QFA algumas perguntas abertas a respeito de outros alimentos/bebidas consumidas na última semana.

As gestantes eram questionadas quanto à freqüência de consumo, na última semana, dos alimentos/bebidas constantes na lista previamente elaborada, categorizando-se os mesmos em nunca, de 1 a 2, de 3 a 4 e de 5 a 7 vezes por semana. Com o objetivo de quantificar essa ingestão, perguntou-se, ainda, quantas vezes por dia cada alimento era consumido e a quantidade, em medidas caseiras, por vez. Quando necessário, verificou-se a forma de preparo de alguns alimentos.

Dada a dificuldade de se estimar as quantidades consumidas de gordura vegetal/animal e de açúcar, e a contribuição importante desses alimentos no conteúdo energético da dieta, empregou-se, também o método de freqüência de compras de alimentos, com o objetivo de quantificar o consumo de gordura vegetal (óleo, azeite, margarina), gordura animal (manteiga, toucinho, banha etc.) e açúcar. Questionando-se, também, a gestante quanto ao número de pessoas que faziam normalmente as refeições em casa.

\subsection{O CONSUMO E O GASTO ENERGÉTICO}

A partir da aplicação da QFA, foi possível estimar o consumo energético/calórico - IE (ingestão energética/calórica) das gestantes. Esta ingestão foi calculada em 3 momentos da gestação. 
O valor energético da alimentação foi calculado empregando-se o Programa de Apoio à Nutrição (Anção et al., 1993) a partir da multiplicação do conteúdo de macronutrientes de cada alimento na porção especificada pela frequiência do consumo diário, somando-se então os resultados.

Os QFAs foram calculados por estudantes de nutrição, devidamente treinadas no manuseio do referido programa. Visando ao controle dos erros de digitação e cálculo dos QFAs, realizou-se duplo cálculo em $10 \%$ da coorte estudada. Este procedimento foi utilizado como uma das estratégias de supervisão de todos os cálculos, sendo realizada por nutricionista.

Quanto ao tamanho das porções de alimentos e as preparações não contidas nesse programa, utilizou-se a tabela elaborada por Pinheiro et al. (1994) ou realizou-se, quando a preparação não foi encontrada nas tabelas, o preparo do alimento para quantificação das diferentes porções em medidas caseiras, seguindo-se os métodos propostos por Trigo (1993), Pinheiro et al. (1994) e Brasil - Ministério da Saúde (1996).

Pela contribuição fundamental no conteúdo calórico das dietas das gorduras e do açúcar de adição, e como dificilmente este dado é obtido diretamente, a partir dos métodos recordatórios de consumo de alimentos, foi utilizada a padronização de consumo de margarina e óleo vegetal proposta por Sachs, 1997, para população idosa. Quanto à padronização do consumo de açúcar, empregou-se a porcentagem de $10 \%$ de adição desse alimento em relação ao volume final das bebidas que a gestante referiu utilizar adocicadas (café, café com leite, chás e sucos).

Com o objetivo de validar essas padronizações, realizou-se em uma sub-amostra de 40 gestantes ( $16 \%$ da amostra total) entre a $4^{\text {a }}$ e a $16^{\text {a }}$ semanas de gestação, a comparação entre as quantidades preestabelecidas de consumo de óleo vegetal, margarina e açúcar com o per capita desses alimentos obtidos a partir do inquérito de compra. Observou-se uma concordância entre a padronização utilizada no consumo de óleo vegetal e 
margarina e a quantidade, per capita, do inquérito de compras de alimentos. Para o açúcar não se verificou essa adequação, indicando que a padronização utilizada pode estar subestimando o consumo deste alimento, provavelmente por não ter sido adicionado ao leite puro (consumido quase que diariamente pelas gestantes) durante o cálculo do QFA (Bloisi et al., 1999). Assim, a partir dessa análise, acrescentou-se a porcentagem de 10\% de açúcar ao volume total de leite consumido pela gestante.

Nesse estudo, com o objetivo de se verificar a validade do QFA empregado, para estimar a ingestão energética, foi calculada a razão entre a ingestão e a taxa de metabolismo basal (TMB). Pelas características deste estudo as alterações corpóreas - peso - poderão ser utilizadas como parâmetros, para se constatar a adequação da estimativa da ingestão energética.

Para verificar a adequação do consumo calórico, estimou-se gasto energético. Calculou-se, primeiramente, a taxa de metabolismo basal, segundo as equações propostas pela OMS (1985), de acordo com a Tabela 2. Foram utilizadas as equações que levam em consideração o peso, a estatura e a idade. $\mathrm{O}$ acréscimo da estatura, não altera de forma significante esse cálculo, diferindo em torno de apenas $10 \%$ daquele estimado somente com a informação do peso. Parece, entretanto, que nas mulheres essa alteração pode ser um pouco maior. Sendo assim, como se dispõe desse dado, optou-se pelo uso das equações completas.

Tabela 2: Equações para estimativa da taxa de metabolismo basal (TMB) por faixa de idade em anos, no sexo feminino (OMS , 1985).

\begin{tabular}{cc}
\hline Idade & Équaçó́tes \\
\hline 18 a 30 & $13,3 P^{*}+334 \mathrm{E}^{\star \star}+35$ \\
31 a 60 & $8,7 \mathrm{P}-25 \mathrm{E}+865$ \\
\hline
\end{tabular}

\footnotetext{
*P $=$ peso $(\mathrm{kg})$

${ }^{* *} E=$ estatura $(m)$
} 
Prentice et al. (1996), em artigo de revisão dos estudos conduzidos nos últimos 10 anos, a respeito da necessidade calórica durante a gravidez e a lactação, considerando: o incremento de tecido adiposo materno, o aumento da TMB neste periodo, as modificações da termogênese dos alimentos, a realização de atividades físicas, a possivel modificação do gasto energético na realização das mesmas e, ainda, a ingestão energética durante a gravidez, propõem diferentes métodos para o cálculo das necessidades energéticas nesse período. Optou-se, portanto, neste estudo, para estimar o gasto energético das gestantes, por um acréscimo na TMB, conforme as fórmulas abaixo, obtendo-se a TMB total (TMB T)

- $\mathrm{TMB}_{\mathrm{T}}=\mathrm{TMB}_{(\mathrm{kcal})}+48_{(\mathrm{kcal})} \ldots \ldots . . .$. primeiro trimestre

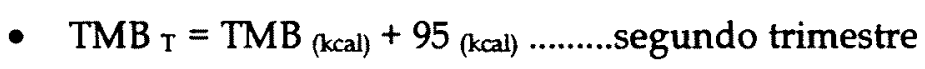

- $\mathrm{TMB}_{\mathrm{T}}=\mathrm{TMB}_{\text {(kcal) }}+262$ (kca) ........terceiro trimestre

Para o cálculo do gasto energético utilizaram-se, primeiramente, as informações a respeito das atividades físicas diárias, coletadas a partir do QFDA , conforme descrito no item 3.3.4, agrupando-se as mesmas, segundo a classificação proposta pelo National Research Councial,1989, em repouso, muito leve, leve e moderada (anexo 8). Posteriormente, ao valor calculado da $\mathrm{TMB}_{\mathrm{T}}$ foi acrescentado, como múltiplos dessa taxa, o gasto energético para o desenvolvimento destes grupos de atividades físicas, considerando-se o tempo empregado na execução das mesmas. Utilizaram-se os múltiplos de gasto energético segundo a TMB, propostos pela OMS (1985). Na Tabela, 3 encontra-se descrita a planilha de cálculos para se estimar o gasto energético das gestantes.

Finalmente, obteve-se a adequação do consumo energético a partir das seguinte fórmula, nos três momentos de coleta dos dados de alimentação: ingestão energética/gasto energético. 
Tabela 3: Planilha de cálculos para estimar o gasto energético

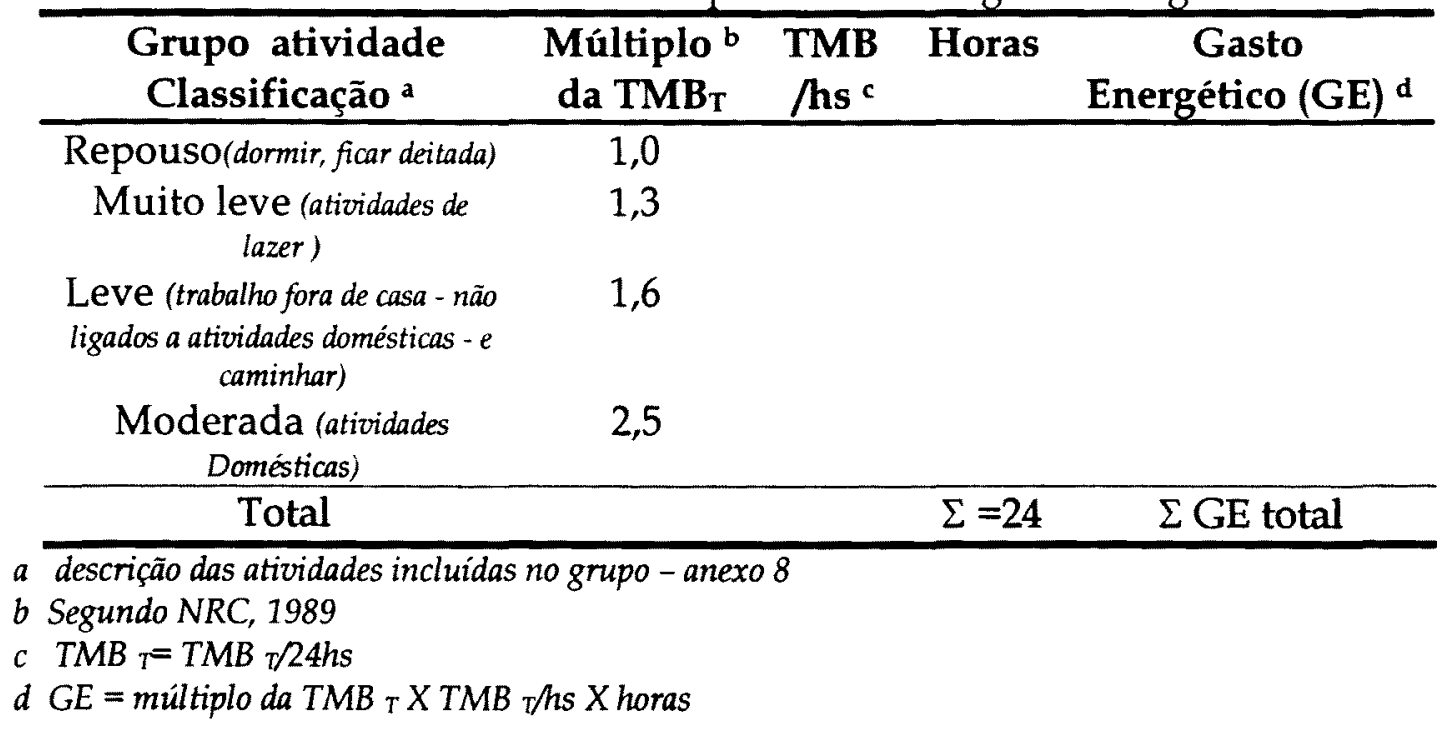

\subsection{OSTADO NUTRICIONAL MATERNO}

\subsubsection{O ESTADO NUTRICIONAL PRÉ-gestaCIONAL E INICIAL}

$O$ estado nutricional materno pré-gestacional e o inicial (na entrada da coorte) foram obtidos pelo índice de massa corpórea (IMC), calculados com o peso pré-gestacional ( $P_{\mathrm{PG}}$ ) referido na primeira entrevista da gestante,

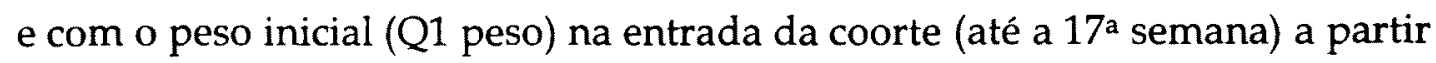
da fórmula: $\mathbf{P}_{P G}$ ou $\mathbf{P}_{\text {INICIAl (kg) } / \text { estatura }}{ }^{2}(\mathrm{~m})$.

Para classificar o estado nutricional pré-gestacional, empregaram-se os pontos de corte sugeridos pelo Institute of Medicine (1990), conforme Tabela 4 . 
Tabela 4: Pontos de corte do IMC $\mathrm{PG}\left(\mathrm{kg} / \mathrm{m}^{2}\right)$ sugeridos para o diagnóstico nutricional pré-gestacional (Institute of Medicine, 1990b)

\begin{tabular}{cc}
\hline IMC $\left(\mathbf{k g} / \mathbf{m}^{2}\right)$ & Estado nutricional \\
\hline$<19,8$ & baixo peso \\
19,8 a 26,0 & peso normal (eutrofia) \\
26,1 a 29,0 & peso elevado (sobrepeso) \\
$>29,0$ & Obesidade \\
\hline
\end{tabular}

O estado nutricional inicial foi obtido a partir da tabela de referência proposta por Atalah et al., em 1997, para classificar as mulheres em: baixo peso, eutrofia, sobrepeso e obesidade, segundo o incremento de IMC esperado, de acordo com a idade gestacional.

\subsubsection{O ESTADO NUTRICIONAL GESTACIONAL}

O ganho de peso total durante a gestação foi calculado a partir da diferença entre o peso inicial (Q1 peso), e o peso final obtido a partir da 32a semana de gestação (Q5 peso). Para se obter esse ganho por semana, dividiuse o ganho total pelas semanas de duração do intervalo entre o Q1 e Q5.

Verificou-se o ganho de peso, para cada gestante, em três períodos, durante a gestação: inicial (Q2 peso-Q1 peso); segundo (Q4 peso-Q2 peso) terceiro (Q5peso-Q4peso). Calculou-se, ainda, o ganho de peso por semanas de gestação, segundo o período. Este foi obtido dividindo-se o total de ganho de peso no período pelas semanas de gestação, referentes aos intervalos de tempo dos respectivos períodos. 


\subsection{A ANÁLISE DOS DADOS}

Para o gerenciamento e análise dos dados, utilizou-se, primeiramente, o programa estatístico Epi Info 6 (Centers for Diease Control \& Prevention, 1994).

A consistência dos dados foi verificada, corrigindo-se os erros de digitação, verificando-se a distribuição das variáveis estudadas. Nos dados de alimentação (cálculo das frequêencias de consumo de alimentos) realizouse a duplicata da digitação em uma sub-amostra das gestantes.

Para descrever as variáveis relacionadas com a mulher, com os antecedentes obstétricos, com o trabalho, com o cigarro e com a antropometria e caracterizar a amostra foram, calculadas as médias com os respectivos desvios-padrão, as medianas e os valores dos percentis 25 e 75 , e também, as proporções, dependendo da distribuição e do tipo de variável. Foram descritos da mesma maneira, para o total da amostra, a ingestão energética, o ganho de peso total e por semana durante a gestação.

Com o intuito de comparar a amostra efetivamente estudada com as perdas de seguimento, foram analisados o comportamento e a distribuição, nos dois grupos, das seguintes variáveis: idade, escolaridade, paridade, intervalo interpratal, hábito de fumar e estado nutricional pré-gestacional e inicial. Para comparar as médias dos dois grupos utilizou-se o teste $t$ de Student. Empregou-se, também, o teste $t$ pareado para verificar a diferença entre as médias no mesmo grupo.

As mudanças no consumo e no gasto energético e o aumento ponderal

Visando a descrever o comportamento do consumo e do gasto energético, e também, descrever o ganho de peso total e por semana, durante 
a gestação nos diferentes períodos, foram calculadas as medianas e o os valores dos percentis 25 e 75, segundo as categorias de IMC inicial.

Verificaram-se, também, as modificações alimentares durante a gestação. Essa informação foi fundamental, principalmente no início da gravidez, onde algumas vezes ocorrem importantes alterações na dieta.

\section{O consumo energético versus o aumento ponderal}

Empregou-se a análise de regressão linear múltipla, para verificar a influência do consumo energético no aumento ponderal, durante a gestação, nos três períodos de observação. Controlou-se em cada um dos modelos o intervalo de tempo, em semanas, entre a realização das medidas, o peso inicial da gestante no período analisado, a idade, a estatura e a paridade.

Para a escolha das variáveis que entraram no modelo final, considerouse a associação destas com a variável resposta (ganho de peso) e com a variável de exposição (consumo energético). Foram mantidas nos modelos finais aquelas variáveis que, mesmo sem significância estatística, modificaram em $20 \%$ ou mais o coeficiente da regressão entre o ganho de peso e o consumo de energia, nos três períodos da gestação analisados.

Para o cálculo das regressões utilizou-se o procedimento específico do programa SAS (SAS Institute, 1990).

\subsection{Aspectos ÉtICOS}

O estudo é de baixo risco; os benefícios suplantam o eventual desconforto de responder a questionários e de submeter-se à avaliação antropométrica. 
A justificativa e objetivos do estudo, e, também, os procedimentos utilizados na pesquisa, foram explicados oralmente às gestantes em linguagem compreensível. Foi garantida a liberdade da gestante de se recusar a participar ou de retirar seu consentimento, em qualquer fase da pesquisa, sem penalização alguma e sem prejuízo em seu cuidado. Foi igualmente garantida a privacidade, confidencialidade e anonimato das gestantes estudadas.

Não foi obtido o termo de consentimento esclarecido por escrito, porque mais da metade das gestantes da coorte já estavam sendo seguidas pelo estudo anteriormente à constituição do Comitê de Ética da Faculdade de Saúde Pública.

Dada a necessidade de iniciar o acompanhamento antes da $17^{\mathrm{a}}$ semana de gestação, todas as gestantes que aceitaram participar do estudo $(N=261)$ tiveram agendamento da primeira consulta médica com antecipação de cerca de 30 dias em relação à data de agendamento da rotina do serviço. 
RESULTADOS 


\section{RESUltados}

\section{1 A COORTE}

Com o objetivo de descrever as características gerais da coorte estudada, apresentam-se na Tabela 4 as variáveis investigadas neste estudo. Algumas destas foram comparadas com o perfil das mulheres que não completaram o seguimento por abandono e, portanto, foram consideradas perdas.

Observou-se, tanto na coorte estudada como nas gestantes que abandonaram o seguimento, uma média de idade de 24 anos, variando de 18 a 42 nas da coorte e de 18 a 37 anos nas gestantes perdidas.

Em relação à escolaridade, não se verificaram diferenças entre as mulheres que integram a amostra e aquelas que não concluíram o acompanhamento, considerando-se tanto a média de anos estudados, quanto a porcentagem daquelas que não freqüentaram a escola e/ou não sabiam ler e escrever. 
O número médio de filhos e a porcentagem de primíparas foram semelhantes nos dois grupos. A freqüência de gestantes com intervalo interpartal superior a dois anos foi semelhante, nos dois grupos; 68,8\% na coorte estudada e $66,6 \%$ nas perdas de seguimento.

Das gestantes estudadas, $17,6 \%$ eram fumantes e persistiram nesse hábito, durante a gestação. Nas perdas, constatou-se uma freqüência percentual inferior, $15,6 \%$.

Tabela 4: Características gerais da coorte estudada e das gestantes que abandonaram o seguimento (perda)

\begin{tabular}{ccc}
\hline Características & $\begin{array}{c}\text { Coorte } \\
(n=182)\end{array}$ & $\begin{array}{c}\text { Perda } \\
(n=33)\end{array}$ \\
\hline \multicolumn{2}{c}{ Média e desvio padrão } \\
\hline Idade (anos) & $24,4 \pm 5,0$ & $23,7 \pm 4,2$ \\
Escolaridade (anos completos de estudo) & $7,0 \pm 3,3$ & $6,1 \pm 2,9$ \\
Paridade (número prévio de filhos) & $0,8 \pm 1,0$ & $0,9 \pm 1,2$ \\
\hline \multicolumn{2}{c}{ Proporções (\%) } & \\
\hline Não freqüientaram a escola & 2,2 & 0,0 \\
Analfabetas & 5,1 & 0,0 \\
Primíparas & 48,9 & 54,5 \\
Intervalo interpartal > 2 anos & 68,8 & 66,6 \\
Fumantes & 17,6 & 15,6 \\
\hline
\end{tabular}

A Tabela 5, apresenta a comparação entre as gestantes estudadas e as perdas de seguimento com relação ao estado nutricional pré-gestacional e inicial, aos índices antropométricos e a idade gestacional no início da investigação. Em seis mulheres da coorte, que não sabiam referir quanto pesavam antes de engravidar, estimou-se o peso pré-gestacional, a partir do ganho de peso esperádó, segundo os dados de Gueri et al., 1982.

O estado nutricional pré-gestacional das gestantes da coorte revelou uma porcentagem um pouco maior de sobrepeso e obesidade $(16,4 \%)$ do que 
de baixo peso $(14,3 \%)$. A mediana e os percentis 25 e 75 do IMC $_{\text {PRÉ e }}$

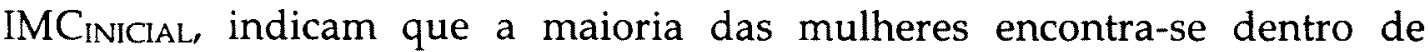
limites adequados para este indicador do estado de nutrição da população adulta.

Chama a atenção, ainda nesta tabela, a elevada prevalência de obesidade pré-gestacional entre as gestantes que não concluíram o seguimento, $18,6 \%$ contra $6,0 \%$ de mulheres da coorte. Essa diferença é confirmada, quando se observam os valores da mediana e do percentil 75 , tanto do peso pré-gestacional, quanto do peso inicial, que são sempre maiores naquelas que abandonaram o seguimento. Em relação aos índices de massa corpórea, as gestantes consideradas perdas não apresentam uma distribuição tão adequada quanto àquela observada entre as mulheres da coorte, pois os valores da mediana, $I_{\text {PRÉ }}$ IMC INICIAL estão próximos dos pontos de corte indicativos de peso excessivo na população adulta feminina. Verificou-se uma diferença estatisticamente significante entre as médias dos índices antropométricos analisados, com exceção da estatura, das gestantes da coorte e das que abandonaram o seguimento (anexo 9).

Comparando-se as médias dos pesos pré-gestacional e inicial, 57,6 $( \pm 9,2)$ e $58,5 \mathrm{~kg}( \pm 9,9)$, respectivamente, verificou-se uma diferença estatisticamente significante entre eles $(t=3,77 \quad p=0,0002)$. A média das diferenças entre o peso inicial e pré-gestacional foi de $0,89 \mathrm{~kg} \pm 3,2$. Nas próximas análises, as gestantes serão estratificadas segundo o estado nutricional inicial, isto é, na entrada na coorte, considerando-se o peso diretamente aferido e a idade gestacional. 
Tabela 5: Distribuição percentual das gestantes estudadas e das perdas de seguimento segundo o estado nutricional pré-gestacional e inicial, índices antropométricos e idade gestacional no início do estudo.

\begin{tabular}{|c|c|c|c|c|}
\hline \multirow[b]{2}{*}{ Estado nutricional } & \multicolumn{2}{|c|}{ Coorte $(n=182)$} & \multicolumn{2}{|c|}{ Perdas $(n=33)$} \\
\hline & $\begin{array}{c}\text { Pré⿱一𫝀} \\
n(\%)\end{array}$ & $\begin{array}{c}\text { Inicial }^{* *} \\
n(\%)\end{array}$ & $\begin{array}{c}\text { Pré } \\
n(\%)\end{array}$ & $\begin{array}{l}\text { Inicial } \\
n(\%)\end{array}$ \\
\hline Baixo peso & $26(14,3)$ & $36(19,8)$ & $5(15,6)$ & $6(18,2)$ \\
\hline Eutrofia & $126(69,3)$ & $109(59,9)$ & $20(62,5)$ & $15(45,5)$ \\
\hline Sobrepeso & $19(10,4)$ & $25(13,7)$ & $1(3,1)$ & $7(21,2)$ \\
\hline Obesidade & $11(6,0)$ & $12(6,6)$ & $6(18,8)$ & $5(15,1)$ \\
\hline Sem informação & - & - & 1 & - \\
\hline Índices antropométricos & \multicolumn{2}{|c|}{$P 25-M d-P 75$} & \multicolumn{2}{|c|}{$P 25-M d-P 75$} \\
\hline Estatura (m) & \multicolumn{2}{|c|}{$1,55-1,58-1,62$} & \multicolumn{2}{|c|}{$1,54-1,58-1,64$} \\
\hline Peso pré-gestacional (kg) & \multicolumn{2}{|c|}{$52,0-56,0-63,0$} & \multicolumn{2}{|c|}{$49,5-61,0-70,0$} \\
\hline Peso inicial (kg) & \multicolumn{2}{|c|}{$52,1-57,3-62,8$} & \multicolumn{2}{|c|}{$50,7-65,5-73,0$} \\
\hline $\operatorname{IMC} C_{P R E}\left(\mathrm{~kg} / \mathrm{m}^{2}\right)$ & \multicolumn{2}{|c|}{$20,5-22,5-24,6$} & \multicolumn{2}{|c|}{$20,7-24,0-25,8$} \\
\hline $\operatorname{IMC} \operatorname{INICIAL}_{\left(\mathrm{kg} / \mathrm{m}^{2}\right)}$ & \multicolumn{2}{|c|}{$21,0-22,6-24,9$} & \multicolumn{2}{|c|}{$21,3-24,4-29,8$} \\
\hline Idade gestacional inicial (sommes) & \multicolumn{2}{|c|}{$9-12-14$} & \multicolumn{2}{|c|}{$10-11-14$} \\
\hline
\end{tabular}

Observa-se, na Tabela 6, que a média da idade gestacional das mulheres na entrada na coorte foi de 11,3 semanas; $85,7 \%$ das gestantes iniciaram o seguimento até a $14^{\text {a }}$ semana, portanto, ainda no primeiro trimestre de gestação. Verificou-se uma gestante com idade gestacional de 17 semanas. No segundo momento de investigação, a idade gestacional média foi de 16,2 semanas; $90 \%$ com idade inferior a $20^{\text {a }}$ semana. Na terceira observação, 66,5\% das mulheres apresentavam neste momento uma idade gestacional igual ou superior a $21^{\mathrm{a}}$ semana. No último momento (4a observação), constatou-se cerca de $61 \%$ das mulheres com 35 semanas ou mais de gestação. 
Tabela 6: Média e desvio padrão e valores mínimos e máximos da idade gestacional por ocasião das observações.

\begin{tabular}{cccc}
\hline & & \multicolumn{2}{c}{ Idade gestacional (semanas) } \\
\cline { 4 - 4 } Observações & $\mathbf{N}$ & Média $\pm \mathrm{DP}$ & $\begin{array}{c}\text { Variação } \\
\text { Min-max }\end{array}$ \\
\hline Entrada/primeira - Q1 & 182 & $11,3 \pm 2,8$ & $2-17$ \\
Segunda - Q2 & 182 & $16,2 \pm 2,9$ & $6-22$ \\
Terceira - Q4 & 182 & $22,4 \pm 2,3$ & $17-31^{\star}$ \\
Quarta - Q5 & $175^{\star \star}$ & $35,6 \pm 1,4$ & $31-40$
\end{tabular}

*Três gestantes com idade gestacional acima da $28^{a}$ semana foram excluídas das análises do consumo energético e do aumento ponderal durante a gestação, nesse intervalo.

** Sete gestantes com parto prematuro

$\mathrm{Na}$ Figura 4, verificam-se os diferentes períodos de análise do consumo de energia e do ganho de peso durante a gestação.

Figura 4: Períodos de observação da ingestão energética (IE) e do ganho de peso durante a gestação

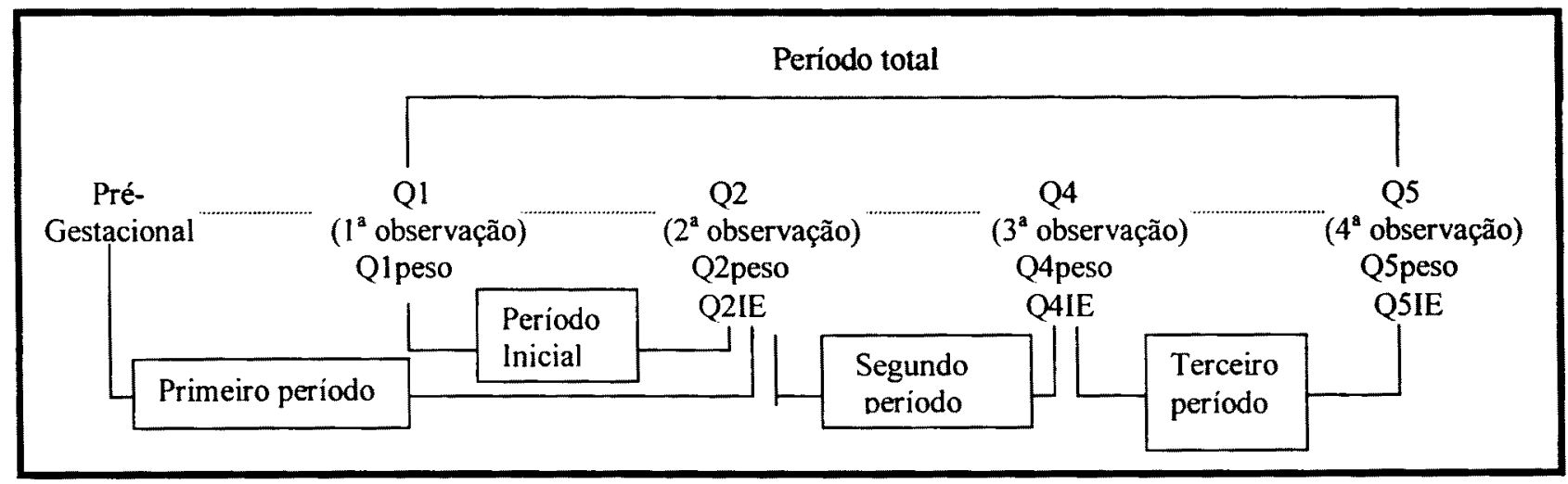

Na Tabela 7, observa-se o trabalho das mulheres, nos três períodos de observação. Essa informação será importante para o cálculo do gasto energético e, portanto, para a adequação da ingestão energética. Verifica-se que menos de $50 \%$ das mulheres trabalham fora de casa, e que este percentual vai diminuindo ao longo da gestação, principalmente, entre o primeiro e o terceiro período ( $48 \%$ e $29 \%$ respectivamente). 
O tipo de atividade/ocupação das mulheres está ligado diretamente ao trabalho doméstico; cerca de 50\% apresentam as seguintes atividades: empregada doméstica (maior proporção - 31,8\%), diarista, auxiliar de limpeza, babá, auxiliar de cozinha e copeira. Entre as demais verificou-se uma freqüência maior de vendedoras $(8,0 \%)$, seguida de caixa, auxiliar de escritório, secretária, garçonete, costureira, operária e gerente de restaurante.

Tabela 7: Distribuição no número e porcentagem de gestantes que trabalham fora segundo o período gestacional

\begin{tabular}{cccc}
\hline \multirow{2}{*}{ Trabalho } & \multicolumn{3}{c}{ Período } \\
\cline { 2 - 4 } & Primeiro & Segundo & Terceiro \\
& $n(\%)$ & $n(\%)$ & $n(\%)$ \\
\hline Sim & $88(48,3)$ & $74(40,7)$ & $50(28,9)$ \\
Não & $94(51,7)$ & $101(55,5)$ & $108 .(62,4)$ \\
Sem informação & - & $7(3,8)$ & $15(8,7)$ \\
Total & 182 & 182 & 173 \\
\hline
\end{tabular}

Apresentam-se na Tabela 8 as principais características das gestantes da coorte. Todas essas variáveis podem influenciar a relação entre a ingestão energética e o ganho ponderal durante a gestação.

Verificou-se na coorte $19,8 \%$ de gestantes com baixo peso (BXP), 13,7\% com sobrepeso (SBP) e 6,6\% classificadas com obesidade (OBS) no início da gestação. A porcentagem de mulheres com peso excessivo (sobrepeso mais obesidade) foi um pouco superior à ocorrência de baixo peso, a partir do diagnóstico nutricional realizado na entrada das mulheres no estudo.

$\mathrm{Na}$ Tabela 8 , observa-se que $50 \%$ ou mais das gestantes encontram-se na faixa etária de 18 a 25 anos, independentemente do estado nutricional inicial. Constata-se uma porcentagem maior de mulheres de baixo peso, entre aquelas com idade entre 18 a 20 anos (30,2\%). A média de idade entre as mulheres classificadas com sobrepeso e obesidade foi superior à das gestantes com baixo peso e eutróficas no início da gestação. 
Tabela 8: Distribuição das gestantes segundo as variáveis estudadas e o estado nutricional inicial ${ }^{*}$

\begin{tabular}{|c|c|c|c|c|c|}
\hline \multirow[b]{2}{*}{ Variáveis } & \multicolumn{5}{|c|}{ Estado nutricional inicial } \\
\hline & $\begin{array}{c}\text { BXP } \\
36 \quad(19,8) \\
n \quad(\%)\end{array}$ & $\begin{array}{c}\text { EUT } \\
109(59,9) \\
n\end{array}$ & $\begin{array}{c}\text { SBP } \\
25(13,7) \\
n \quad(\%)\end{array}$ & $\begin{array}{c}\text { OBS } \\
12(6,6) \\
n \quad(\%)\end{array}$ & $\begin{array}{c}\text { Total } \\
182(100) \\
n \quad(\%)\end{array}$ \\
\hline \multicolumn{6}{|l|}{ Idade (anos) } \\
\hline 18 a 20 & $13(30,2)$ & $25(58,1)$ & $3(7,0)$ & $2(4,7))$ & $43(100)$ \\
\hline 21 a 25 & $16(22,2)$ & $41(56,9)$ & $11(15,3)$ & $4(5,6)$ & $72(100)$ \\
\hline 26 a 30 & $6(14,0)$ & $28(65,1)$ & $5(11,6)$ & $4(9,3)$ & $43(100)$ \\
\hline 31 a 39 & $1(4,5)$ & $13(59,1)$ & $6(27,3)$ & $2(9,1)$ & $22(100)$ \\
\hline 40 ou mais & $\therefore$ & $2(100)$ & $\therefore$ & $\therefore$ & $2(100)$ \\
\hline Média DP & $22,1 \quad 3,4$ & $24,75,1$ & $25,75,6$ & $26,1 \quad 5,1$ & $24,4 \quad 5,0$ \\
\hline \multicolumn{6}{|c|}{ Escolaridade (anos de estudo) } \\
\hline Nenhuma & $1(25,0)$ & $3(75,0)$ & - & - & $4(100)$ \\
\hline 1 a 4 & $11(22,0)$ & $33(66,0)$ & $3(6,0)$ & $3(6,0)$ & $50(100)$ \\
\hline 5 a 8 & $13(18,6)$ & $38(54,2)$ & $12(17,2)$ & $7(10,0)$ & $70(100)$ \\
\hline 9 a 11 & $11(23,4)$ & $26(55,3)$ & $8(17,0)$ & $2(4,2)$ & $47(100)$ \\
\hline $12 \mathrm{ou}+$ & - & $6(75,0)$ & $2(25,0)$ & - & $8(100)$ \\
\hline Sem infor. & - & 3 & - & - & 3 \\
\hline Média DP & $6,6 \quad 3,0$ & $7,0 \quad 3,6$ & $7,8 \quad 2,9$ & $7,6 \quad 2,9$ & $7,0 \quad 3,3$ \\
\hline \multicolumn{6}{|c|}{ Paridade (número prévio filhos) } \\
\hline Primíparas & $20(22,5)$ & $56(62,9)$ & $9(10,1)$ & $4(4,5)$ & $89(100)$ \\
\hline 1 a 2 & $12(16,0)$ & $44(58,7)$ & $13(17,3)$ & $6(8,0)$ & $75(100)$ \\
\hline 3 ou + & $2(18,2)$ & $6(54,5)$ & $2(18,2)$ & $1(9,1)$ & $11(100)$ \\
\hline Sem infor. & $2(5,4)$ & $3(2,8)$ & $1(4,0)$ & $1(8,3)$ & $7(100)$ \\
\hline Média $D P$ & $0,7 \quad 0,9$ & $0,7 \quad 0,9$ & $1,0 \quad 1,2$ & $0,8 \quad 0,9$ & $0,8 \quad 1,0$ \\
\hline \multicolumn{6}{|c|}{ Intervalo interpartal (anos) } \\
\hline - de 1 & - & $2(66,7)$ & - & $1(33,3)$ & $3(100)$ \\
\hline 1 a 1,5 & $2(22,2)$ & $4(44,4)$ & $2(22,2)$ & $1(11,1)$ & $9(100)$ \\
\hline 1,5 a 2 & $3(27,3)$ & $6(54,5)$ & $2(18,2)$ & - & $11(100)$ \\
\hline+ de 2 & $9(14,3)$ & $38(60,3)$ & $11(17,5)$ & $5(7,9)$ & $63(100)$ \\
\hline Sem infor. & 2 & 3 & 1. & 1 & 7 \\
\hline \multicolumn{6}{|c|}{ Hábito de fumar } \\
\hline Sim & $3(9,4)$ & $22(68,7)$ & $5(15,6)$ & $2(6,3)$ & $32(100)$ \\
\hline Não & $25(23,1)$ & $65(60,3)$ & $13(12,0)$ & $5(4,6)$ & $108(100)$ \\
\hline Ex-fumante & $2(7,4)$ & $15(55,6)$ & $6(22,2)$ & $4(14,8)$ & $27(100)$ \\
\hline Sem infor. & $6(16,7)$ & $7(6,4)$ & $1(4,0)$ & $1(8,3)$ & $15(100)$ \\
\hline \multicolumn{6}{|c|}{ No de cigarros/dia } \\
\hline Média DP & $6,7 \quad 6,4$ & $8,1 \quad 6,5$ & $8,0 \quad 7,4$ & $6,0 \quad 0,0$ & $7,8 \quad 6,2$ \\
\hline
\end{tabular}


O número médio de anos que as mulheres estudaram foi de 6,6 a 7,8 anos. Notou-se, porém, que cerca de $30 \%$ das gestantes estudaram de 1 a 4 anos. Assim, apesar de um número médio de anos estudados aceitável, a freqüência de baixa escolaridade na coorte foi expressiva. Esse número de anos de estudos tendeu a ser mais elevado nas gestantes com sobrepeso e obesidade inicial.

Em relação à paridade, encontrou-se que cerca da metade das gestantes eram primíparas, constatando-se, ainda, um diferencial segundo o diagnóstico nutricional inicial. A porcentagem de primíparas foi inferior nas mulheres com sobrepeso $(36,0 \%)$ e obesas $(33,3 \%)$; nos outros diagnósticos a porcentagem foi igual ou superior a $50 \%$. Quanto ao intervalo interpartal, notou-se que mais de $60 \%$ o apresentavam acima de dois anos, a não ser entre as gestantes com baixo peso, nas quais verificou-se um valor um pouco inferior.

A porcentagem de mulheres que referiram fumar durante a gravidez variou de 8,3 a $20,2 \%$. O número médio de cigarros fumados por dia foi de 7,8 . 


\subsection{A ALIMENTAÇÃo}

Com o objetivo de descrever a alimentação e o consumo energético das gestantes, foram estudadas 166 mulheres, em três períodos durante a gestação. Na Figura 5, apresentam-se os intervalos entre essas observações e o número de mulheres em cada período.

Figura 5: Períodos de observação da ingestão energética das gestantes, média e desvio-padrão dos intervalos (semanas)

Pré-

$$
\text { Q1 }
$$
(1 ${ }^{\text {a }}$ observação)

Q2 ( $2^{\mathrm{a}}$ observação)

Q4 ( $3^{a}$ observação)

Q5

Gestacional

$$
16,0 \pm 2,8
$$

Primeiro $\mathrm{N}=166$

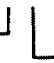

Segundo $N=163^{*}$

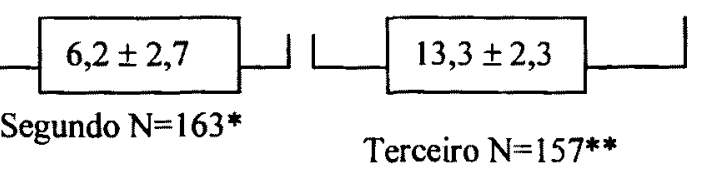

* Excluídas 3 gestantes com idade gestacional > 28 semanas na terceira observação-Tabela 6 ** 9 gestantes sem informação na quarta observação - nascimento prematuro

Com relação aos intervalos entre as observações, notou-se que esses foram adequados para se verificar alguma modificação no consumo e no gasto energético. No segundo período, $92 \%$ das gestantes tiveram esse intervalo com uma diferença igual ou superior a 4 semanas e $35 \%$ delas acima de 8 . No terceiro intervalo, não se verificaram problemas, pois o valor mínimo foi àe 7 semanas, dessa forma, superior a 1 mês.

Ao final do primeiro período, quando foi aplicado o primeiro questionário de freqüência de consumo de alimentos (QFA), 25\% das 
mulheres apresentavam uma idade gestacional de até 14 semanas e cerca de $78 \%$ das gestantes realizaram esta observação até a 18 a semana de gestação, sendo possível, assim, caracterizar a alimentação dessas mulheres ainda no primeiro e no início do segundo trimestre de gestação*. No término do segundo período, $79,7 \%$ das gestantes apresentavam idade gestacional entre a $20^{\mathrm{a}}$ e a $24^{\mathrm{a}}$ semana, obtendo-se, assim, uma observação próxima da metade do segundo trimestre. No terceiro período, $83 \%$ das gestantes encontravamse entre a $35^{\mathrm{a}}$ e a $38^{\mathrm{a}}$ semana de gestação e cerca de $14 \%$ delas realizaram esta observação entre a $32^{\mathrm{a}}$ e a $34^{\mathrm{a}}$ semana, caraterizando, portanto, uma medida da alimentação no terceiro trimestre de gravidez.

Na Tabela 9, apresenta-se a percepção das gestantes quanto à modificação da sua alimentação em relação ao início da gravidez, nos três períodos da gestação, segundo o estado nutricional inicial.

Tabela 9: Distribuição percentual das gestantes que referiram modificar sua alimentação, segundo o estado nutricional inicial nos três períodos da gestação

\begin{tabular}{ccccccc}
\hline $\begin{array}{c}\text { Estado } \\
\text { Nutricional } \\
\text { Inicial }\end{array}$ & \multicolumn{9}{c}{$\begin{array}{c}\text { Modificação } \\
\text { Período }\end{array}$} \\
\cline { 2 - 8 } & $N$ & $n(\%)$ & $N$ & $n(\%)$ & $n$ & $\begin{array}{c}\text { Perceiro } \\
(\%)\end{array}$ \\
\hline Baixo peso & 35 & $29(82,9)$ & 34 & $6(17,6)$ & 32 & $14(43,8)$ \\
Eutrofia & 96 & $70(72,9)$ & 94 & $53(56,4)$ & 93 & $44(47,3)$ \\
Sobrepeso & 24 & $16(66,7)$ & 24 & $9(37,5)$ & 22 & $13(59,1)$ \\
Obesidade & 11 & $10(90,9)$ & 11 & $8(72,7)$ & 10 & $8(80,0)$ \\
\hline Total & 166 & $125(75,3)$ & 163 & $76(46,6)$ & 157 & $79(50,3)$ \\
\hline
\end{tabular}

$1^{\circ}$ trimestre de gestação: até a $14^{\mathrm{a}} ; 2^{\circ}$ trimestre: $15^{\mathrm{a}}$ a $28^{\mathrm{a}}$ semanas e $3^{\circ}$ trimestre: a partir da $28^{\mathrm{a}}$ semana. 
Verificou-se uma tendência de maior modificação na alimentação no primeiro período da gestação, quando as mulheres relataram intolerância a alguns alimentos, pela ocorrência de enjôos e/ou náuseas; a alteração na dieta foi maior entre as gestantes com obesidade e baixo peso no primeiro período da gestação. Essas modificações tendem a diminuir no segundo período, em todos os grupos, aumentando no terceiro periodo, a não ser nas mulheres eutróficas, no início da gestação. Nas obesas, a modificação da dieta aconteceu durante toda a gestação, sendo que de forma mais importante no primeiro e no terceiro períodos gestacional.

Observa-se na Tabela 10, o tipo de modificação alimentar relatado pelas mulheres. As mudanças de preferências alimentares têm como referência a alteração do tipo de alimentos utilizados pela gestante, por exemplo troca de um alimento por outro, intolerância e/ou desejo por um alimento, não significando aumento ou diminuição da ingestão alimentar. Apesar do número pequeno de mulheres é possível verificar as modificações alimentares segundo o estado nutricional inicial, no gráfico 1 . No primeiro período, 33\% das gestantes diminuíram a ingestão de alimentos, sendo que, entre as com sobrepeso e/ou obesidade, foi maior a proporção, respectivamente, $62,5 \%$ e $70 \%$, que referiram este tipo de alteração. No segundo período analisado, houve uma inversão, pois $21,5 \%$ das gestantes informaram ter aumentado as quantidades ingeridas, sendo a maior frequiência deste tipo de alteração, observada entre as gestantes classificadas com baixo peso $(66,7 \%)$. A diminuição da ingestão alimentar, ainda no segundo período, é a principal modificação na dieta das mulheres com sobrepeso, no início da gestação (55,6\%). Durante o terceiro período, verificou-se uma tendência semelhante ao do segundo, com um maior número de mulheres aumentando a quantidade de alimentos $(25,5 \%)$. 
Tabela 10: Distribuição percentual do tipo de modificação alimentar relatado pela gestante, segundo o período de gestação

\begin{tabular}{cccc}
\hline Tipo de & \multicolumn{3}{c}{ Período } \\
Modificação & $\begin{array}{c}\text { Primeiro } \\
n(\%)\end{array}$ & $\begin{array}{c}\text { Segundo } \\
n(\%)\end{array}$ & $\begin{array}{c}\text { Terceiro } \\
n(\%)\end{array}$ \\
\hline Não modificou & $41(24,7)$ & $87(53,4)$ & $78(49,7)$ \\
Aumento das quantidades & $42(25,3)$ & $35(21,5)$ & $40(25,6)$ \\
Diminuição das quantidades & $55(33,1)$ & $23(14,1)$ & $25(16,0)$ \\
Mudança das preferências & $28(16,9)$ & $18(11,0))$ & $14(9,0)$ \\
\hline Total & $166(100)$ & $163(100)$ & $157(100)$ \\
\hline
\end{tabular}

Ainda no Gráfico 1, verifica-se que as gestantes, com baixo peso prégestacional, foram as que mais relataram ter aumentado as quantidades ingeridas, principalmente no segundo e terceiro trimestres. Diferentemente, as mulheres com sobrepeso indicaram, já no primeiro período, uma diminuição na sua alimentação, o que persistiu durante o segundo e o terceiro períodos. As gestantes obesas aumentaram a quantidade de alimentos durante o segundo e o terceiro períodos da gestação.

Gráfico 1: Tipo de modificação alimentar segundo o período gestacional e estado nutricional inicial(baixo peso-BXP; eutrofia-EUT, sobrepeso-SBP e obesidade-OBS.

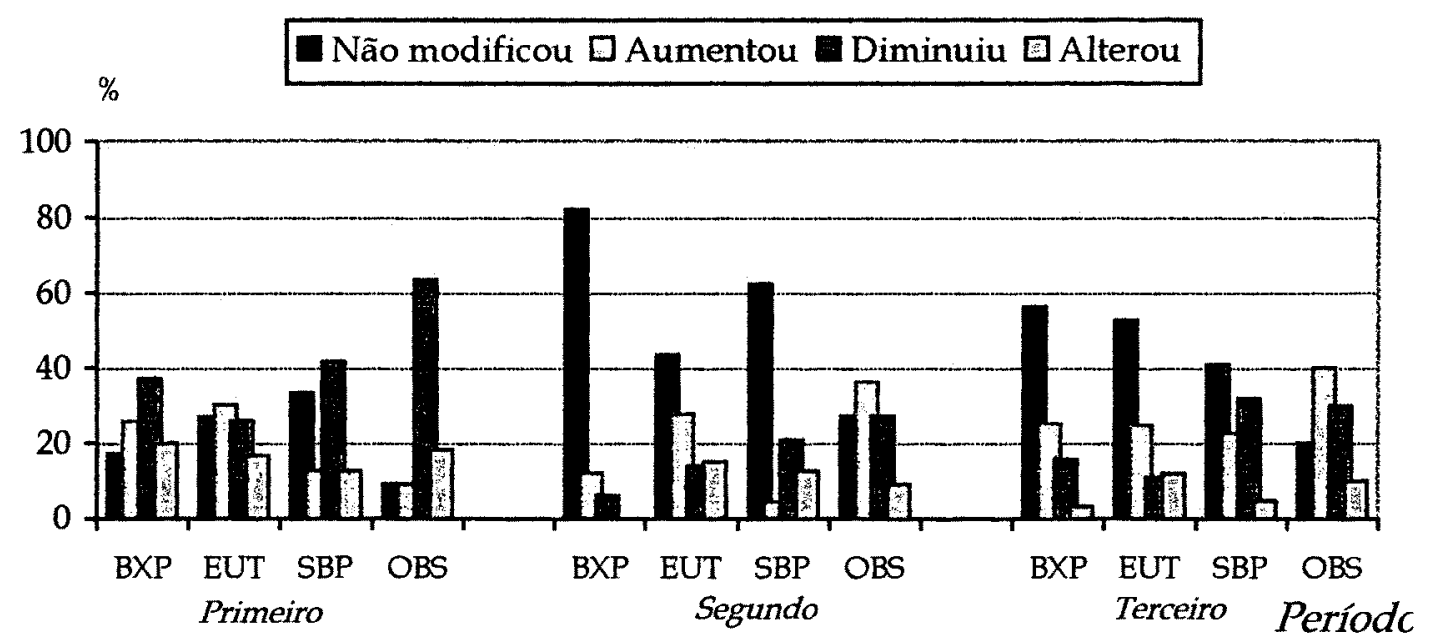


A mudança de preferências alimentares apareceu com maior frequiência no primeiro período da gestação. As principais alterações relatadas pela mulheres foram: o aumento da preferência por alimentos mais ácidos - limão - e a diminuição do consumo de leguminosas, no caso o feijão, e carnes, associada a um aumento na ingestão de frutas e hortaliças.

Ressalta-se na Tabela 11 que, daquelas que modificaram a alimentação, apenas cerca de 20 a 30\% receberam alguma orientação para tal. Essa orientação foi maior no terceiro período da gestação $(29,1 \%)$; no segundo período, observou-se maior proporção de mulheres com obesidade que receberam alguma orientação. Nas gestantes consideradas de baixo peso inicial, houve uma tendência no aumento dessa orientação do primeiro para o terceiro período de gestação.

Tabela 11: Orientação alimentar nas gestantes que modificaram a sua dieta, segundo o estado nutricional inicial nos três períodos da gestação.

\begin{tabular}{cccc}
\hline & \multicolumn{3}{c}{$\begin{array}{c}\text { Orientação } \\
\text { Período }\end{array}$} \\
\cline { 2 - 4 } Estado nutricional & Primeiro & $\begin{array}{c}\text { Segundo } \\
n(\%)\end{array}$ & $\begin{array}{c}\text { Terceiro } \\
N(\%)\end{array}$ \\
\hline Baixo peso & $5(17,2)$ & - & $5(35,7)$ \\
Eutrofia & $18(25,7)$ & $14(26,4)$ & $13(29,5)$ \\
Sobrepeso & $1(6,3)$ & $1(11,1)$ & $3(23,1)$ \\
Obesidade & $3(30,0)$ & $5(62,5)$ & $2(25,0)$ \\
Total & $27(21,6)$ & $20(26,3)$ & $23(29,1)$ \\
$\mathrm{N}$ & 125 & 76 & 79 \\
\hline
\end{tabular}

Nas gestantes que receberam orientação para modificar a alimentação, observou-se que, no primeiro período da gestação, esta foi prestada, na maioria das vezes, por familiares e amigos (55,5\%) e cerca de $30 \%$ receberam a orientação de profissionais da saúde $(22,2 \%$ orientação médica). No segundo e terceiro períodos gestacionais, constatou-se um aumento 
progressivo da orientação alimentar por parte dos profissionais de saúde, respectivamente 58,3 e 73,9\%, sendo sempre maior a orientação médica.

Na Tabela 12, independentemente do período da gestação analisado, mais de $80 \%$ das mulheres realizaram o desjejum, o almoço e o jantar. As refeições com menor percentual foram o lanche da noite seguido pelo lanche da manhã. O lanche da tarde foi praticado por mais de $60 \%$ das gestantes.

É interessante verificar que as gestantes aumentaram o número de refeições realizadas, entre o primeiro e o segundo período da gestação, mantendo este perfil durante o terceiro momento gestacional. Essa tendência só não foi verificada para o lanche da manhã.

Tabela 12: Distribuição das gestantes segundo o tipo de refeição realizada nos três período de gestação

\begin{tabular}{cccc}
\hline Refeição & \multicolumn{3}{c}{ Periodo } \\
\cline { 2 - 4 } & $\begin{array}{c}\text { Primeiro } \\
n(\%)\end{array}$ & $\begin{array}{c}\text { Segundo } \\
n(\%)\end{array}$ & $\begin{array}{c}\text { Terceiro } \\
n(\%)\end{array}$ \\
\hline Desjejum & $136(81,9)$ & $147(90,2)$ & $146(92,9)$ \\
Lanche da manhã & $85(51,2)$ & $83(50,9)$ & $74(47,1)$ \\
Almoço & $151(91,0)$ & $159(97,5)$ & $151(96,2)$ \\
Lanche da tarde & $102(61,4)$ & $114(69,9)$ & $109(69,4)$ \\
Jantar & $137(82,5)$ & $147(90,2)$ & $140(89,2)$ \\
Lanche da Noite & $63(38,0)$ & $64(39,3)$ & $67(42,7)$ \\
\hline Total & 166 & 163 & 157 \\
\hline
\end{tabular}

Quanto à contribuição percentual dos macronutrientes, no valor calórico total da dieta, verifica-se no Gráfico 2, que em todos os períodos gestacionais, a distribuição mostrou-se sempre dentro dos valores recomendados para uma alimentação normal e saudável. Essa distribuição, também, não revelou diferenças, segundo o estado nutricional prégestacional. 
Gráfico 2: Distribuição percentual dos macronutrientes em relação ao valor calórico da dieta (VCT), segundo o período da gestação.

\section{proteínas $\square$ gorduras $\square$ carboidratos}

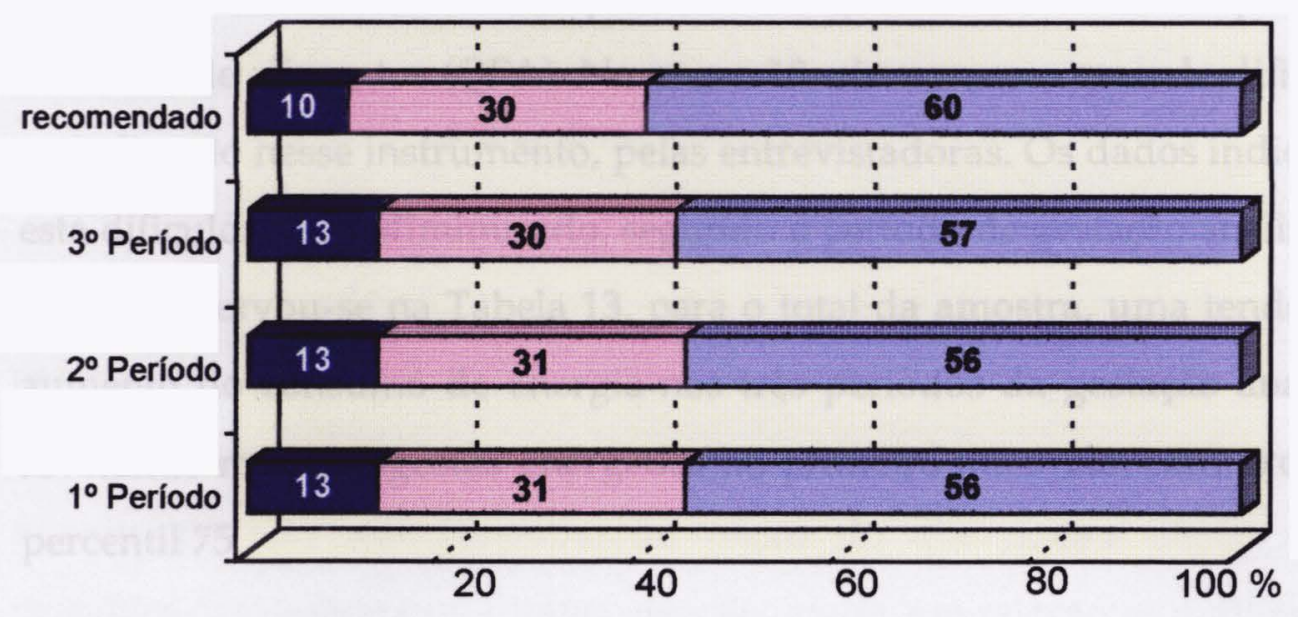




\subsection{O CONSUMO ENERGÉTICO}

Como já mencionado, para estimar o consumo de energia das gestantes da coorte, foram aplicados os questionários de freqüência de consumo de alimentos (QFA). No anexo 10, observa-se o grau de dificuldade na aplicação nesse instrumento, pelas entrevistadoras. Os dados indicam que esta dificuldade foi diminuindo, segundo o período de gestação analisado.

Observou-se na Tabela 13, para o total da amostra, uma tendência de aumento do consumo de energia nos três períodos da gestação analisados, revelando menor ingestão energética no primeiro intervalo, com exceção do percentil 75 .

Tabela 13: Ingestão energética, segundo o estado nutricional inicial e o periodo da gestação - mediana e percentis 25 e75

(P25 - Md - P75) média e desvio padrão

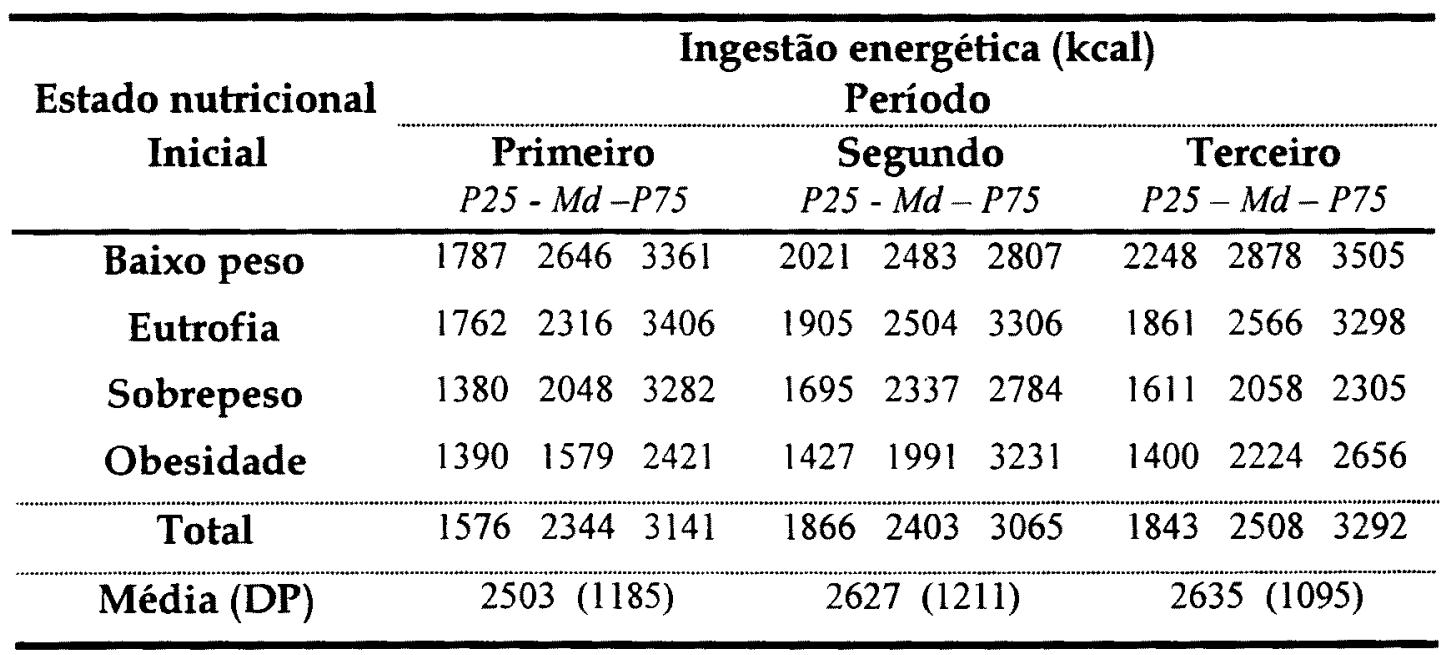

Quanto à ingestão energética, segundo o estado nutricional, verificase, também, na Tabela 13, que foram as mulheres com baixo peso inicial que apresentaram maior ingestão energética durante toda a gestação, em relação aos valores da mediana, com exceção do segundo período, em que a ingestão 
energética desse grupo foi discretamente inferior à das gestantes eutróficas. Comparando-se os valores do percentil 75 das gestantes com baixo peso inicial com os das eutróficas, observa-se que esses foram menores no primeiro e segundo períodos da gestação Nas mulheres com baixo peso, eutróficas e obesas, o consumo energético foi aumentando, segundo os períodos da gravidez.

Comportamento inverso ao verificado nas gestantes com baixo peso inicial foi observado nas mulheres com sobrepeso e/ou obesidade, nas quais notou-se menor ingestão energética, durante toda a gravidez. As obesas apresentaram menor consumo de calorias durante a gestação; somente no terceiro período esse consumo foi maior do que aquele observado nas gestantes com sobrepeso. Chama atenção, ainda, em relação às mulheres com sobrepeso, o fato de que a ingestão energética foi superior no segundo período, quando comparada ao terceiro.

$\mathrm{Na}$ Tabela 14, é apresentada a distribuição da ingestão energética nos períodos gestacionais analisados. Nota-se uma diminuição da porcentagem de gestantes com ingestão energética menor que $1000 \mathrm{kcal}$, durante o três períodos, de 4,8\% para 1,3\%. Quando essas dietas, com valores muito baixos de calorias, foram analisadas separadamente, observou-se a associação dessa baixa ingestão energética com quadros de intolerância alimentares, provocados por enjôos e náuseas. Nesses casos, foram verificadas dietas com valores inferiores a $500 \mathrm{kcal} / \mathrm{dia}$ ( 3 gestantes, todas no primeiro período de gestação, em relação ao estado nutricional inicial, verificou-se uma eutrófica, uma com sobrepeso e uma gestante com baixo peso).

A elevada ingestão energética - valores superiores a $4000 \mathrm{kcal}$ também foi observada em um percentual em torno de $10 \%$ das gestantes, sendo maior a sua ocorrència no segundo momento $(12,0 \%)$. Essas dietas foram analisadas e revelaram uma consistência entre a ingestão, sempre alta, nos três períodos e, o relato das gestantes de terem aumentado o seu 
consumo de alimentos. Nestes casos, foram verificadas dietas com valores superiores a $6000 \mathrm{kcal} / \mathrm{dia}$ (5 gestantes, todas no segundo periodo da gestação).

Tabela 14: Distribuição das gestantes segundo categorias de ingestão energética nos três períodos de gestação.

\begin{tabular}{cccc}
\hline & \multicolumn{3}{c}{ Período } \\
\cline { 2 - 4 } $\begin{array}{c}\text { Ingestão energética } \\
\text { (kcal) }\end{array}$ & $\begin{array}{c}\text { Primeiro } \\
n(\%)\end{array}$ & $\begin{array}{c}\text { Segundo } \\
n(\%)\end{array}$ & $\begin{array}{c}\text { Terceiro } \\
n(\%)\end{array}$ \\
\hline 1000 ou - & $8(4,8)$ & $6(3,7)$ & $2(1,3)$ \\
$1001-2000$ & $51(30,7)$ & $44(27,0)$ & $48(30,6)$ \\
$2001-3000$ & $60(36,1)$ & $68(41,7)$ & $55(35,0)$ \\
$3001-4000$ & $31(18,7)$ & $25(15,3)$ & $35(22,3)$ \\
+ de 4000 & $19(9,6)$ & $20(12,3)$ & $17(10,8)$ \\
\hline Total & $166(100)$ & $163(100)$ & $157(100)$ \\
\hline
\end{tabular}

Com o objetivo de verificar a adequação da ingestão energética e, também, da precisão dessa estimativa a partir do QFA, apresentam-se nas Tabela 15 e 16 as taxas de metabolismo basal total $\left(\mathrm{TMB}_{\mathrm{T}}\right)$ e a razão entre o consumo de energia e esta taxa nos três períodos da gestação.

Tabela 15: $\mathrm{TMB}_{\mathrm{T}}$ segundo o estado nutricional inicial e o período da gestação - mediana e percentis 25 e 75 (P25 Md P75)

\begin{tabular}{|c|c|c|c|c|c|c|c|c|c|}
\hline \multirow{2}{*}{$\begin{array}{l}\text { Estado nutricional } \\
\text { inicial }\end{array}$} & \multicolumn{9}{|c|}{ Taxa de metabolismo basal total (kcal) } \\
\hline & \multicolumn{3}{|c|}{$\begin{array}{c}\text { Primeiro } \\
P 25-M d-P 75\end{array}$} & \multicolumn{3}{|c|}{$\begin{array}{c}\text { Segundo } \\
P 25-M d-P 75\end{array}$} & \multicolumn{3}{|c|}{$\begin{array}{c}\text { Terceiro } \\
P 25-M d-P 75\end{array}$} \\
\hline Baixo peso & 1226 & 1270 & 1337 & 1311 & 1358 & 1430 & $\overline{1545}$ & 1599 & 1649 \\
\hline Eutrofia & 1339 & 1389 & 1448 & 1424 & 1478 & 1538 & 1647 & 1726 & 1801 \\
\hline Sobrepeso & 1435 & 1460 & 1526 & 1502 & 1546 & 1653 & 1714 & 1803 & 1895 \\
\hline Obesidade & 1650 & 1731 & 1801 & $1706^{\circ}$ & 1801 & 1893 & 1927 & 2033 & 2081 \\
\hline Total & 1316 & 1390 & 1462 & 1395 & 1481 & 1547 & 1634 & 1714 & 1808 \\
\hline
\end{tabular}


Tabela 16: Razão entre a ingestão energética e a $\mathrm{TMB}_{\mathrm{T}}$, segundo o estado nutricional inicial e o período da gestação - média e desvio padrão e valores mínimo e máximo.

\begin{tabular}{|c|c|c|c|}
\hline \multirow{2}{*}{$\begin{array}{c}\text { Estado nutricional } \\
\text { inicial }\end{array}$} & \multicolumn{3}{|c|}{$\begin{array}{c}\text { Razão IE/ TMB } \\
\text { Período }\end{array}$} \\
\hline & $\begin{array}{c}\text { Primeiro } \\
X \quad D P(\text { mín - máx. })\end{array}$ & $\begin{array}{c}\text { Segundo } \\
X D P(\min -m a ́ x)\end{array}$ & $\begin{array}{c}\text { Terceiro } \\
X D P(\min -\text { máx. })\end{array}$ \\
\hline Baixo peso & $2,1 \quad 1,0(0,3-5,2)$ & $2,0 \quad 1,1(0,7-5,1)$ & $1,9 \quad 0,7(0,8-4,0)$ \\
\hline Eutrofia & $1,8 \quad 0,8(0,1-4,3)$ & $1,8 \quad 0,8(0,6-4,7)$ & $1,6 \quad 0,6(0,4-3,5)$ \\
\hline Sobrepeso & $1,4 \quad 0,7(0,2-2,7)$ & $1,5 \quad 0,5(0,5-2,8)$ & $1,2 \quad 0,4(0,6-2,4)$ \\
\hline Obesidade & $1,1 \quad 0,4(0,5-1,7)$ & $1,2 \quad 0,7(0,5-2,3)$ & $1,0 \quad 0,3(0,6-1,5)$ \\
\hline Total & $1,8 \quad 0,8(0,1-5,2)$ & $1,8 \quad 0,7(0,5-5,1)$ & $1,5 \quad 0,7(0,4-4,0)$ \\
\hline
\end{tabular}

Verifica-se, a partir da Tabela 16, que a média da razão entre o consumo energético e a $\mathrm{TMB}_{\mathrm{T}}$ está acima de 0,9 , taxa esta considerado adequada, em todos os períodos estudados. No entanto, observaram-se nos valores mínimos, razões inferiores a 0,9, indicando que algumas gestantes subestimaram a sua alimentação. Notou-se, ainda, que os menores valores ocorreram durante o primeiro período.

$\mathrm{Na}$ Tabela 17, pode-se notar o gasto energético que foi calculado, levando-se em conta o nível de atividade física. Esse gasto variou de 1659 a $3725 \mathrm{kcal}$, respectivamente, o menor valor do percentil 25, nas mulheres com baixo peso inicial no primeiro período, e percentil 75 nas gestantes obesas no terceiro período da gestação analisado. 
Tabela 17: Gasto energético, segundo o estado nutricional inicial e o período da gestação - mediana e percentis 25 e75 (P25 - Md- P75)

\begin{tabular}{|c|c|c|c|c|c|c|c|c|}
\hline \multirow{3}{*}{$\begin{array}{c}\begin{array}{c}\text { Estado nutricional } \\
\text { inicial }\end{array} \\
\text { Baixo peso }\end{array}$} & \multicolumn{8}{|c|}{$\begin{array}{c}\text { Gasto energético (kcal) } \\
\text { Período }\end{array}$} \\
\hline & \multicolumn{2}{|c|}{$\begin{array}{c}\text { Primeiro } \\
P 25-M d-P 75\end{array}$} & \multicolumn{3}{|c|}{$\begin{array}{c}\text { Segundo } \\
P 25-M d-P 75\end{array}$} & \multicolumn{3}{|c|}{$\begin{array}{c}\text { Terceiro } \\
P 25-M d-P 75\end{array}$} \\
\hline & 1659.1895 & 2035 & 1846 & $19 \overline{46}$ & 2210 & 2147 & 2285 & 2608 \\
\hline Eutrofia & 19242043 & 2308 & 2020 & 2188 & 2445 & 2393 & 2542 & 2840 \\
\hline Sobrepeso & $2048 \quad 2255$ & 2532 & 2159 & 2391 & 2608 & 2292 & 2591 & 2852 \\
\hline Obesidade & $2373 \quad 2558$ & 2702 & 2512 & 2592 & 2930 & 2719 & 3034 & 3725 \\
\hline Total & $1895 \quad 2055$ & 2337 & 1995 & 2201 & 2483 & 2296 & 2539 & 2834 \\
\hline
\end{tabular}

O consumo de calorias mostrou-se adequado ao gasto energético, conforme verifica-se na Tabela 18. Em todos os períodos da gestação, encontrou-se uma adequação do consumo energético com uma mediana que variou de 62 a 133\%. As menores adequações ocorreram nas gestantes com obesidade inicial.

Tabela 18: Adequação da ingestão energética, segundo o estado nutricional inicial e o período da gestação - mediana e percentis 25 e75 (P25 - Md - P75)

\begin{tabular}{|c|c|c|c|c|c|c|c|c|c|}
\hline \multirow{3}{*}{$\begin{array}{c}\begin{array}{c}\text { Estado nutricional } \\
\text { Inicial }\end{array} \\
\text { Baixo peso }\end{array}$} & \multicolumn{9}{|c|}{$\begin{array}{c}\text { Adequação da ingestão energética } \\
\text { Período }\end{array}$} \\
\hline & \multicolumn{3}{|c|}{$\begin{array}{c}\text { Primeiro } \\
P 25-M d-P 75\end{array}$} & \multicolumn{3}{|c|}{$\begin{array}{c}\text { Segundo } \\
P 25-M d-P 75\end{array}$} & \multicolumn{3}{|c|}{$\begin{array}{c}\text { Terceiro } \\
P 25-M d-P 75\end{array}$} \\
\hline & 0,88 & 1,33 & 1,68 & 0,95 & 1,20 & 1,66 & 0,98 & 1,20 & 1,63 \\
\hline Eutrofia & 0,79 & 1,12 & 1,67 & 0,84 & 1,13 & 1,51 & 0,70 & 0,98 & 1,30 \\
\hline Sobrepeso & 0,59 & 0,88 & 1,41 & 0,65 & 1,01 & 1,24 & 0,61 & 0,77 & 0,95 \\
\hline Obesidade & 0.53 & 0,62 & 0,94 & 0,57 & 0,79 & 1,28 & 0,47 & 0,66 & 0,81 \\
\hline Total & 0,70 & 1,10 & 1,54 & 0,80 & 1,10 & 1,45 & 0,70 & 1,00 & 1,30 \\
\hline
\end{tabular}


No Gráfico 3, observa-se o consumo e o gasto energético, segundo o estado nutricional inicial. Nota-se que, na coorte, o consumo foi maior que o gasto energético nos dois primeiros períodos da gestação; já, no terceiro intervalo, eles foram semelhantes. Essa tendência também foi verificada entre as mulheres eutróficas, no início da gestação.

Nas mulheres com baixo peso, verificou-se um consumo energético sempre superior ao gasto, comportamento inverso ao observado nas obesas, que apresentaram um gasto energético superior ao consumo, em todos os momentos analisados. Nas gestantes com sobrepeso, além de uma diminuição do consumo energético entre o segundo e terceiro períodos, observou-se neste intervalo um gasto superior ao consumo energético. 
Gráfico3: Consumo e gasto energético - valores da mediana, segundo o estado nutricional inicial

\section{BXP - baixo peso}

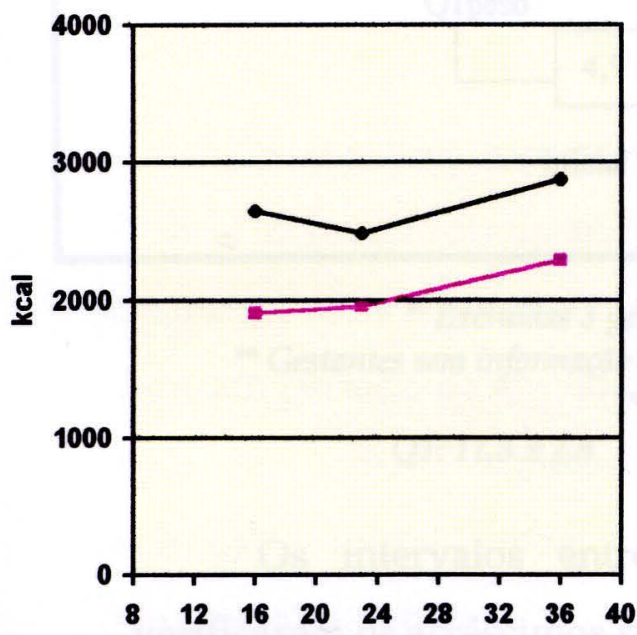

SBP - sobrepesosemanas de gestação

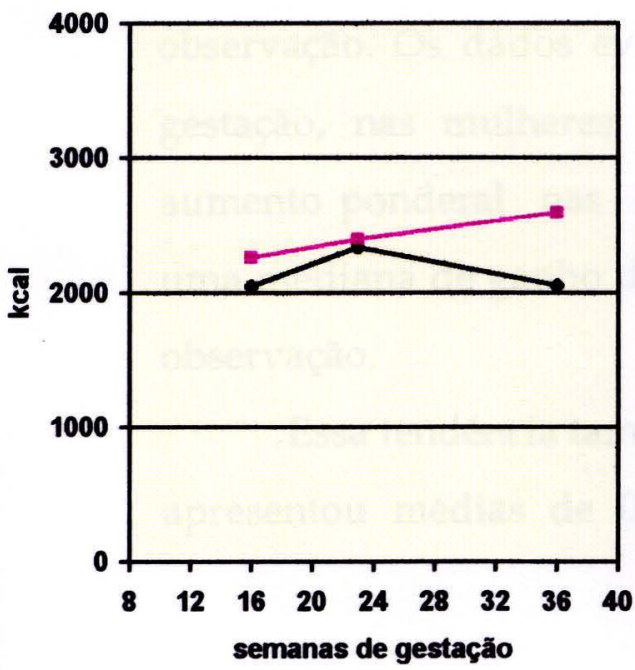

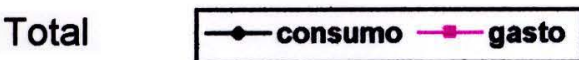

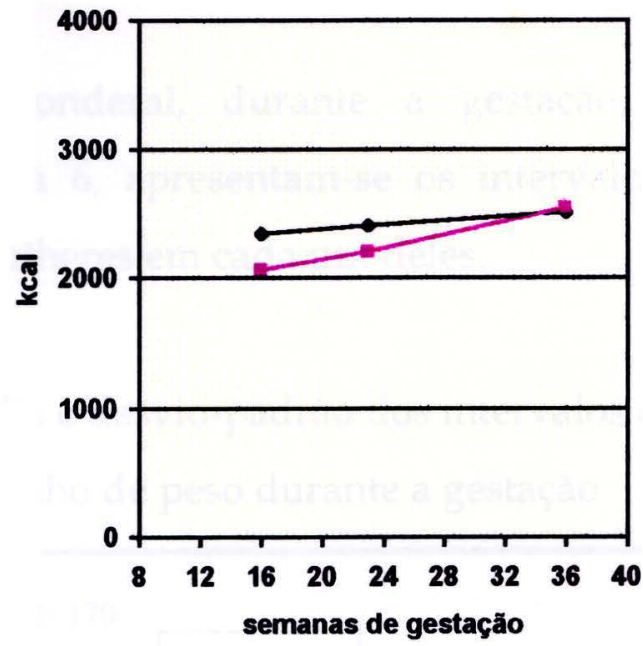

EUT - eutrófica

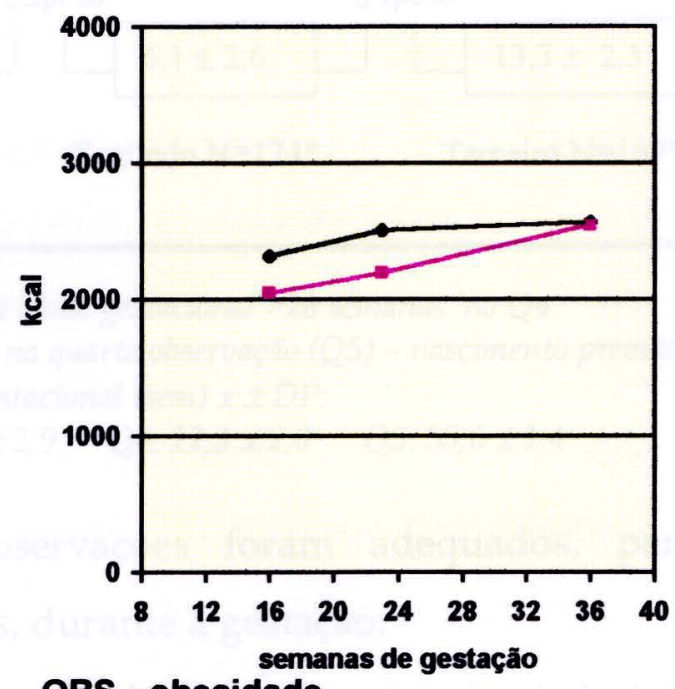

OBS - obesidade

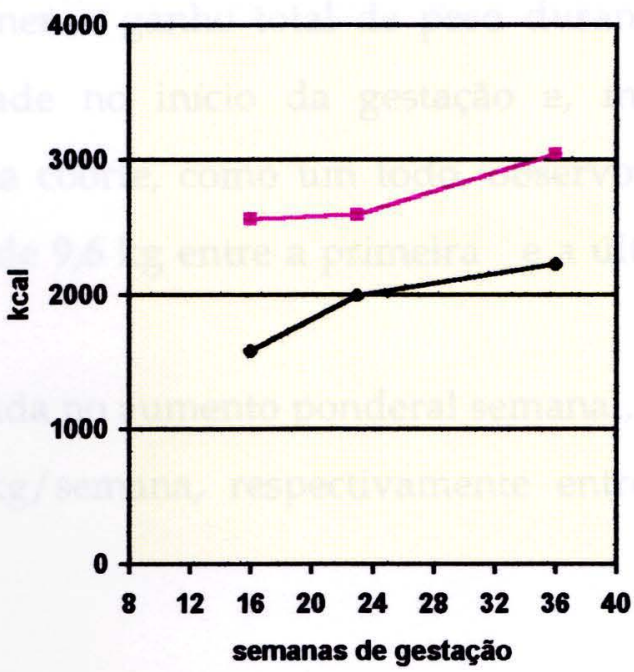




\subsection{O AUMENTO PONDERAL}

$\mathrm{Na}$ análise do aumento ponderal, durante a gestação, foram analisadas 177 mulheres. Na Figura 6, apresentam-se os intervalos entre essas observações e o número de mulheres em cada um deles.

Figura 6: Períodos, média e desvio-padrão dos intervalos de observação (semanas) do ganho de peso durante a gestação

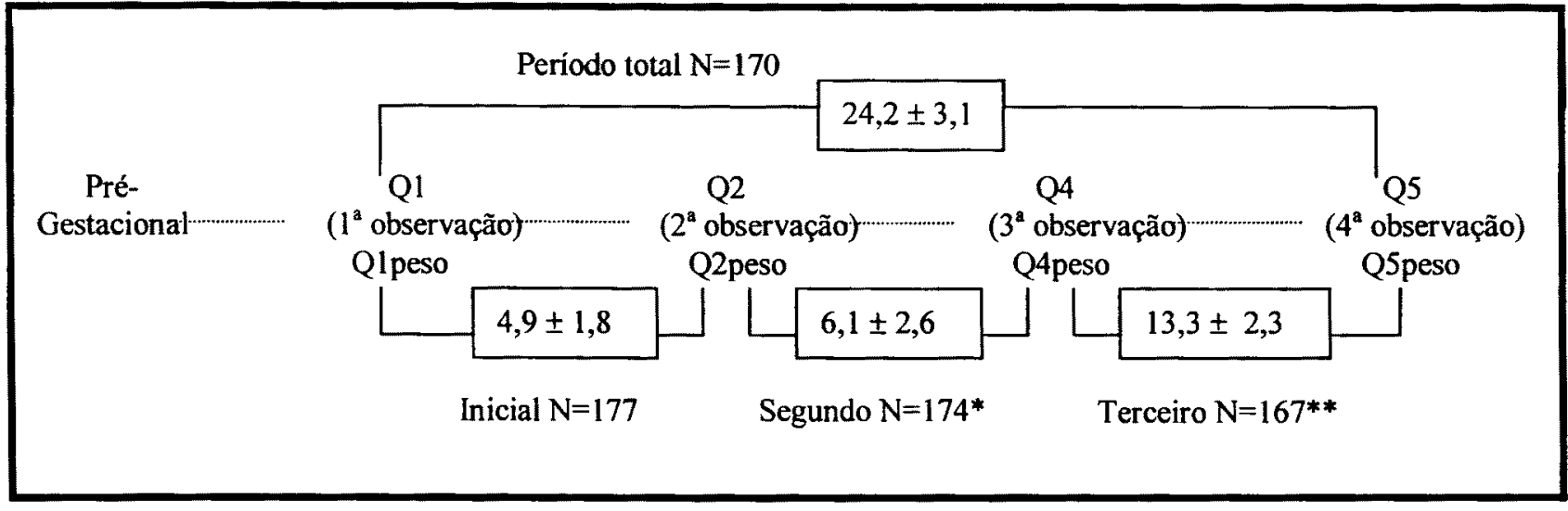

* Excluidas 3 gestantes com idade gestacional $>28$ semanas no Q4

** Gestantes sem informação de peso (7) na quarta observação (Q5) - nascimento prematuro

*** idade gestacional (sem) $x \pm D P$ :

Q1: $11,3 \pm 2,8 \quad Q 2: 16,2 \pm 2,9 \quad Q 4: 22,3 \pm 2,0 \quad$ Q5: $35,6 \pm 1,4$

Os intervalos entre as observações foram adequados, para se verificarem os acréscimos ponderais, durante a gestação.

Verifica-se, na Tabela 20, o ganho de peso durante o período total de observação. Os dados evidenciaram menor ganho total de peso durante a gestação, nas mulheres com obesidade no início da gestação e, maior aumento ponderal nas eutróficas. $\mathrm{Na}$ coorte, como um todo, observou-se uma mediana de ganho de peso total de $9,6 \mathrm{~kg}$ entre a primeira e a última observação.

Essa tendência também foi notada no aumento ponderal semanal, que apresentou médias de 0,45 a $0,31 \mathrm{~kg} /$ semana, respectivamente entre as 
mulheres eutróficas e obesas, no início da gestação (Tabela 20). A média de ganho de peso das gestantes com baixo peso foi muito próximo ao das eutróficas, $0,42 \mathrm{~kg} / \mathrm{semana}$.

Tabela 20: Ganho de peso total e por semana durante a gestação, segundo estado nutricional inicial

\begin{tabular}{ccccccc}
\hline & & \multicolumn{4}{c}{ Ganho de peso $(\mathrm{kg})$} \\
\cline { 3 - 7 } $\begin{array}{c}\text { Estado nutricional } \\
\text { Inicial }\end{array}$ & $\mathrm{N}$ & \multicolumn{3}{c}{ Total } & \multicolumn{2}{c}{$\begin{array}{c}\text { Semana } \\
\text { Média desvio padrão }\end{array}$} \\
\hline Baixo peso & 33 & 7,7 & 9,4 & 12,3 & 0,42 & 0,12 \\
Eutrofia & 103 & 8,3 & 10,0 & 13,6 & 0,45 & 0,15 \\
Sobrepeso & 23 & 7,2 & 8,9 & 11,2 & 0,38 & 0,14 \\
Obesidade & 11 & 4,0 & 7,3 & 10,7 & 0,31 & 0,18 \\
\hline Total & 170 & 7,7 & 9,6 & 12,7 & 0,43 & 0,15 \\
\hline
\end{tabular}

Os menores incrementos de peso ocorreram no início da gestação (Tabela 21), verificando-se, nesse intervalo, ganhos de peso nulos, entre as mulheres com sobrepeso, e mesmo negativos nas gestantes obesas. No segundo período da gravidez, evidencia-se, ainda na Tabela 21, um ganho de peso por semana semelhante entre as gestantes, com exceção das com obesidade inicial, onde este incremento foi menor. Contrariamente à tendência de menor incremento de peso nas mulheres com obesidade, observada no período inicial e no segundo período, estas apresentaram um ganho ponderal semanal semelhante ao das demais mulheres, no terceiro intervalo da gestação. 
Tabela 21: Ganho de peso total no período inicial e por semana no segundo e terceiro períodos, segundo o estado nutricional no início da gestação mediana e percentis 25 e 75 (P25 - Md - P75)

\begin{tabular}{|c|c|c|c|}
\hline \multirow{4}{*}{$\begin{array}{c}\text { Estado } \\
\text { Nutricional } \\
\text { Inicial }\end{array}$} & \multicolumn{3}{|c|}{$\begin{array}{c}\text { Ganho de peso }(\mathrm{kg}) \\
\text { Período }\end{array}$} \\
\hline & \multirow{3}{*}{$\begin{array}{c}\text { Inicial } \\
\text { Total } \\
P 25-M d-P 75\end{array}$} & Segundo & Terceiro \\
\hline & & \multicolumn{2}{|c|}{ Semanal } \\
\hline & & $P 25-M d-P 75$ & $P 25-M d-P 75$ \\
\hline Baixo peso & $\begin{array}{lll}0,5 & 1,2 & 1,9\end{array}$ & $\begin{array}{lll}0,32 & 0,50 & 0,63\end{array}$ & $\begin{array}{lll}0,33 & 0,43 & 0,51\end{array}$ \\
\hline Eutrofia & $0,7 \quad 1,4 \quad 2,2$ & $\begin{array}{lll}0,34 & 0,47 & 0,70\end{array}$ & $\begin{array}{lll}0,35 & 0,47 & 0,63\end{array}$ \\
\hline Sobrepeso & $0,0 \quad 1,0 \quad 2,2$ & $\begin{array}{lll}0,27 & 0,43 & 0,52\end{array}$ & $\begin{array}{lll}0,34 & 0,37 & 0,51\end{array}$ \\
\hline Obesidade & $\begin{array}{lll}-0,5 & -0,4 & 1,8\end{array}$ & $\begin{array}{lll}0,15 & 0,25 & 0,38\end{array}$ & $\begin{array}{lll}0,23 & 0,43 & 0,59\end{array}$ \\
\hline Tota & $\begin{array}{lll}0,4 & 1,3 & 2,2\end{array}$ & $\begin{array}{lll}0,31 & 0,45 & 0,60\end{array}$ & $\begin{array}{lll}0,30 & 0,43 & 0,57\end{array}$ \\
\hline
\end{tabular}

Observaram-se incrementos ponderais por semana (Tabela 21) semelhantes no segundo e no terceiro períodos, indicando, portanto, um acréscimo de peso constante, a partir do segundo trimestre de gestação. Essa tendência foi diferenciada, considerando-se o estado nutricional inicial, pois, nas mulheres com baixo peso e com sobrepeso, evidenciou-se um acréscimo ponderal menor, e, nas com obesidade, este ganho foi mais intenso durante o terceiro período da gestação.

É interessante notar, ainda nessa tabela, uma semelhança do aumento ponderal por semana entre as mulheres, independentemente do estado nutricional inicial, no terceiro período de gestação. Foram as gestantes com baixo peso e eutrofia inicial que apresentaram o maior ganho de peso semanal no início e durante o segundo período de gravidez.

\subsection{O CONSUMO ENERGÉTICO E O AUMENTO PONDERAL}

Com o objetivo de verificar a influência do consumo energético, sobre o desempenho de ganho de peso ao longo da gestação, foram estudadas 161 gestantes. Apresentam-se na Tabela 24 os resultados das regressões lineares 
múltiplas, realizadas nos três períodos da gestação. Os modelos foram construídos para cada intervalo, controlando-se o tempo entre as observações em semanas, o peso inicial do período, a estatura, a idade e a paridade. As variáveis foram centralizadas na mediana. Nessas análises o consumo energético foi transformado em Joules, considerando-se $1000 \mathrm{Kcal}=4$,2Joules

A paridade (primípara ou não) foi incluída no modelo, porque, na regressão do terceiro período, observou-se uma mudança do coeficiente superior a $20 \%$, a partir da entrada dessa variável.

Tabela 24: Coeficientes das regressões lineares múltiplas* entre o aumento ponderal e o consumo energético, segundo os períodos da gestação.

\begin{tabular}{cccc}
\hline Periodo & Coeficiente & Intervalo de confiança (95\%) & $\mathbf{P}$ \\
\hline Inicial & 0,046995 & $0,006049-0,087941$ & 0,0259 \\
Segundo & 0,061748 & $0,014086-0,109409$ & 0,0121 \\
Terceiro & $-0,011912$ & $-0,091877-0,068053$ & 0,7698
\end{tabular}

* Ajustados pelo peso inicial $(\mathrm{kg})$, estatura $(\mathrm{cm})$, intervalo de tempo entre as observaçōes (semanas), idade (anos) e paridade (primipara e não primípara).

O consumo de energia associou-se, positivamente, ao aumento ponderal no início da gestação. No segundo período, metade do segundo trimestre de gestação, o consumo de calorias também está relacionado com o ganho de peso nesse intervalo. No terceiro intervalo, não se encontrou uma associação com significância estatística entre o consumo energético e o incremento de peso, no último trimestre de gestação.

A seguir, apresentam-se as equações das regressões lineares múltiplas, nos três períodos da gestação:

- $\mathrm{Q} 2$ peso $=58,117993+0,046995(\mathrm{Q} 2 \mathrm{VCT})+0,969933(\mathrm{Q} 1$ peso) $+0,284299$ (início) + 0,042501(idade) 0,054907 (paridade) $+0,020408$ (estatura)

- $\mathrm{Q} 4$ peso $=60,795755+0,061748(\mathrm{Q} 4 \mathrm{VCT})+0,972169(\mathrm{Q} 2$ peso $)+0,408305$ (segundo $)+0,023726$ (idade) 0,542235 (paridade) $+0,020453$ (estatura)

- $\mathrm{Q} 5$ peso $=67,370024-0,011912(\mathrm{Q} 5 \mathrm{VCT})+1,037823(\mathrm{Q} 4$ peso $)+0,497217$ (terceiro) $-0,121716$ (idade) 1,193375 (paridade) $+0,032769$ (estatura

Onde: 


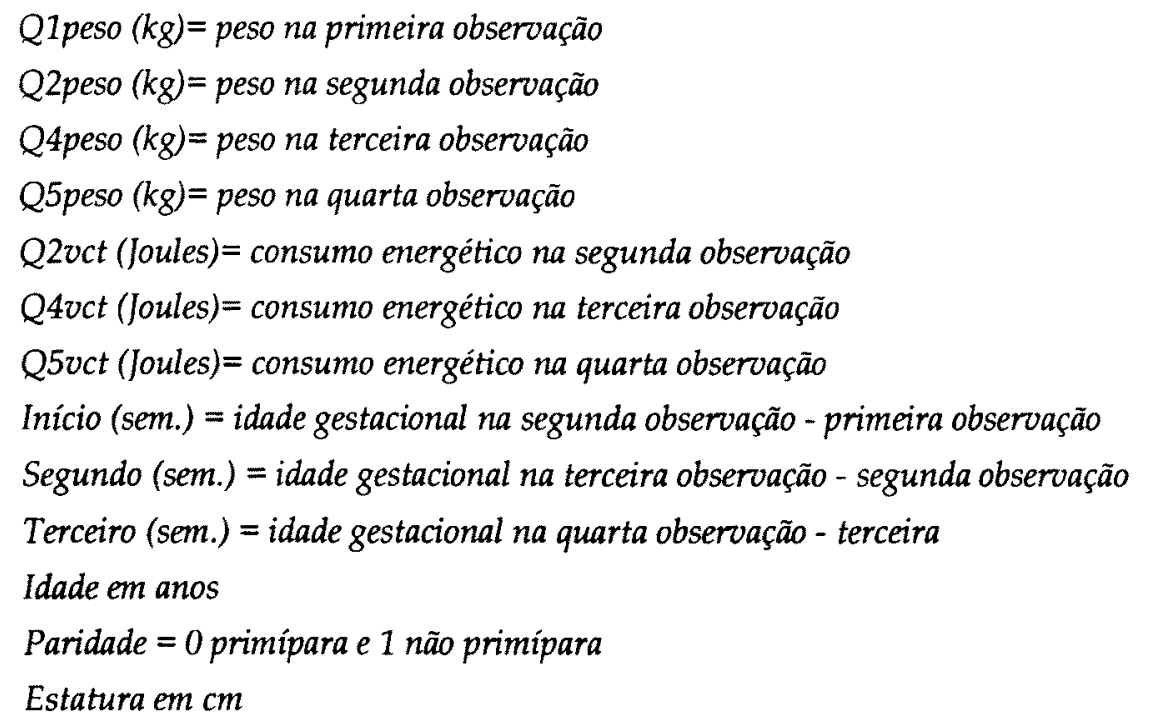

A partir dessas equações foi construído o gráfico 4. Observa-se nesse gráfico que o mesmo consumo energético influencia de forma diferente o aumento ponderal.* Assim, no primeiro período, para as gestantes com baixo peso, eutrofia, sobrepeso e obesidade inicial, consumindo uma dieta com $2.000 \mathrm{kcal}$, notou-se um ganho de peso respectivamente de 1,8; 1,6; 1,4 e 0,8 $\mathrm{kg}$, o que está adequado para as gestantes com eutrofia e obesidade, mas nas com baixo peso representa um acréscimo abaixo do preconizado $(2,3 \mathrm{~kg})$ e nas com sobrepeso um aumento superior ao recomendado $(0,9 \mathrm{~kg})$. No segundo período da gestação, para um consumo de $2.200 \mathrm{kcal}$, verificou-se um aumento ponderal semanal muito próximo do recomendado, isto é, 0,52; 0,$47 ; 0,45$ e $0,37 \mathrm{~kg}$, (recomendado 0,49; 0,44 e $0,3 \mathrm{~kg}$ ), para as mulheres com baixo peso, eutrofia e peso excessivo. Já no último período de observação uma alimentação com $2.500 \mathrm{kcal}$, representou um aumento ponderal excessivo nas gestantes com obesidade e sobrepeso inicial $(0,56 \mathrm{~kg} /$ semana).

\footnotetext{
* Recomendação de aumento ponderal durante a gestação, segundo o Institute of Medicine, 1990c
} 
Gráfico 4: Ganho de peso durante a gestação segundo o estado nutricional inicial (BXP - baixo peso; EUT - eutrofia; SBP - sobrepeso e OBS - obesidade) para uma ingestão energética de $2.000,2.200$ e 2.500 kcal, respectivamente, no início, segundo e terceiro intervalos de
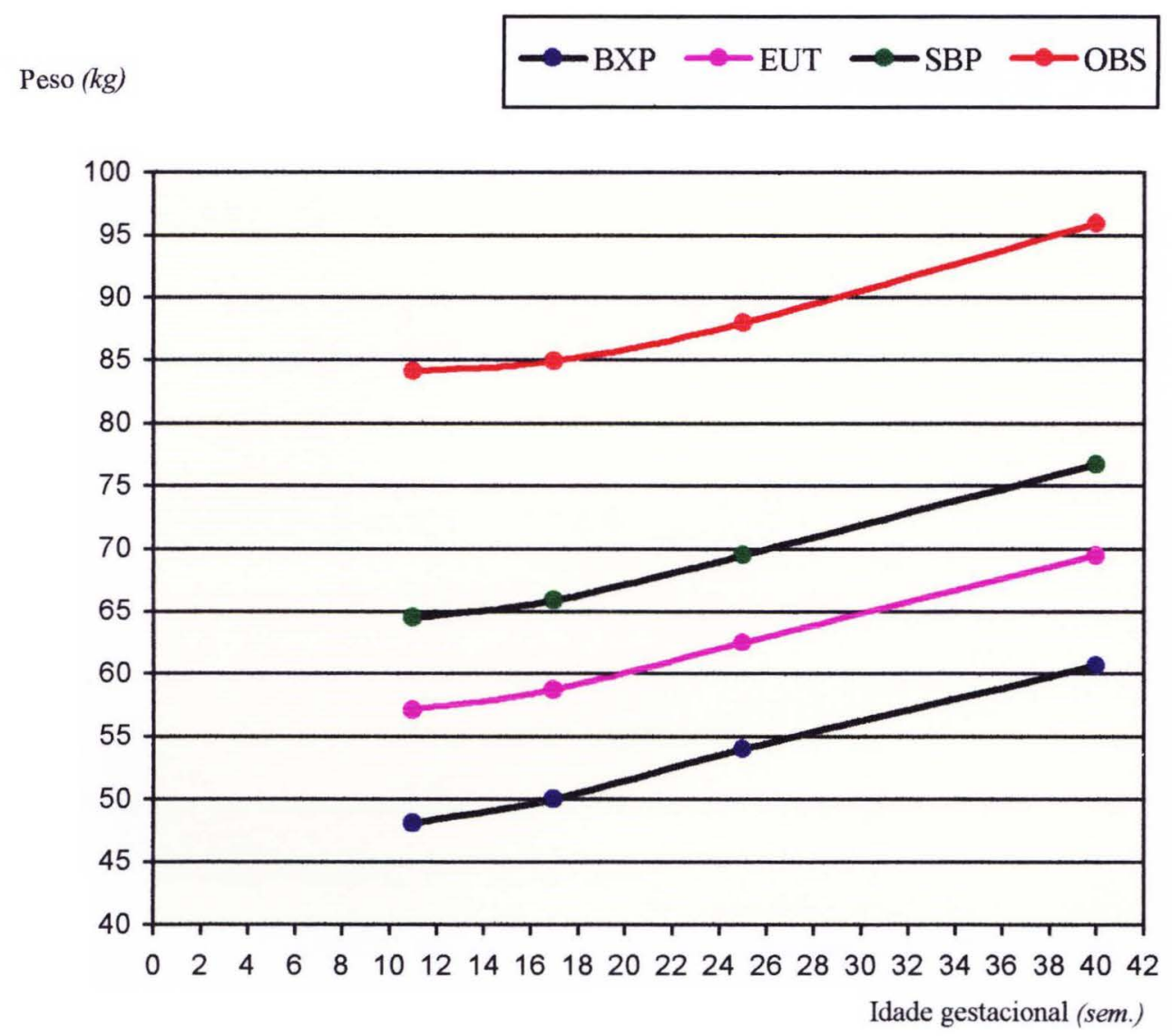

*Para o cálculo utilizaram-se as fórmulas obtidas a partir da análise de regressão linear múltipla.

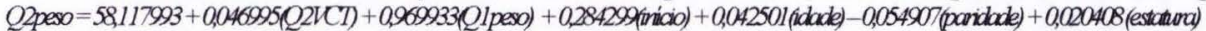

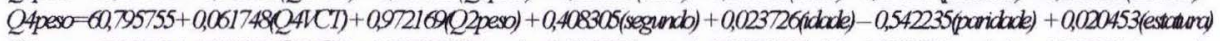

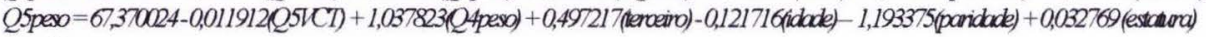

Onde:

Q1peso $=48,1 \mathrm{~kg}$ (peso médio nas gestantes com baixo peso)

$57,1 \mathrm{~kg}$ (peso médio nas gestantes com eutrofia)

$64,5 \mathrm{~kg}$ (peso médio nas gestantes com sobrepeso)

$84,1 \mathrm{~kg}$ (peso médio nas gestantes com obesidade)

Inicio $=6$ semanas Segundo $=8$ semanas Terceiro $=14$ semanas

Paridade $=0 \quad$ Idade $=24$ anos Estatura $=159,0 \mathrm{~cm}$ 


\section{DISCUSSÃO}

\section{1 A COORTE E AS PERDAS}

Como etapa preliminar à discussão dos resultados desse estudo, examinar-se-á a comparibilidade entre as gestantes efetivamente estudadas e as perdas de seguimento, por abandono.

Talvez o primeiro comentário a ser feito seja a propósito da diferença observada entre as gestantes que concluíram o seguimento e aquelas que o abandonaram (perdas). Sem dúvida, as gestantes consideradas perdas apresentam um estado nutricional pré-gestacional e inicial diferenciado, com uma freqüência muito maior de obesas, informação confirmada, analisandose a mediana e os valores dos percentis 25 e 75 , tanto do peso pré-gestacional referido, quanto do peso na entrada da coorte, que são sempre maiores do que aqueles observados nas mulheres que integraram a coorte. Não se constataram diferenças entre as outras variáveis comparadas (idade, escolaridade, paridade, intervalo interpartal e hábito de fumar ). 
Como o objetivo geral desse estudo é o de verificar a influência da ingestão energética no ganho de peso durante a gestação, sendo estas variáveis diretamente ligadas ao estado nutricional pré-gestacional, é provável que essa perda tenha influenciado os resultados observados. $\mathrm{O}$ menor ganho de peso e a menor ingestão energética verificados entre as mulheres com sobrepeso e obesidade, no início da gestação, poderia apresentar um viés pela perda maior de mulheres obesas. É factível supor que as obesas, que continuaram na investigação, apresentavam um comportamento diferenciado em relação ao seu estado nutricional e, também, à sua alimentação. As que abandonaram a coorte, provavelmente dado ao tipo de investigação, que realizou diversas medidas das dimensões corpóreas e questionou a mulher em relação à sua dieta, já no início da investigação, não quiseram se expor a este tipo de estudo.

Por outro lado, notam-se em publicações da década de 90 resultados semelhantes aos verificados nesse estudo; com as mulheres obesas apresentando um menor incremento ponderal durante a gestação e, mesmo, um acréscimo inferior de tecido adiposo ao longo deste período (Abrams \& Parker, 1990; Parham, et al., 1990; Lederman et al., 1997; Paxton, et al., 1998).

Bergmann et al. (1997), estudando o efeito do consumo energético no ganho líquido de peso, durante a gestação, segundo categorias de IMC inicial, verificaram um incremento ponderal menor $(4,3 \mathrm{~kg})$ nas gestantes com IMC alto, antes da gestação, em relação às com índice médio e baixo, respectivamente, 6,2 e 5,7 kg. Observaram, também, uma freqüência menor de dietas categorizadas com alto conteúdo calórico, entre as mulheres com IMC mais elevado.

Schieve et al. (1998), em uma investigação com 173.066 mulheres de diferentes etnias nos Estados Unidos da América, também encontraram um ganho de peso menor entre as gestantes com obesidade pré-gestacional, 
inferior, inclusive, àquele verificado nas gestantes com sobrepeso, antes da gestação.

Os resultados observados nessa investigação, em relação ao aumento ponderal e ao consumo energético durante a gestação, estão em consonância com outras investigações com objetivos semelhantes aos deste estudo.

\subsection{AS CARACTERÍSTICAS DA COORTE}

A propósito das características das gestantes pode-se concluir que essa coorte é composta de mulheres jovens, em sua maioria primíparas, com escolaridade semelhante à dos chefes de domicílios da região sudeste (IBGE,1997), porém com cerca de 30\% delas apresentando 4 ou menos anos de estudo e, portanto, de baixa escolaridade. $O$ intervalo interpartal, superior a dois anos, indica, no que diz respeito aos aspectos nutricionais, um intervalo aceitável em relação a uma nova gestação. A porcentagem de mulheres fumantes esta próxima à observada em São Paulo, sendo que o número médio de cigarros fumados por dia foi baixo/moderado (Monteiro et al., 1999).

A média de idade, superior entre as mulheres com sobrepeso e obesidade, reforça a associação dessa variável com a ocorrência de obesidade na população adulta. A relação do aumento de peso corpóreo com a idade tem sido evidenciada em várias investigações, tanto em homens, quanto em mulheres (Sichieri,1998; Souza,1999). Essa tendência também foi verificada nas investigações relacionadas à nutrição e gestação (Wolfe et al., 1991; Bergmann et al., 1997).

A média de número de filhos foi semelhante, segundo o estado nutricional no início da gestação, observou-se, entretanto, uma porcentagem menor de primíparas nas gestantes com sobrepeso e obesidade. A paridade 
tem sido apontada como um possível fator de risco no desenvolvimento da obesidade entre as mulheres, porém, nem sempre, a associação entre o número de filhos e/ou gestações e a ocorrência desta doença tem sido revelada (Smith et al., 1994 Boardley et al., 1995). Brown et al. (1994), com o objetivo de testar a hipótese de que a gestação, ou a história reprodutiva está associada a um progressivo ganho de peso e, conseqüentemente, com a ocorrência da obesidade, encontraram, a partir de um estudo com 41.184 mulheres pós-menopausa, uma forte associação entre idade e ganho de peso e uma fraca associação entre a paridade e o aumento ponderal e/ou mesmo o desenvolvimento de obesidade.

Com a finalidade de estudar a influência da história reprodutiva no ganho de peso de mulheres brasileiras de 15 a 49 anos, Coitinho (1998) investigou 2.338 mulheres, provenientes, da Pesquisa Nacional sobre Demografia e Saúde - PNDS, 1996. A autora encontrou uma associação entre a paridade e IMC atual significativa, mas que foi modificada pelo nível de IMC, apresentado pela mulher antes da primeira gravidez. Apenas nas mulheres que tinham índices de massa corpórea prévios, iguais ou inferiores a $21 \mathrm{~kg} / \mathrm{m}^{2}$, a paridade correspondeu a aumento de peso.

A associação entre o hábito de fumar e o ganho de peso durante a gestação não é totalmente clara. Alguns estudos indicam um menor consumo energético entre as mulheres com esse hábito e um menor acréscimo ponderal durante esse período, entre aquelas que fumam no decorrer da gestação. Esse efeito, porém, depende do número de cigarros utilizados por dia (Picone et al., 1982). Entretanto, em outras investigações não se observou esta associação, quando outras variáveis foram controladas (Smithells et al., 1977). Boardeley et al. (1995), analisando 345 mulheres, brancas e negras, de 7 a 12 meses pós-parto, com o objetivo de verificar o impacto da dieta, do nível de atividade física e de outros fatores na mudança ponderal após o parto, não verificaram associação entre o hábito de fumar, ingestão alimentar e 
ganho de peso durante a gestação. Desta forma, como no presente estudo observou-se uma freqüência moderada de fumantes $(17,6 \%)$ e a quantidade média de cigarro utilizado por dia foi inferior a $10 \mathrm{e}$, ainda, o número de gestantes sem esta informação foi de $8 \%$, decidiu-se não utilizar essa variável na análise do efeito da ingestão energética no aumento ponderal durante a gestação.

O trabalho da mulher fora de casa no primeiro período da gestação, revelou uma frequência semelhante à observada na população feminina, no município de São Paulo; cerca de 50\% das mulheres desempenham atividades remuneradas (Monteiro, 1999). É interessante notar que esse percentual foi gradualmente diminuindo no decorrer da gestação, chegando ao terceiro período com apenas $28,9 \%$ de gestantes trabalhando fora. Por um lado, este dado pode apoiar a hipótese de que as mulheres diminuem a sua atividade física durante a gestação, por outro, entretanto, inclusive observando-se o tipo de ocupação/atividade desenvolvida pelas mulheres da coorte, pode revelar uma relação trabalhista não formal e frágil. Sem a garantia, portanto, do direito da mulher trabalhadora não perder o seu emprego durante e após a gestação.

O tipo de atividade/ocupação das mulheres estudadas foi eminentemente ligado ao trabalho doméstico, o que dificultou a realização do questionário de freqüência de atividades físicas diárias - QFAD, pois, nem sempre as gestantes incluíram essas atividades, também domésticas, mas realizadas no trabalho fora de casa, nesse item do questionário. Levando, provavelmente, a uma diminuição do grau de atividade física, importante componente no cálculo do gasto energético. Também pode ter dificultado a obtenção desta informação a porcentagem de $50 \%$ ou mais de mulheres que não trabalhavam fora de casa e, assim, apresentavam uma dificuldade maior em quantificar o tempo e o tipo de atividade realizada durante o dia. 
Em relação ao estado nutricional pré-gestacional, observou-se uma ocorrência de baixo peso, inferior ao peso excessivo antes da gestação $14,3 \%$ de baixo peso e $16,4 \%$ de sobrepeso/obesidade pré-gestacional. No início da gestação, evidenciou-se uma porcentagem um pouco superior de mulheres com peso excessivo (sobrepeso e obesidade), 20,3\%, quando comparada à ocorrência de baixo peso - 19,8\%. Essas informações confirmam a necessidade de se implantarem ações de nutrição durante a atenção prénatal, visando não só garantir um adequado ganho de peso nas gestantes com baixo peso e peso excessivo pré-gestacional, diminuindo, assim, o risco de retardo de crescimento intra-uterino, mas também, contribuindo para o controle e para a prevenção do sobrepeso e da obesidade entre as mulheres.

A ocorrência de sobrepeso e obesidade verificada nesse estudo é inferior à prevalência observada para o Brasil em 1989, mesmo quando comparada com a frequiência, na população feminina, da região sudeste área urbana - 29\% (Souza, 1999). A frequência de baixo peso foi semelhante à encontrada por Coitinho,1998, a partir dos dados da PNDS, 1996, na mesma faixa etária, utilizando se como valor de corte um IMC menor do que 18,5 $\mathrm{kg} / \mathrm{m}^{2}-6,2 \%$ na referida pesquisa e $5,6 \%$ nesse estudo.

A "Pesquisa sobre padrões de vida - PPV, 1997" - , revelou nas mulheres da região sudeste uma tendência à estabilização ou, mesmo, de diminuição da prevalência de obesidade em algumas idades, quando comparada aos resultados da PNSN, 1989. Entretanto, a ocorrência de obesidade $(6,6 \%)$, verificada neste estudo, foi inferior à observada na PPV, 1997 - 12,4\% para todas as idades (Monteiro \& Conde, 1999).

A estatura das mulheres da coorte é semelhante à mediana observada na população feminina adulta do sudeste brasileiro (BRASIL, 1991). A mediana e os percentis 25 e 75 do IMC pré-gestacional são um pouco menores do que aqueles verificados na população feminina, talvez, por essa coorte ser de mulheres mais jovens. 
O menor valor de IMC pré-gestacional das gestantes estudadas pode ser devido, também, à informação recordatória do peso antes da gestação. Alguns estudos na literatura reafirmam a possibilidade de se utilizar a informação do peso referido pelos indivíduos, mas estes mesmos trabalhos apontam para diferenças nesta informação, relacionadas ao gênero e ao estado nutricional, levando, dependendo destas características, os informantes a subestimar e/ou superestimar esta informação (Stewart et al., 1987; Rowland, 1990).

Em trabalho realizado com 93 gestantes negras americanas de baixa renda, Stevens-Simon et al. (1992), encontraram uma boa acurácia entre o peso pré-gestacional recordado e o registrado antes da gestação, entretanto, verificaram que as gestantes com sobrepeso tendem a subestimar o seu peso e as mulheres desnutridas a superestimar esta informação. Portanto, como neste estudo, dispunha-se da informação do peso logo no início da gestação (Q1 - idade gestacional média de 11 semanas), optou-se por realizar a avaliação nutricional e a estimativa do aumento ponderal, a partir do peso diretamente aferido.

\subsection{A alimentaçÃo e o Consumo energético}

Os resultados, com referência à alimentação das gestantes estudadas, revelaram que as mesmas consomem dietas adequadas quanto à distribuição dos macronutrientes, nos três períodos analisados. $O$ fracionamento da alimentação também aparece de forma clara, pois as gestantes aumentam a frequiência das refeições, principalmente dos lanches, ao longo do periodo gestacional. Essa tem sido uma recomendação alimentar durante a gestação, objetivando maior aporte de calorias e de nutrientes e, ainda, uma intervenção alimentar, visando à diminuição de algumas das principais 
queixas das gestantes, como náuseas, enjôos, azia e mesmo obstipação intestinal.

A modificação da alimentação ocorre de maneira importante durante o primeiro período da gestação, sendo que a principal alteração nesse momento é a diminuição da ingestão alimentar. É interessante observar, não só neste momento, mas também ao longo da gestação, uma diferenciação do tipo de alteração alimentar segundo o estado nutricional inicial; as mulheres com sobrepeso referem diminuir as quantidades já no início da gestação, mantendo esse comportamento até o final . Somente, no terceiro momento, é que o aumento das quantidades vai aparecer com uma freqüência próxima a $40 \%$. Comportamento inverso foi observado entre as mulheres com baixo peso inicial, as quais referem diminuir as quantidades de alimentos consumidos somente no primeiro período da gravidez. Nas gestantes obesas, verificou-se uma inversão do tipo de modificação alimentar do primeiro para o segundo momento da gestação; no primeiro intervalo, mais de $60 \%$ delas informaram ter diminuído as quantidades de alimentos ingeridos; já no segundo momento, o aumento das quantidades é a modificação alimentar que aparece com maior freqüência.

Ainda, no que diz respeito ao tipo de modificação realizada pelas mulheres, parece que a alteração da preferência alimentar ocorre ao longo da gestação e com maior intensidade no início, onde essas alterações podem freqüentemente estar associadas à ocorrência maior de enjôos e náuseas.

A partir dessas informações, é possível supor que existe desde o início da gestação uma preocupação das mulheres em relação à sua alimentação. Parece que o aumento e/ou a diminuição das quantidades de alimentos consumidos não estão associados a uma orientação específica, pois foi só em cerca de $30 \%$, durante toda a gestação, que as mulheres referiram ter sido orientadas a alterar a sua dieta. Nas mulheres com sobrepeso e/ou obesidade, a diminuição das quantidades de alimentos consumidos aparece 
como a principal modificação, indicando, provavelmente, uma preocupação em não ganhar peso de forma excessiva. Nas gestantes com baixo peso, talvez, a preocupação esteja mais ligada à procura de uma alimentação mais adequada para esse período, principalmente, em relação à criança que está sendo gerada; daí o aumento das quantidades de alimentos ingeridos aparecer nesse grupo como a forma mais freqüente de alteração alimentar.

Dois pontos merecem ser destacados neste momento, tendo como referência as orientações nutricionais durante o pré-natal. Primeiro, parece haver de forma clara, por parte das mulheres, um conhecimento de que a sua alimentação está de alguma forma associada ao bom desenvolvimento da gestação e ao crescimento fetal. $O$ segundo ponto, talvez preocupante, que pode estar associado a um medo por parte das mulheres de se tornarem obesas, ou mesmo de aumentarem de forma excessiva o seu peso corpóreo, é a diminuição das quantidades de alimentos consumidos levando, portanto, a um menor aumento ponderal, sem que essa orientação tenha de fato alguma justificativa. Reforçando, assim, a crença comum e até popular, de que a gravidez pode representar a principal causa da obesidade feminina (Coitinho, 1998; WHO,1997)

Os resultados, aqui apresentados, podem auxiliar os profissionais de saúde, quando do planejamento das ações de nutrição durante o pré-natal, em especial nesse momento, em que uma das diretrizes da política nacional de alimentação e nutrição proposta pelo Ministério da Saúde é a da promoção de práticas alimentares e estilos de vida saudáveis, incentivando, desta forma, a elaboração de guias alimentares nos diferentes momentos do ciclo vital (Brasil, 1999).

As gestantes podem aderir de maneira mais eficiente às orientações em relação à sua alimentação, e, assim, é importante aconselhá-las a um ganho de peso adequado, informando de maneira correta a relação entre o aumento ponderal durante a gestação e o peso do recém-nascido e o 
desenvolvimento da obesidade. Neste sentido, a orientação dietética pode desempenhar uma papel fundamental na prevenção do baixo peso ao nascer, problema ainda importante de nutrição e saúde pública em nosso meio e, também, contribuir na prevenção e/ou controle da obesidade feminina, principal problema de saúde pública e nutrição entre as mulheres (Horta, 1997; Monteiro et al., 1999; Monteiro \& Conde, 1999).

Estimou-se a ingestão energética a partir da aplicação do questionário de frequiência de consumo de alimento - QFA - em três momentos, durante a gestação. Apesar desse método de inquérito alimentar ser, atualmente, um dos mais empregados em estudos epidemiológicos, ainda existem problemas que podem afetar com maior ou menor intensidade os estudos, que trabalham com ingestão de alimentos, obtidos a partir desta e/ou de outras metodologias de investigação alimentar. Entretanto, alguns cuidados e/ou análises podem ser realizados, objetivando conhecer a validade e a acurácia do instrumento utilizado e mesmo da estimativa do consumo energético e/ou de nutrientes que este possibilitou (Willet,1990b).

No presente estudo, observou-se uma média da razão entre o consumo de calorias e a taxa de metabolismo basal acima de 0,9 , indicando, portanto, que o instrumento utilizado para se estimar essa ingestão estava adequado. Os menores valores dessa razão foram verificados no primeiro momento da gestação, porém, nesse periodo, houve uma concordância entre a percepção da gestante, em relação ao tipo de modificação alimentar, e essas taxas. Foi nesse intervalo que se observaram as maiores freqüências de diminuição do consumo alimentar e menor ingestão energética, em todos os diagnósticos nutricionais iniciais.

Segundo Willett (1990c), o peso e a altura, que refletem o tamanho corpóreo e são realizadas diretamente, podem ser utilizadas como aferições indiretas do consumo de calorias, pois as alterações ponderais serão resultado do balanço energético. Nessa investigação, observou-se um 
aumento da ingestão energética ao longo da gestação que foi acompanhado também por um aumento ponderal. Verificou-se, ainda, nas mulheres com menor consumo energético, menor incremento ponderal - gestantes com sobrepeso e obesidade -, sendo que o contrário também foi notado, maior consumo de calorias associado a um maior aumento de peso, entre as eutróficas e as com baixo peso antes da gestação.

Contudo, quando se compara, levando-se em conta o estado nutricional inicial, o consumo energético e o ganho de peso durante a gestação, percebe-se que, entre as gestantes com obesidade e sobrepeso, pode ter ocorrido um sub-registro de alimentos, principalmente durante o terceiro período de gravidez. Nas mulheres com sobrepeso há uma diminuição do consumo energético no terceiro intervalo, nesse mesmo momento nota-se, também, um ganho de peso menor em relação ao segundo período de gestação. Analisando-se esses dois momentos nas gestantes com obesidade inicial, fica evidente que, nesse grupo, o sub-registro de alimentos pode ter sido maior, pois verificou-se uma ingestão energética um pouco superior no terceiro período somente nos valores da mediana, em relação ao segundo, entretanto o incremento de peso nesse mesmo momento, foi superior ao do segundo momento, 0,25 e 0,43 kg/semana, respectivamente. A hipótese de que pode ter ocorrido uma subestimação da ingestão energética, nas gestantes com obesidade inicial, em especial no terceiro período de gestação, pode ser confirmada observando-se a adequação dessa ingestão. No terceiro período a adequação do consumo calórico foi inferior ao do segundo, 0,66 e 0,79 , respectivamente, entretanto, o aumento ponderal semanal do terceiro período foi, praticamente, o dobro do observado no segundo período.

Dessa forma, pode-se concluir que a estimativa do consumo energético das gestantes da coorte está adequada, constatando-se, entretanto, um possível erro no terceiro período da gestação, pois as mulheres com obesidade inicial podem ter subestimado o seu consumo energético. 
Em um inquérito de base domiciliar representativo do município do Rio de Janeiro, realizado em 1995-1996, Sichieri (1998), encontrou nas mulheres com idade de 19 a 45 anos uma razão entre o consumo de energia e a estimativa de metabolismo basal de 1,99 (19 a 25 anos) e 1,87 ( 26 a 45 anos). O consumo energético foi obtido, a partir de um questionário de frequêencia de consumo de alimentos semiquantitativo, para adultos, previamente validado em uma amostra de funcionários da Universidade do Estado do Rio de Janeiro. Os dados observados nessa pesquisa, a despeito das diferenças metodológicas e do estado fisiológico (grávidas e não grávidas), são comparáveis aos verificados em nossa investigação.

Pode-se questionar a validade do QFA utilizado nesse estudo, pois segundo Willett (1990a), diferentemente dos métodos recordatórios de 24 horas ou de outras metodologias que podem ser aplicadas em qualquer população, os inquéritos de frequêencia de consumo de alimentos, realizados a partir de uma lista previamente definida de alimentos, devem ser validados em função da população a ser avaliada, pois a entrada ou não de um ou mais itens de consumo freqüente, afetam o instrumento de forma importante. Porém a lista de alimentos utilizada no QFA foi construída a partir, além da informação dos alimentos mais comumente consumidos pela população adulta em área urbana no município de São Paulo (Dieese,1987), com a experiência no emprego dessa metodologia em outras investigações com grupos etários diferentes, também do município de São Paulo, e da utilização de recordatórios alimentares de 24 horas com gestantes, durante o atendimento pré-natal, na Disciplina de Obstetrícia do Departamento de Tocoginecologia da Unifesp-Epm (Sachs et al., 1987; Lopez et al., 1988; Sachs et al., 1989; Sachs et al., 1990; Najas et al., 1992; Tudisco, 1993; Najas et al., 1994; Sampaio, 1997; Bassicheto et al.,1998). Aplicou-se o diário alimentar de 3 dias, em um sub-grupo da coorte, verificando-se, a partir deste registro, uma adequação da lista de alimentos constantes no QFA; os itens que 
apareceram com maior freqüência no diários alimentar estavam contidos no questionário (anexo 11).

O consumo de energia observado é próximo àquele evidenciado na população adulta do Estudo Multicêntrico sobre o Consumo Alimentar em 5 cidades brasileiras (Galeazzi et al., 1997). A ingestão energética das gestantes da coorte só foi superior aos valores observados em mulheres não gestantes, de 19 a 45 anos, na cidade de Goiânia (2004 e 1816 kcal). Em outros municípios - Rio de Janeiro, Campinas e Curitiba -, constararam-se estimativas muito semelhantes às verificadas nessa coorte.

A mediana de consumo de energia aumentou de forma progressiva, respectivamente, 2344, 2403 e $2508 \mathrm{kcal}$, no primeiro, segundo e terceiro períodos da gestação. Não se observou um aumento progressivo do consumo de calorias durante a gestação, nas mulheres com baixo peso e sobrepeso inicial. Nas com baixo peso, notou-se uma mediana de ingestão calórica menor no segundo período, quando comparado ao primeiro.

Murphy \& Abrams. (1993), com o objetivo de avaliar o consumo energético, durante a gestação e lactação, estudaram uma coorte de 458 mulheres participantes do "Continuing Survey of Food Intakes". As autoras não verificaram um aumento linear da ingestão calórica durante a gravidez. Houve um incremento dessa ingestão do primeiro para o segundo que, praticamente, manteve-se durante o terceiro trimestre de gravidez, tanto nas mulheres brancas quanto nas negras. Os valores de consumo de energia, observados nessa investigação, respectivamente 1580, 1839 e 1818 kcal, no primeiro, segundo e terceiro trimestre de gravidez, foram menores do que aqueles encontrados nesse estudo. Ainda, segundo as autoras, como a referida pesquisa não havia sido desenhada com esse objetivo específico, pode ter ocorrido uma subestimação do consumo energético entre as mulheres da coorte. 
Em uma investigação realizada com 56 gestantes suecas, com o objetivo de contribuir na elucidação da relação entre ingestão alimentar, atividade física e acréscimo de tecido adiposo durante a gestação, Langhoff et al. (1987), verificam um consumo de energia de 2.192 e $2.257 \mathrm{kcal}$, na $17^{\mathrm{a}} \mathrm{e}$ 33a semana de gestação, respectivamente. Esses valores estão próximos à ingestão calórica verificada nas gestantes da coorte.

Ao estudar uma amostra de 78 gestantes equatorianas, residentes em zona urbana, Weigel et al. (1991), verificaram uma ingestão energética em dois momentos do terceiro trimestre de 2.660 a $2.666 \mathrm{kcal}$. Esse consumo de calorias é um pouco superior ao observado nas gestantes da coorte, também, durante o terceiro trimestre de gestação, $2.508 \mathrm{kcal}$.

Constata-se que a estimativa do consumo de energia encontrada neste estudo está muito próxima aos valores identificados em outras investigações que também avaliaram este consumo entre gestantes. Picone et al. (1982) observaram em 60 gestantes uma ingestão média de $2.003 \mathrm{kcal}$ durante a gestação, no grupo com ganho de peso adequado; naquelas onde o aumento ponderal foi classificado como baixo, notaram um ingestão de $1.941 \mathrm{kcal}$. Com o objetivo de verificar a relação entre o ganho de peso durante a gestação de adolescentes e mulheres de grupos minoritários, observando, também, o papel da ingestão energética e de outros nutrientes nessa associação, Scholl \& Hediger (1995) encontraram uma ingestão energética (entre as gestantes adultas) de $2.358 \mathrm{kcal}$ nas com aumento ponderal adequado e de $2.185 \mathrm{kcal}$ naquelas com ganho de peso inadequado.

Essa tendência de menor ingestão energética entre as obesas e maior naquelas com baixo peso tem sido evidenciada em algumas investigações, como as já referidas anteriormente (Picone et al., 1982 e Scholl \& Hediger, 1995). Em nosso estudo, verificou-se que as mulheres com baixo peso, antes da gestação, apresentaram uma ingestão energética maior do que a observada entre as gestantes eutróficas (a não ser no segundo período, em 
que este consumo foi semelhante a deste grupo), com sobrepeso e obesidade no início da gestação. O consumo de energia foi menor entre as gestantes obesas que apresentaram durante o primeiro e o segundo períodos da gestação uma ingestão energética inferior aos outros grupos. No terceiro momento analisado, verificou-se que o consumo de calorias das obesas foi superior ao das mulheres com sobrepeso. Bergmamm et al. (1997), também encontraram esta tendência, em estudo realizado com 156 mulheres na Alemanha. Nas gestantes classificadas como baixo peso (IMC<20) observaram maior freqüência de dietas categorizadas com alto conteúdo calórico (48\%); nas mulheres classificadas no grupo com IMC alto foi maior a ocorrência de dietas com baixo conteúdo energético (46\%).

É possível, como já mencionado anteriormente, que as gestantes com obesidade inicial tenham subestimado o seu consumo energético, entretanto, constata-se, também, neste grupo de mulheres o menor ganho de peso durante a gestação, quando se compara este ganho com o verificado nas gestantes eutróficas e com baixo peso, no início da gestação.

A associação entre o consumo energético e o aumento ponderal na gestação nem sempre tem sido revelada de forma significante ou demostrada com uma forte relação. A lacuna dessa associação deve estar diretamente ligada à dificuldade própria das metodologias de inquérito alimentar de estimar a ingestão de energia, da quase ausência de instrumentos e/ou de técnicas capazes de medir o custo energético da gravidez, no âmbito populacional, além, de outras características maternas que podem influenciar a utilização de energia durante este período e, ainda, a impossibilidade de uma medição da adaptação metabólica individual (Institute of Medicine, 1990b; Abrams, 1994).

Segundo Abrams (1994), em trabaiho de revisão, a necessidade de energia durante a gestação pode variar de 0 a $120.000 \mathrm{kcal}$, dependendo não só do estado nutricional pré-gestacional, como também da disponibilidade 
extra de alimentos ou da habilidade em reduzir o gasto energético, além de outros fatores, desconhecidos, que influenciam a necessidade calórica durante a gestação. Reforçando, assim, a hipótese de que o gasto energético é muito mais variável do que se acreditava anteriormente, e dependente de inúmeras características, ainda não conhecidas, ou de difícil medição, como já demostrado em outras investigações, em diferentes populações, com aferição direta do gasto durante a gravidez, (Durnin, 1987; Poppitt et al., 1993; Piers et al., 1995; Prentice et al., 1996). Desta forma, ainda, segundo Abrams em 1994, existem evidencias científicas que sugerem não ser possível predizer o requerimento energético baseado em características maternas, entretanto a avaliação do consumo alimentar, o gasto energético - incluindo, aí a atividade física - o ganho de peso durante a gestação, além de outros fatores, possibilitam uma aproximação do balanço energético individual.

Nesse sentido, os estudos que objetivam avaliar o impacto da ingestão energética no aumento ponderal, durante a gestação, necessitam da informação e/ou do controle do gasto energético (Institute of Medicine, 1990 a; Abrams, 1993). Segundo Willett (1990b), o principal determinante do gasto energético é, sem dúvida, o nível de atividade física diária, pois a variação encontrada deste gasto relacionado com o gênero, a idade, o peso e a estatura é relativamente pequena. Dessa forma, neste estudo, tentando controlar o gasto energético, aplicou-se um questionário de freqüência de atividades físicas diárias, incluindo as atividades domésticas, os deslocamentos a pé para o trabalho, compras, escola etc., as atividades de lazer e as realizadas no trabalho fora de casa.

Observou-se uma dificuldade na aplicação do mesmo e, também, percebeu-se uma dificuldade na quantificação do tempo gasto na realização de cada uma das atividades e na classificação dessas em categorias - leve, moderada, intensa. Apesar das dificuldades foi possível calcular o gasto 
energético das gestantes e, portanto, verificar a adequação do consumo energético.

Verificou-se na coorte que o consumo de calorias foi superior ou muito próximo ao gasto energético, a não ser nas mulheres com obesidade inicial, nas quais o gasto foi sempre superior ao consumo de energia, e nas gestantes com sobrepeso, que no terceiro intervalo apresentaram um gasto maior em relação à ingestão energética (gráfico 4). Entretanto, pode-se aferir, comparando-se essas variáveis com o aumento de peso no período e mesmo semanal, que o balanço energético foi positivo em todos os intervalos analisados, com exceção das mulheres com obesidade inicial, no primeiro intervalo, no qual se verificaram ganhos ponderais negativos ou nulos, indicativos, portanto, de um balanço energético negativo.

A diferença entre o gasto e o consumo de energia pode estar associada a uma superestimação do nível de atividade física realizada pelas gestantes, pois percebeu-se que, na maioria das vezes, mesmo entre as gestantes com ocupação fora de casa, houve uma atividade física muito leve entre as mulheres da coorte. Outro dado, que pode ter superestimado o gasto energético entre as gestantes, foi o próprio adicional de energia acrescido nas taxas de metabolismo basal, indicando, talvez, que as recomendações de calorias para este grupo estejam acima do necessário. É possível, também, que tenha ocorrido uma subestimação do consumo de calorias, principalmente entre as mulheres com obesidade inicial, em especial no terceiro período da gestação, como já referido.

Murphy \& Abrams (1993), verificaram um consumo energético sempre inferior ao gasto, que foi obtido a partir do RDA (1989), considerando-se, também, o nível de atividade física. As autoras, como já exposto, observaram um consumo energético menor do que o evidenciado nesse estudo, e comentam que o consumo de calorias, abaixo do recomendado, pode estar apontando um erro nesta estimativa e/ou, 
também, uma inadequação das recomendações de energia durante a gestação.

Dessa forma, pode-se concluir, ao se analisarem as adequações do consumo calórico e os aumentos ponderais durante a gestação, que a estimativa do consumo foi satisfatória, mesmo verificando-se entre as gestantes com obesidade inicial uma possível subestimação da ingestão energética. Entretanto, é plausível supor que, de fato, as gestantes apresentaram menor ingestão de calorias do que as mulheres com eutrofia e baixo peso, pois evidenciou-se, também nessas mulheres um menor ganho de peso durante a gestação. Provavelmente, o efeito da estimativa de menor consumo de energia, ocorra com maior intensidade no terceiro período de gestação.

\subsection{O AUMENTO PONDERAL DURANTE A GESTAÇÃo}

A última recomendação de aumento ponderal, durante a gestação, publicada pelo Institute of Medicine, 1990c, prevê incrementos de peso diferenciados, segundo o período da gestação, tendo como referência o estado nutricional pré-gestacional, avaliado a partir do IMC. Comparando os ganhos de peso por semana, segundo o período gestacional observado nas gestantes estudadas com essas diretrizes, verificou-se: nas mulheres com baixo peso inicial um valor semelhante ao recomendado, 0,5 kg/semana, a partir do $2^{\circ}$ trimestre de gravidez; no terceiro período, porém, o incremento foi inferior $(0,43 \mathrm{~kg} /$ semana) e apenas o valor obtido do percentil 75 foi igual ao preconizado; nas eutróficas e nas com sobrepeso no início da gestação, o aumento ponderal por semana foi de $0,47 \mathrm{~kg}$ e $0,43 \mathrm{~kg}$, respectivamente, portanto, acima da recomendação $\left(0,4\right.$ e $0,3 \mathrm{~kg} /$ semana, a partir do $2^{\circ}$ 
trimestre de gravidez); no terceiro período, observou-se, nas mulheres com sobrepeso, um valor mais próximo ao recomendado, 0,37 kg. Nas obesas o ganho de peso por semana durante o segundo período foi de $0,25 \mathrm{~kg}$, dentro da recomendação, no terceiro intervalo, contudo, este valor foi superior ao preconizado. Desta maneira, mesmo se considerando que as recomendações do Institute of Medicine levam em conta o estado nutricional pré-gestacional e que as gestantes da coorte foram estratificadas segundo este diagnóstico no início da gestação, pode-se concluir que as mulheres que integraram esse estudo não apresentaram um ganho de peso de acordo com essas recomendações.

Nesse estudo, o aumento de peso, observado entre a $11^{\mathrm{a}} \pm 2,8$ e a $36^{\mathrm{a}} \pm$ 1,4 semana de gestação, não se distanciou dos recomendados por esse Instituto. Assim, é possível concluir que, nas gestantes eutróficas e com sobrepeso inicial, ocorreu um incremento ponderal excessivo; já nas mulheres com baixo peso, o aumento esteve abaixo do esperado, portanto, insuficiente, e finalmente, nas obesas verificou-se um acréscimo ponderal próximo ao esperado, a não ser no terceiro período em que estas mulheres ganharam peso, também, de forma excessiva.

Abrams (1994), em artigo de revisão, reporta várias investigações com diferentes coortes de gestantes - brancas, negras, com baixo e/ou alto poder aquisitivo - , onde se constatou que apenas em torno de 30 a $40 \%$ das gestantes apresentam um aumento ponderal próximo as recomendações do Institute of Medicine (1990b). Segundo, a mesma autora, cerca de um terço apresenta um incremento ponderal menor que o preconizado e $30 \%$ acima dessas recomendações.

A proposta de ganho de peso durante a gestação, preconizada pelo Institute of Medicine (1990b) tem sido amplamente utilizada. Os valores de aumento ponderal recomendados por este Instituto são maiores, dependendo do estado nutricional pré-gestacional, do que orientações anteriores. Dessa 
forma, algumas investigações, com o objetivo de avaliar a pertinência e a validade destas diretrizes, foram realizadas nos últimos anos (Johnson \& Yancey, 1996).

Parker \& Abrams (1991), com o objetivo de analisar essa recomendação em relação à freqüência de recém-nascidos pequenos e grandes para idade gestacional e de cesáreas, concluíram que as recomendações de aumento ponderal propostas por este Instituto reduzem o risco de ocorrência dos eventos analisados.

Ao verificarem as implicações do ganho de peso durante a gestação, segundo as recomendações do Institute of Medicine (1990), na retenção de tecido adiposo pós-parto, Keppel \& Taffel (1993), avaliaram uma amostra de mulheres do "1988 National Maternal and Infant Health Survey" e concluiram que, entre as mulheres brancas, o aumento ponderal na gravidez, segundo as recomendações, não levou a uma retenção de tecido adiposo pós-parto (10 a 18 meses após o parto). Já, nas mulheres negras seria necessário implantar ações visando a uma orientação, para reduzir a retenção do acréscimo de gordura pós-parto. Shieve et al. (1998), examinaram a associação entre o ganho de peso na gravidez, segundo a adequação da recomendação do Institute of Medicine, 1990, e o peso do recém-nascido, concluindo que a diretriz proposta por esse Instituto para as mulheres com baixo peso e/ou eutróficas está adequada. Porém, a recomendação para as gestantes com sobrepeso e/ou obesidade devem ser revistas

Assim, parece que a recomendação de aumento de peso na gravidez, proposta pelo Institute of Medicine, pode ser utilizada, servindo como uma diretriz no momento do aconselhamento/orientação do ganho ponderal individual, durante o pré-natal. Apesar do incremento de peso das gestantes da coorte não estar dentro dos valores recomendados por este Instituto, observou-se um acréscimo de peso maior nas mulheres eutróficas e com baixo peso no início da gestação e um aumento menor entre as gestantes com 
sobrepeso e obesidade inicial, de acordo, portanto, com os pressupostos que foram utilizados nessa recomendação. Outros trabalhos já haviam apontado para a necessidade de se estipularem aumentos ponderais diferenciados, segundo o estado nutricional pré-gestacional, visando não só prevenir o nascimento de recém-nascidos de baixo peso, mas também controlar o ganho de peso e, principalmente, a retenção desse incremento ponderal após o parto nas mulheres (Naeye,1979; Brown et al. 1986; Abrams \& Laros, 1986; Kramer, 1987; Brown, 1988; Krasovec \& Anderson, 1991; Andreazza, 1993; Perry et al., 1995).

Ao se analisar o ganho de peso por semana, segundo o período de gestação, não se observou um incremento ponderal constante desde o início da gestação. Na coorte, verificou-se um ganho de peso menor no período inicial e com a mesma intensidade a partir do segundo trimestre de gestação. Essa tendência também foi verificada nas gestantes eutróficas. Nas obesas, no início da gestação, o incremento de peso foi mais intenso durante o terceiro período; nas mulheres com baixo peso, identificou-se uma pequena desaceleração deste aumento do segundo para o terceiro trimestre de gravidez.

Dawes \& Grudzinskas (1991), em uma pesquisa retrospectiva com 1.145 gestantes inglesas, observaram um ganho de peso por semana, segundo o período da gestação, semelhante aos encontrados nesta investigação, constatando um incremento maior de peso entre a $16^{\mathrm{a}}$ e $28^{\mathrm{a}}$ semana de gestação. Outras investigações a respeito do aumento ponderal durante a gravidez, encontraram um ganho de peso mais intenso durante o segundo trimestre e, portanto, não de forma linear a partir do segundo trimestre (Fescina, 1983; Krasovec, 1991; Andreazza, 1993). Apesar de incrementos ponderais próximos aos encontrados nesta investigação, não se constatou um ganho de peso maior durante o segundo período de gestação. 


\subsection{O CONSUMO ENERGÉTICO E O AUMENTO PONDERAL}

Observou-se uma associação positiva entre o consumo energético e aumento ponderal no início e no segundo período da gestação, controlandose o intervalo de tempo entre as medidas , o peso no início de cada período, a idade, a paridade e a estatura. Essa associação nem sempre foi revelada em outras investigações, principalmente pela dificuldade e pelos erros inerentes às metodologias de inquérito alimentar, que visam a estimar o conteúdo energético e de nutrientes da alimentação habitual de grupos da população (Willett, 1990 a; Institute of Medicine, 1990b).

A inclusão da idade e da paridade nos modelos de regressão linear múltipla, entre o ganho de peso durante a gestação e o consumo de energia nos diferentes períodos da mesma, visou ao controle das duas variáveis, pois algumas pesquisas têm verificado uma associação entre elas e o aumento ponderal na gravidez (Abrams \& Parker, 1990; Bergmann et al., 1997).

A não associação entre a ingestão energética e o ganho de peso no terceiro período da gestação (a partir da $32^{a}$ semana) pode estar ligada ao próprio momento da gestação. Nesse período, o crescimento fetal é mais intenso, e o acúmulo de gordura nos tecidos maternos praticamente não ocorre mais, pois, este já aconteceu de forma mais intensa nos dois trimestres anteriores (Viegas et al., 1987; Institute of Medicine, 1990c; Villar et al., 1992).

Picone et al. (1982), concluíram, a partir de uma investigação com 60 gestantes americanas, que uma baixa ingestão calórica está associada a um pequeno aumento ponderal durante a gestação. Langhoff-Roos et al. (1987), só verificaram uma associação positiva entre a ingestão energética e o acréscimo de gordura na $17^{\mathrm{a}}$ semana de gestação; nas mulheres da coorte esta semana está incluída no período inicial, no qual se observou, também, uma associação entre estas variáveis. Bergmaann et al. (1997) encontraram uma 
relação positiva entre a ingestão energética e o ganho de peso durante a gestação, independentemente dos índices de massa corpórea iniciais.

Os resultados observados nesse estudo indicaram uma associação positiva entre a ingestão energética e o ganho de peso na gravidez, durante o primeiro e início do segundo trimestre de gestação. Em um momento da gestação, portanto, em que ainda é possível a realização de intervenções, visando a um ganho de peso suficiente para garantir, não só um crescimento fetal satisfatório, mas também um acúmulo adequado de gordura, para prevenir o desenvolvimento da obesidade pós-parto.

Verificou-se, também, com os exemplos construídos com as equações obtidas a partir na análise de regressão linear múltipla do aumento ponderal durante a gestação, segundo o estado nutricional inicial, para uma ingestão energética de $2.000,2.200$ e $2.500 \mathrm{kcal}$, que as recomendações do conteúdo calórico das dietas das gestantes parecem ser mais adequadas nas mulheres com baixo peso e eutrófica no início da gestação. Nas gestantes com sobrepeso e obesidade, considerando-se uma atividade física leve, observouse, no segundo e terceiro período da gestação, uma adequação da ingestão energética em torno de 90 a $80 \%$ e um aumento ponderal acima do preconizado pelo Institute of Medicine $(1990 \mathrm{c})$, o que pode estar indicando que as recomendações energéticas durante a gestação podem estar superestimadas, principalmente, nesse grupo de mulheres. Estes resultados corroboram as conclusões dos trabalhos de Murphy \& Abrams (1993) e Abrams (1994) que reforçam a hipótese de que o gasto energético é muito mais variável do que se acreditava, e dependente de inúmeras características e que, portanto, as recomendações de energia durante a gestação podem estar inadequadas e, não devem ser utilizadas de forma generalizada.

Desta forma, as ações de nutrição durante o pré-natal devem buscar um orientação alimentar e nutricional que considere não só a estimativa de aumento ponderal recomendada, mas também o estado nutricional da 
mulher, os seus hábitos alimentares e a sua atividade física, entre outros aspectos, objetivando uma prescrição dietética mais adequada a cada gestante. Estas atividades devem ocorrer, prioritariamente, no primeiro e segundo trimestres de gestação.

\section{6 CONSIDERAÇÕES FINAIS}

Algumas considerações devem ser realizadas em relação aos limites desta investigação. Trata-se de uma estudo efetuado em um único serviço de pré-natal, portanto, a generalização dos resultados e conclusões apresentados aqui deve considerar esta questão. A validade externa desses resultados deverá ser melhor analisada.

O fato da seleção precoce das gestantes, isto é, antes da $17^{a}$ semana de gestação na entrada na coorte, pode ter levado a um erro de seleção, pois, estas mulheres chegavam mais cedo ao serviço, indicando, talvez, um preocupação maior com a sua saúde. Este fato pode explicar que, mesmo tratando-se de um grupo de gestantes de baixa renda e com pouca escolaridade, tenha se observado um aumento ponderal e uma ingestão energética tão próximas das recomendações.

Um outro problema, que pode ou não ter enviesado os resultados dessa investigação, é o número de perdas de seguimento. Como já referido no item 5.1, as mulheres que abandonaram a coorte apresentavam indicadores antropométricos diferentes daqueles das gestantes que integraram o estudo; a ocorrência de obesidade no início da gestação foi superior nas gestantes que abandonaram o seguimento.

Os intervalos de tempo entre as observações do consumo energético e do aumento ponderal, principalmente, entre a primeira e a segunda observação, podem não ter sido suficientes para se detectar alterações nessas 
variáveis. Entretanto, este menor intervalo parece não ter influenciado de forma importante as conclusões deste estudo, pois verificou-se uma associação estatisticamente significante entre o consumo energético e o ganho de peso durante a gestação no primeiro e segundo períodos analisados, o que não se observou no terceiro intervalo de gestação.

A dificuldade na estimativa do gasto energético das gestantes ocorreu não só pelo instrumento de coleta das informações das atividades físicas diárias, mas também por uma indefinição na literatura de quais são as reais necessidades energéticas, durante este período do ciclo vital. Essa dificuldade dificultou o controle desta variável na análise da associação entre o consumo de energia e o aumento ponderal durante a gestação. $O$ não controle do gasto energético tem sido apontado como um dos motivos para a ausência de associação observada em algumas investigações entre o consumo de energia e o aumento ponderal.

Mesmo com essas limitações, os resultados encontrados permitem algumas conclusões em relação ao efeito do consumo energético no aumento ponderal durante a gestação. Assim, este trabalho poderá contribuir na construção de orientações nutricionais e alimentares mais direcionadas à gestante durante o seu atendimento de pré-natal, com objetivo não só da prevenção do retardo de crescimento intra-uterino, mas também da manutenção da saúde da mulher. Essa investigação aponta, ainda, para a necessidade de se aprofundar tanto a análise quanto a avaliação das recomendações nutricionais, em especial do requerimento energético durante este período do ciclo vital. 
CONCLUSÕES 


\section{CONCLUSÕES}

- As gestantes da coorte estudada consumiram dietas adequadas em relação à distribuição dos macronutrientes, nos três períodos da gestação analisados. $O$ fracionamento da alimentação ocorreu de forma adequada, com as mulheres aumentando o número de refeições ao longo da gravidez.

- A modificação da alimentação aparece, já, no primeiro período da gestação, sendo mais freqüente, neste momento, a diminuição da ingestão alimentar; a partir daí, o aumento de quantidades é a alteração mais relatada pelas mulheres da coorte. Ao longo da gestação, observou-se uma tendência de diferenciação dessas alterações segundo o estado nutricional inicial. A alteração das preferências alimentares ocorre durante a gravidez, com maior intensidade no primeiro intervalo analisado.

- A mediana de consumo energético aumentou de forma progressiva durante a gestação. Esse comportamento não foi observado nas mulheres com sobrepeso, as quais diminuíram o consumo de energia do segundo 
para o terceiro período da gestação. Também, nas que tinham baixo peso inicial, verificou-se menor ingestão calórica no segundo momento analisado, quando comparado ao primeiro período da gestação. A menor ingestão energética ocorreu entre as gestantes com sobrepeso e obesidade no início da gestação, e os maiores consumos foram observados nas eutróficas e nas gestantes com baixo peso.

- Nas mulheres estudadas, o consumo de calorias foi superior ou muito próximo ao gasto energético, a não ser nas gestantes com obesidade inicial, nas quais o gasto foi sempre superior ao consumo de energia, e nas com sobrepeso inicial, que no terceiro intervalo, também apresentaram este comportamento. Observou-se, portanto, uma adequação do consumo de energia, indicando um balanço energético positivo durante toda a gestação, com exceção das mulheres com obesidade inicial que perderam peso no primeiro intervalo, demonstrando, assim, um balanço energético negativo, naquele momento da gestação

- A estimativa do consumo de energia foi satisfatória, pois evidenciou-se uma adequação dessa ingestão que foi acompanhada de incrementos positivos de peso ao longo da gravidez. Nas gestantes com obesidade, é possível ter ocorrido uma subestimação do consumo de calorias.

- As gestantes eutróficas e com sobrepeso, no início da gestação, apresentaram um aumento ponderal acima do recomendado; nas com baixo peso, observou-se um acréscimo ponderal inferior ao esperado. $O$ ganho de peso, durante a gestação, nas obesas, foi próximo ao proposto para este grupo de mulheres, a não ser no terceiro período da gravidez em que elas experimentaram um aumento ponderal excessivo. 
- O acréscimo de peso durante a gravidez foi maior nas mulheres eutróficas e naquelas com baixo peso no início da gestação. $O$ menor incremento ponderal foi evidenciado nas gestantes com sobrepeso e obesidade.

- A associação entre o consumo de energia e o ganho de peso durante a gestação foi positiva no primeiro e no segundo trimestres de gestação, portanto em um momento da gravidez em que é possível a realização de intervenções nutricionais/alimentares, visando a um aumento ponderal suficiente para garantir, não só um ótimo crescimento fetal, mas também um acúmulo adequado de gordura nos tecidos maternos, prevenindo e/ou controlando o desenvolvimento da obesidade pós-parto. 


\section{REFERÊNCIAS}

ABRAMS, B. - Weight gain and energy intake during pregnancy. Clin Obstet Gynecol 1994; 37: 515-527.

ABRAMS, B. F. \& LAROS, R. K. - Prepregnancy weight, weight gain and birth weight. Am J Obstet Gynecol. 1986; 154: 503-9.

ABRAMS, B. F. \& PARKER, J. D. - Maternal weight gain in women with good pregnancy outcome. Obstet Gynecol. 1990; 76(1): 1-7.

ANÇÃO, M. S.; CUPPARI,L.; TUDISCO,E.S.; DRAIBE,S. A . \& SIGULEM, D. Programa de apoio à nutrição [programa de computador].versão 2.01. São Paulo: Centro de Informática em Saúde da Escola Paulista de Medicina Universidade Federal de São Paulo; 1993.

ANDREAZZA, R. - Avaliação nutricional de gestantes e sua relação com o peso do recém-nascido. São Paulo, 1993. [Tese de mestrado - Escola Paulista de Medicina].

ANDREAZZA, R.; SOUZA, A .L. M.; WAJSBERG, M. \& TUDISCO, E. S. Avaliação nutricional da gestante: utilização de curvas de monitoração. In: Resumos do $3^{\circ}$ Congresso Brasileiro de Epidemiologia; 1995 set 12; Salvador, Brasil.

ATALAH, E. S.; CASTILLO,C. L.; CASTRO,R. S. \& ÁLDEA, A P. - Propuesta de un nuevo estándar de evaluación nutricional en embarazadas. Rev Méd Chile. 1997; 125: 1429-1436.

BAECKE, J.A H.; BUREMA, J. \& FRIJTERS, J.E.H. - A short questionnarie for the measurement of habitual physical activity in epidemiological studies. Am J Clin Nutr. 1982; 36: 936-42.

BASSICHETO, K. C.; NAJAS, M. S.; ANDREAZZA, R. \& RAMOS, L. R. Padrão de consumo de gordura na dieta de idosos e sua relação com a dislipidemia. In: Resumos $6^{\circ}$ Congresso da Sociedade Brasileira de Nutrição; 1999 dez; São Paulo, Brasil.

BEATON, G. H.; BUREMA, J. \& RITENBAUGH, C. - Errors in the interpretation of dietary assessments. Am J Clin Nutr. 1997; 65(suppl): 1100S-7S. 
BERGMANN, M. M.; FLAGG, E. W.; MIRACLE-McMAHILL, H. L. \& BOEING, H. - Energy intake and net weight gain in pregnant women according to body mass index (BMI) status. Int J Obes Relat Metab Disord. 1997; 21: 1010-7.

BLACKBURN, M.W. \& CALLOWAY, D. H. - Basal metabolic rate and work energy expenditure of mature, pregnant women. J Am Diet Assoc. 1976 a; 69: 24-8.

BLACKBURN, M.W. \& CALLOWAY, D. H. - Energy expenditure and consumption of mature, pregnant and lactating women. J Am Diet Assoc. 1976b; 69: 29-37.

BLAIR, S.N. et al. Assessment of habitual physical activity by a seven-day recall in a community survey and controlled experiments. Am J Epidemiol. 1985;122: 794-804.

BLOISI, M.; CALIA, J.; SOUZA, A L. M.; BENÍCIO, M. H.; ANDREAZZA, R. - Comparação do consumo de açúcar e gordura vegetal obtido a partir de dois métodos de inquérito alimentar em gestantes atendidas em serviço de pré-natal, São Paulo. In: Livro de resumos do $5^{\circ}$ Congresso Nacional da Sociedade Brasileira de Alimentação e Nutrição; 1993 dez 5-8; São Paulo, Brasil. São Paulo: Sociedade Brasileira de Alimentação e Nutrição; 1999. p. 141.

BOARDLEY,D.J.; SARGENT,A.C.; HUSSEY,J. \& SHARPE,P.A. - The relationship between diet, activity, and other factors, and postpartum weight change by race. Obstet Gynecol. 1995; 86: 834-8.

BRASIL. Ministério da Saúde. Instituto Nacional de Alimentação e Nutrição - Condições nutricionais da população brasileira: adultos e idosos. Pesquisa nacional sobre saúde e nutrição. Brasília, 1991, 39p.

BRASIL. Ministério da Saúde. Instituto Nacional de Alimentação e Nutrição. Secretaria de Programas Especiais - Registro fotográfico para inquéritos dietéticos: utensílios e porções. Goiânia; 1996, 74p.NEPA UNICAMP/DNUT - UFG.

BRASIL. Ministério da Saúde. Secretaria de Políticas de Saúde - Política nacional de alimentação e nutrição. Brasília; 1999 
BRIEFEL, R.R.; SEMPOS, C. T.; McDOWELL, M. A ; CHIEN, S. \& ALAIMO,K. - Dietary methods research in the third National Health and Nutrition Examination: underreporting of energy. Am J Clin Nutr. 1997; 65 (suppl): 1203S-9S.

BROWN, J. E.; BERDAN, K. W.; SPLETT, P.; ROBINSON, M. \& HARRIS, L.J. - Prenatal weight gains related to the birth of healthy-size infants to lowincome women. J Am Diet Assoc. 1986; 86: 1679-83.

BROWN, J. E. - Weight gain during pregnancy what is "optimal" ? Clin Nutr. 1988; $7: 181-90$.

BROWN, J. E.; KAYE,S.A. \& FOLSOM,A.R. - Parity-related weight change in women. I. J. Obesity. 1992; 16(9): 627-31.

BROWN, J. E.; BUZZARD, M.; JACOBS, D. R.; HANNAN, P. J.; KUSHI, L. H.; BARROSSO, G. M. \& SCHMID, L.A . - A food frequency questionnaire can detect pregnancy-related changes in diet.J Am Diet Assoc. 1996; 96: 26266.

BURKE, B.S. - The dietary history as a tool in rearch. J Am Diet Assoc. 1947 23: $1041-6$.

CENTER FOR DISEASE CONTROL \& PREVENTION, USA. - Epi info. [programa de computador]. version 6.02. Geneve: WHO, 1994

COGSWELL, M. E. \& YIP, R. - The influence of fetal and maternal factors on the distibuition of birhweight. Seminars in Perinatology. 1995; 19: 222-24.

COITINHO, D. C. - A influência da história reprodutiva no índice de massa corporal de mulheres brasileiras. São Paulo, 1998. [ Tese de Doutorado Faculdade de Saúde Pública da Universidade de São Paulo].

DAWES, M.G. \& GRUDZINSKAS, J. G. - Patterns of maternal weight gain in pregnancy. British J of Obstet Gynaecology.1991; 98:195-201.

DAWES, M. G.; GREEN, J. \& ASHURST, H. - Routine weighing in pregnancy. British Med J 1992; 6825: 487-89.

DEPARTAMENTO INTERSINDICAL DE ESTATÍSTICAS E ESTUDOS SOCIOECONÔMICOS -DIEESE - Consumo alimentar da população do município de São Paulo., 1987. 
DURNIN, J.V.G.A - A longitudinal, multi-national study of the energy requirements of pregnant and lactating women. Nestlé Foundation Annual Report. 1982; 47-62.

DURNIN, J.V.G.A - Energy requirements of pregnancy: an integrate study in 5 countries: background and methodology. Nestlé Foundation Annual Report. 1986; 33-8.

DURNIN, J. V. G. A . - Energy requirements of pregnancy: na integration of the longitudinal data from the five-country study. Lancet. $1987 ; 2: 1131-33$.

FORBES, G.B. - Body composition: influence of nutrition, disease, growth, and aging. In: SHILS, M.E.; OLSON, J. A \& SHIKE, M. (eds) - Modern nutrition in health and disease. 8 ed. Philadelphia, Lea \& Febiger, 1994. p. 781-801.

GALEAZZI, M. A . M.; DOMENE, S. M. A . \& SICHIERI, R. - Estudo multicêntrico sobre consumo alimentar. Cadernos de Debate. 1997; (vol. Esp.).

GARNER, P.; KRAMER, M. S. \& CHALMERS, I. - Might efforts to increase birthweight in undernourished women do more harm than good? Lancet. 1992; 340: 1021-22.

GIBSON, R.S. - Food consumption of individuals. In:___ Principles of nutritional assessment. New York, Oxford University Press, 1990. p. 37-54

GUERI, M.; JUTSUM, P. \& SORHAINDO, B. - Anthropometric assessment of nutritional status in pregnant women: a reference table of weight-for-height by week of pregnancy. Am J Clin Nutr. 1982; 35: 609-11.

HARALDSDOTTIR, J. \& VAN STAVEREN,W.A - Food frequency. In: CAMERON, M.E. \& VAN STAVEREN, W. A .,ed. - Manual on methodology for food consumption studies. Oxford, Oxford University Press, 1988. P 925.

HORTA, B. L.; BARROS, F. C.; HALPERN, R. \& VICTORA, C. G. - Baixo peso ao nascer en duas coortes de base populacional no sul do Brasil. Cad Saúde Públ. 1996; 12 (suppl 1): 27-31.

HYTTEN, F.E. -Nutrition In: HYTTEN, F.E. \& CHAMBERLAIN, G. eds. Clinical physiology in obstetrics. Part 2. Nutrition e metabolism. Oxford: Blackwell Scientific Publications, 1980: 163-92p. 
IBGE - Instituto Brasileiro de Geografia e Estatística - Contagem da população: resultados relativos à população e domicílios - 1996. Rio de Janeiro; 1997. (IBGE - vol.,2).

INSTITUTE OF MEDICINE (USA). SUBCOMMITE ON NUTRITIONAL STATUS AND WEIGHT GAIN DURING PREGNANCY. Introduction In: - Nutrition during pregnancy. Washington, D. C., National Academy Press, 1990a. P. 27-36.

INSTITUTE OF MEDICINE (USA). SUBCOMMITE ON NUTRITIONAL STATUS AND WEIGHT GAIN DURING PREGNANCY. Energy requeriments, energy intake, and associated weight gain during pregnancy. In: Academy Press, 1990b. P. 137-75.

INSTITUTE OF MEDICINE (USA). SUBCOMMITE ON NUTRITIONAL STATUS AND WEIGHT GAIN DURING PREGNANCY. Total amount and pattern of weight gain: physiologic and maternal determinants In:

Nutrition during pregnancy. Washington, D. C., National Academy Press, 1990c. P. 137-75.

JACOBS, D.R. et al. - Validity and realiability of short physical activity history: cardia and Minnesota heart program. J Cardiopulmonary Rehabil. $1989 ; 9: 448-59$.

JAQUE-FORTUNATO, S. V.; KHODIGUIAN, N.; ARTAL, R. \& WISWELL, R. A - Body composition in pregnancy. Seminars in Perinatology 1996; 4: 340-42.

JELLIFE, D. B. \& JELLIFE, E. F. P. - Community nutritional assessment. New York: Oxford University Press, 1989.

JOHNSON, J. W. C.; LONGMATE, J. A \& FRENTZEN, B. - Excessive maternal weight and pregnancy outcome. Am J Obstet Gynecol. 1992; 167: 353-72.

JOHNSON,J.W.C. \& YANCEY,M.K. - A critique of the new recommendations for weight gain in pregnancy. Am J Obstet Gynecol.1996; 174: 254-58.

KEPPEL,K.G.\&TAFFEL,S.M. - Pregnancy-related weight gain and tetention: implications of the 1990 Institute of medicine guidelines. Am J Public Health. 1993; 83:1100-3. 
KRAMER, M. S. - Determinants of low birth weight: methodological assessment and meta-analysis. Bull World Health Organ. 1987; 65: 663-737.

KRASOVEC, R. \& ANDERSON, M. A ., ed. - Maternal nutrition and pregnancy outcomes: anthropometric assessment. Washington, D. C.; 1991 (Pan American Health Organization - Scientific Publication, 529).

KRASOVEC, R. - Weight in pregnancy: back grouns issues. In: $\&$ ANDERSON, M. A ., ed. - Maternal nutrition and pregnancy outcomes: anthropometric assessment. Washington, D. C.; 1991. P.15-28 ( Pan American Health Organization -Scientific Publication, 529).

LANGHOFF-ROOS,J.; LINDMARK,G.; KILBERG,E.; GEBRE-MEDHIN,M. Energy inteke and physical activity during pregnancy in relation to maternal fat accretion and infant birthweight. Br J Obstet. Gynaecol. 1987; 94: 1178-85.

LAWRENCE. M.; MCKILLOP, F. M. \& DURNIN, J. V. G. A . - Women who gain more fat during pregnancy may not have bigger babies: implications for recommended weight gain during pregnancy. British J Obstet Gynecol. 1991; 98: 254-59.

LECHTIG, A . - Predicting risk of delivering low birthweight babies: wich indicator is better? J Trop Pediatr 1988; 34: 34-40.

LEDERMAN, S.A. - The effect of pregnancy weight gain on later obesity. Obstet Gynecol. 1993; 82:148-55.

LEDERMAN,S.L.;PAXTON,A.;HEYMSFIELD,S.B.;WANG,J.;THORTON,J.\& PIERSON,R.N. - Body fat and water changes during pregnancy in women with different body weight and weight gain. Obstetrics \& Gynecology. 1997; 90: 483-8.

LOHMAN, T. G.; ROCHE, A S. \& MARTORELL, R. ed. - Anthropometric standardization reference manual. Human Kinetics Books, 1988.

LOPEZ, R. D.; TUDISCO, E.S.; ANDREAZZA, R.; SACHS, A.; SANTANA, R. M.; UCHIYMA, M.; KULAY, M. N. C. \& CAMANO, L. - Estimation of iron biovailability in overweight pregnant's diets. In: Abstracts World Congress of Gynecology and Obstetrics; 1988; Rio de Janeiro, Brasil.

LUKASKI, H. C.; SIDERS, W. A.; NIELSEN, E. J. \& HALL, C. B. - Total body water in pregnancy: assessment by using bioelectrical impedance. Am. J. Clin. Nutr. 1994; 59: 578-85. 
MANSON, J. E.; COLDITZ, G. A \& STAMPFER, M. J. - Parity, ponderosity, and the paradox of a weight-preoccupied society. JAMA. 1994; $271: 1788-90$. MERCHANT, K. \& MARTORELL, R. - Frequent reproductive cycling: does it lead to nutritional depletion of mothers? Progress in Food and nutrition science. $1988 ; 12: 339-69$.

MONTEIRO, C. A.; MONDINI, L.; SOUZA, A. L. M. \& POPKIN, B. M. - Da desnutrição para a obesidade: a transição nutricional no Brasil. In:

MONTEIRO, C. A. org. Velhos e novos males da saúde no Brasil - a evolução do país e de suas doenças. São Paulo, Ed. Hucitec, 1995. p. 247-55.

MONTEIRO, C.A . org. - Como e por que melhoram (ou pioram) os indicadores de saúde e nutrição na infância? $O$ caso da cidade de São Paulo na Segunda metade do século XX. São Paulo, 1999. Universidade de São Paulo - Núcleo de Pesquisas Epidemiológicas em Nutrição e Saúde.

MONTEIRO, C.A.; BENÍCIO, M. H. A \& ORTIZ, L.P. - Tendência secular do peso ao nascer no município de São Paulo. In: MONTEIRO, C.A . org. Como e por que melhoram (ou pioram) os indicadores de saúde e nutrição na infância? O caso da cidade de São Paulo na Segunda metade do século XX. São Paulo, 1999. Universidade de São Paulo - Núcleo de Pesquisas Epidemiológicas em Nutrição e Saúde.

MONTEIRO, C. A \& CONDE, W. L. - A tendência secular da obesidade segundo estratos sociais: nordeste e sudeste do Brasil, 1975-1989-1997. In: MONTEIRO, C. A org. Padrões de alimentação e doenças crônicas não transmissiveis no Brasil: subsidios para o estabelecimento de guias alimentares para população brasileira. São Paulo, 1999. Universidade de São Paulo - Núcleo de Pesquisas Epidemiológicas em Nutrição e Saúde.

MURPHY, S.P. \& ABRAMS, B.F. - Changes in energy intakes during pregnancy and lactation in national sample of US women. Am J Public Health. 1993; 83: 1161-63.

NAEYE, R. L. - Weight gain and the outcome of pregnancy. Am. J. Obstet. Gynecol. 1979; 135: 3-9.

NAJAS, M. S.; ANDREAZZA, R.; SOUZA, A.L. M.; SACHS, A; JULIANO, Y. \& TUDISCO, E. S. - Tratamento dietético da obesidade. Rev Nutr PUCCAMP. 1992; 5: 143-156. 
NAJAS, M. S.; ANDREAZZA, R.; SOUZA, A.L. M.; SACHS, A; GUEDES, A C. B.; SAMPAIO, L.R.; RAMOS, L. R. \& TUDISCO, E. S. - Padrão alimentar de idosos de diferentes estratos socioeconomicos residentes em localidade urbana da região sudeste, Brasil. Rev Saúde Pública. 1994; 28: 187-91.

NATIONAL RESEARCH COUNCIL - Energy. In: - Recommended dietary allowances. 10ed. Washington, D.C.: National Academy Press, 1989. p. 24-38.

NOGUEIRA, M. I. - Assistência pré-natal: prática de saúde a serviço da vida. São Paulo: Editora HUCITEC, 1994.

ÖHLIN, A. \& RÖSSNER, S. - Maternal body weight development after pregnancy. Int J Obesity. 1990; 14: 159-73.

ORGANIZACÍON MUNDIAL DE LA SALUD - Necessidades de energia y de proteínas . Ginebra; 1985. (FAO/ OMS/UNU - Série de Informes Técnicos, 724).

OSLER, M.; DE GROOT, L.C.P.G.M. \& ENZI, G. - Life-style: physicial activities and activities of daily living. Eur J Clin Nutr. 1991; 45 (suppl. 3): 138-51.

PARHAM,E.S.; ASTROM,M.F. \& KING,S.H. - The association of pregnancy weight gain with the mother's postpartum weight. J. Am. Diet Assoc. 1990; 90: 550-54.

PARKER, J.D. \& ABRAMS,B. - Prenatal weight gain advice: an examination of the recent prenatal weight gain recommendations of the Institute of Medicine. Obstet Gynecol 1992; 79:664-9.

PAXTON, A.; LEDERMAN, S.A.; HEYMSFIELD, S. B.; WANG, J.; THORNTON, J.C. \& PIERSON JR, R. N. - Anthropometric equations for studying body fat in pregnant women. Am J Clin Nutr. 1998; 67: 104-10.

PERRY, G.S.; YIP,R. \& ZYRKOWSKI, C. - Nutritional risk factors among lowincome pregnant US women: the centers for diease control and prevention (CDC) pregnancy nutrition surveillance system, 1979 thorugh 1993.

Seminars in Perinatology. 1995; 19: 211 - 21.

PICONE,T.A.; ALLEN,L.H.; SCHRAMM,M.M.; OLSEN,P.N. - Pregnancy outcome in north american women I effects of siet, cigarette smoking, and psychological stress on maternal weigth gain. Am. J. Clin. Nutr. 1982; 36: 1205-13. 
PIERS, L. S.; DIGGAVI, S. N.; THANGAM, S.; VAN RAAIJ, J. M. A .; SHETTY, P.S. \& HAUTVAST, J. G. A . J. - Changes in energy expenditure, anthropometry, and energy intake during the course of pregnancy and lactation in well-nourished indian women. Am J Clin Nutr. 1995; 61: 501-13.

PINHEIRO, A.B.V.; LACERDA, E.M.; BENZEECRY, E.H.; GOMES, M.C.S.; COSTA, V.M. - Tabela para avaliação de consumo alimentar em medidas caseiras. 2.ed. Rio de Janeiro: Produção Independente, 1994.

POPPITT, S. D.; PRENTICE, A M.; JÉQUIER, E.; SCHUTZ, Y. \& WHITEHEAD, R.G. - Evidence of energy sparing in Gambia women during pregnancy: a longitudinal study using whole-body calorimetry. Am J Clin Nutr. 1993; 57: 353-64.

PRENTICE, A. M.; SPAAIJ, C. J. K.; GOLDBERG, G.R.; POPPITT, S. D.; VAN RAAIJ, J. M. A .; TOTTON, M.; SWANN, D. \& BLACK, A . E. - Energy requirements of pregnant and lactating women. Eur J Clin Nutr. 1996; 50 (suppl 1): 82-110.

ROBINSON, S.; GODFREY, K.; OSMOND, C.; COX, V. \& BARKER, D. Evaluation of a food frequency quetionnaire use to assess nutrient intakes in pregnant women. Eur J Clin Nutr. 1996; 50: 302-8.

RODIN, J.; RADKE-SHARPE, N.; REBUFFÉ-SCRIVE, M. \& GREENWOOD, M.R.C. - Weight cycling and fat distribution. Int J Obesity.1990; 14:303-10.

RÖSSNER, S. - Pregnancy, weight gain in obesity. Int J Obesity. 1992; 16: 145-47.

ROSSO, P. - A new chart to monitor weight gain during pregnancy. Am J Clin Nutr. 1985; 41: 644-52.

ROWLAND,M.L. - Self-reported weight and height. Am. J. Clin. Nutr.1990 52(6):1125-33.

SACHS, A.; ANDREAZZA,R.; VIGORRITO, N.M.; SANTANA, R.M. LOPEZ, R.D.; USHYAMA, M. \& TUDISCO, E. S. - Atendimento de nutrição em ambulatório de pré-natal. In: Resumos do $1^{\circ}$ Congresso da Sociedade Brasileira de Alimentação e Nutrição; 1987 dez; São Paulo, Brasil.

SACHS, A ; TUDISCO, E.S.; ANDREAZZA, R.; SIGULEM, D. \& GUERRA, C. C. - Biodisponibilidade de ferro em dietas de trabalhadores rurais. Bol Soc Brasileira de Hematologia e Hemoterapia. 1989; 11: 107-10. 
SACHS, A ; VIGORITTO, N. M.; MATTAR, R. \& TUDISCO, E.S. - Padrão alimentar de gestantes adolescentes em São Paulo na $1^{\text {a }}$ consulta de pré-natal. In: Resumos da $2^{a}$ Jornada Latinoamericanas e $3^{\text {a }}$ Jornada Brasileira de Ginecologia Infanto-juvenil; 1990 mar; São Paulo, Brasil.

SACHS, A - Hábito alimentar e estado nutricional de pacientes idosos ambulatoriais, pré e pós-diagnóstico de doença pulmonar obstrutiva crônica. São Paulo, 1997. [Tese de doutorado - Universidade Federal de São Paulo].

SALLIS,J.F. et al - Phisical activity assessment methodology in five-city project. Am J Epidemiol. 1985; 121: 91-106.

SAMPAIO, R. L. - Avaliação da dieta de idosos residentes no município de São Paulo. São Paulo; 1997. [Dissertação de Mestrado - FCA/FEA/FSP USP].

SAS Institute - SAS/STAT [programa de computador]. Version 6. Edition. Cary, NC: SAS Institute, Inc., 1990.

SCHIEVE, L.A.;COGSWELL,M.E. \& SCANLON,K.S. - An empiric evaluation of the institute of medine's pregnancy weight gain guidelines by race.

Obstetrics \& Gynecology. 1998; 91: 878-84.

SCHOLL, T. A \& HEDIGER, M. L. - Weight gain, nutrition, and pregnancy outcome: findings from the Camden Study of teenage and minority gravidas. Seminars in Perinatology. 1995; 171-181.

SICHIERI, R. - Epidemiologia da obesidade. Rio de Janeiro: ed uerj, 1998

SMITH, D. E.; LEWIS, C.E.; CAVENY, J. L.; PERKINS, L. L.; BURKE, G. L. \& BILD, D. E. - Longitudinal changes in adiposity associated with pregnancy: The CARDIA Study. JAMA. 1994; 271: 1747-51.

SOUZA, A .L.M - Renda e escolaridade como determinantes da obesidade feminina nas diferentes regiões brasileiras. São Paulo; 1999 [Dissertação de mestrado - Faculdade de Saúde Pública da USP]

SUSSER, M. - Maternal weight gain infant birth weight, and diet: causal sequences. Am J Clin Nutr. 1991; 53: 1384- 96.

STEVENS-SIMON,C.; ROGHMANN,K.J. \& MCNARNEY,E.R. - Relationship of self-reported prepregnancy weight and weight gain during pregnancy to maternalbody habitus and age. J Am Diet Ass. 1992; 92: 85-87,1992. 
STEWART,A.W.; JACKSON,R.T.; FORD,M.A. \& BEAGLEHOLE,R. Understimation of relative weight by use of self-reported and height and weight. Am. J. Epidemiol. 1987; 125(1): 122-26.

THOMPSON, F. E.; MOLER, J. E.; FREEDMAN, L. S.; CLIFFORD, C.K.; STABLES, G.J. \& WILLETT,W.C. - Register of dietary assessment calibrationvalidation studies: a status report. Am J Clin Nutr. 1997; 65 (suppl): 1142S$7 S$.

TONKELAAR, I.; SEIDELL, J.C.; NOORD, P. A H.; BAANDERS-van HALEWIJN, E. A. \& OUWEHAND, I. J. - Fat distribution in relation to age, degree of obesity, smoking habits, parity and estrogen use: a cross-sectional study in 11.825 dutch women participating in the DOM-project. Int J Obesity. 1990; 14: 753-61.

TRIGO, M. - Metodologia de inquérito dietético: estudo do método recordatório de 24 horas. São Paulo; 1993. [Tese de doutorado - Faculdade de Saúde Pública da Universidade de São Paulo]

TUDISCO, E. S. - Prevalência do diabetes mellitus no municipio de São Paulo: aspectos nutricionais e alimentares. São Paulo; 1993. [Tese de doutorado - Escola Paulista de Medicina].

UNITED NATIONS/UN - How to weight and measure children-assessing the nutritional status of young children in household surveys. National Survey Capability Programme (Preliminary version). Departament of Technical Co-operation for Development and Statistical Office. New York, USA, 1986.

VAN RAAIJ, J. M. A.; VERMAAT-MIEDEMA, S. H.; SCHONK, C. M.; PEEK, M. E. M. \& HAUTVAST, J. G. A. J. - Energy requirements of pregnancy in The Netherlands. Lancet. 1987; 2: 953-55.

VAN RAAIJ, J.M.A; SCHONK, C. M.; VERMAAT-MIEDEMA, S. H.; PEEK, M. E. M. \& HAUTVAST, J. G. A . J. - Body fat mass and metabolic rate in Dutch women before, during, and after pregnancy: a reappraisal of energy cost of pregnancy. Am J Clin Nutr. 1989; 49: 765-72.

VIEGAS, O . A . C.; COLE, T. J. \& WHARTON, B. A . - Impaired fat deposition in pregnancy: na indicator for nutritional intervention. Am J Clin Nutr. 1987; 45: 23-8. 
VILLAR, J.; COGSWELL, M.; KESTLER, E.; CASTILLO, P.; MENENDEZ, R. \& REPKE, J. T. - Effect of fat and fat-free mass deposition during pregnancy on birth weight. Am J Obstet Gynecol. 1992; 5: 1344-52.

YASIN, S.; ALDERSON, M.R.; MARR, J.W.; PATTISON, D.C. \& MORRIS, J.N. - Assessment of habitual physical activity apart from occupation. Brit J prev soc Med. 1967; 21: 163-69.

YU, S. M. \& JACKSON, R. T. - Need for nutrition advice in prenatal care. J Am Diet Assoc. 1995; 9: 1027-29.

WASHBURN, R. \& MONTOYE, H. J. - The assessment of physical activity by questionnaire. Am J Epidemiol 1986; 123: 563-76.

WEIGEL,M.M.; NÁRVÁES,W.M.; LÓPEZ,A. FÉLIX,C.; LOPÉZ P. - Prenatal diet, nutrient intake and pregnancy outcome in urban ecuadorian primiparas. Arch Latinoamericano nutr. 1991; XLI: 21-37.

WILLETT, W. C.- Food frequency methods. In: Nutritional epidemiology. New York, Oxford University Press, 1990 a. p. 69-91

WILLETT, W. C. - Reproducibility and validity of food-frequency questionnaires. In: Nutritional epidemiology. New York, Oxford University Press, 1990b. p. $92-126$

WILLETT, W. C. - Implications of total energy intake for epidemiologic analyses. In: Nutritional epidemiology. New York, Oxford University Press, 1990c. p. $92-126$

WILLETT, W. C. - Future directions in the development of food-frequency questionnaries. Am J Clin Nutr. 1994; 59(suppl): 171S-4S.

WILLETT, W. C.; HOWE,G. R. \& KUSHI, L.H. - Adjustment for total energy intake in epidemiologic studies. Am J Clin Nutr. 1997; 65(suppl): 1220S-8S.

WHO COLLABORATIVE STUDY - Maternal anthropometry and pregnancy outcomes. Bulletin of the World Health Organization. 1995; 73 (suppl): 1-98.

WOLFE, H. M.; ZADOR, I. E.; GROSS, T. L. MARTIER, S. S. \& SOKOL, R. J. The clinical utility of maternal body mass index in pregnancy. Am J Obstet Gynecol. 1991; 164: 1306-10. 
WORLD HEALTH ORGANIZATION - Pregnant and lactating women. In:__ Physical status: the use and interpretation of anthropometry. Geneve; 1995a. (WHO - Technical Report Series, 854] p.37-121

WORLD HEALTH ORGANIZATION - Recommended measurement protocols derivation of indices. In: Physical status: the use and interpretation of anthropometry. Geneve; 1995b. (WHO - Technical Report Series, 854) p. 424-38.

WORLD HEALTH ORGANIZATION - Obesity - preventing and managing the global epidemic. Report. Geneva; 1997 (Report of a WHO Consultation on Obesity). 
ANEXOS 122

ANEXOS 
PARTE 2: A MULHER

nome

código

Q1. Qual c a sua idade?

anos

$1 \quad 1 \quad$ data de nascimento

Q2. Estado onde nasceu? ( coloque o nome intciro do Estado)

( )

(49) est rangeiro

Q3. Temipo de residência em São Paulo:

(1) nasccu em São Paulo

(2) menos de I ano

(3) I ano

(4) 2 a 4 anos

(5) 5 a 9 anos

(6) 10 anos ou mais

(9) กล̃o sabe

Q4. Raça

(1) Branca

(2) Negra

(3) Mulata

(4) Anarela

Q5. Qual o seu estado civil?

(1) solteira

(2) casada

(3) separada

(4) viuva

(5) outro

Q6. Atualmente mora com o seu marido/companheiro?

(1) $\mathrm{Sim}$

(2) Não $\Rightarrow$ (siga Q8)
Q7. Há quanto tempo está com o seu companheiro?
(1) - de 3 meses
(2) de 3 a 5 meses
(3) de 6 a 11 meses
(4) de 1 a 2 anos
(5) + de 2 anos

Q8. Com quem mora ? ( somente para as mulheres sem companheiro)

(1) mora con os pais/familiares

(2) mora sozinha

(3) mora com os amigos

(4) mora com os filhos

(5) mora no local de trabalho

(6) Amparo Maternal

(7) outro:

Q9. Freqüentou escola?

Sim (1)

Não (2)__ $\Rightarrow$ (siga Q13)

Q 10.Até que ano/série cursou? série/ano

(9) não sabe

Q11. De que grau?

(1) $1^{\circ}$ grau

(2) $2^{\circ}$ grau

(3) $3^{\circ}$ grau

(4) antigo primário

( 5 ) antigo ginásio

(6) antigo cientifico/normal

( 7 ) outro

( 9 ) não sabe

Q12. Fez supletivo?

(1) não

(2) de $1^{\circ}$ grau completo

(3) de $2^{\circ}$ grau completo

Apenas para quem tem menos de 4 anos de escolaridade ou nunca frequentou escola

Q13. Sabe ler e escrever?
(i) $\mathrm{Sim}$
(2) Não 
ANEXO 2

PARTE 3: OS ANTECEDENTES OBSTÉTRICOS E MORBIDADE (FICHA CLINICA)

nome

código

Q1. Quantas vezes você já engravidou? (incluir gestação atual) gestações

Q2. Quantos filhos (nascidos vivos) teve até hoje no total? filhos

Q3. Você tcve anteriormente e qual foi o número dos seguintes eventos?

\begin{tabular}{|l|l|l|l|}
\hline Evento & $\begin{array}{l}\text { Sim } \\
(\text { ( })\end{array}$ & $\begin{array}{l}\text { Não } \\
(2)\end{array}$ & $\begin{array}{l}\text { Quantas } \\
\text { vezes? }\end{array}$ \\
\hline Q4. aborto (< de 28 semanas ) & & & Q5. \\
\hline Q6 natimorto (bebê nasceu morto) $\left(^{*}\right)$ & & & Q7. \\
\hline
\end{tabular}

Códigos

IX (I)

$2 \times(2)$

somente para nascidos vivos

\begin{tabular}{|l|l|l|l|}
\hline Q8. morte neonatal (óbito antes de 28 dias) (*) & & & Q9 \\
\hline Q10. baixo peso ao nascer (< de $2500 \mathrm{~g})\left(^{*}\right)$ & & & Q11. \\
\hline Q12. prematuro (<37 semanas) $\left(^{*}\right)$ & & & Q13. \\
\hline
\end{tabular}

$\left(^{*}\right)$ checar os dados com a gestante

Q14. Quando foi o seu último parto?
( 8 ) não se aplica ( $1^{\circ}$ gestação)
(1) menos de 1 ano
(2) I ano -- 1,5 anos
(.3) 1,5 anos -- 2 anos
(4) mais que 2 anos

Q15. Ondc ocorreu o seu último parto?
( 8 ) não sc aplica ( $1^{\circ}$ gestação)
(1) $\mathrm{cm}$ casa
( 2 ) no hospital
Qual 
Vocè jả teve alguns desses problemas de saúde?

\begin{tabular}{|l|l|l|l|}
\hline \multirow{2}{*}{ Problema } & \multicolumn{3}{c|}{ Ocorrência } \\
\hline & (1) sim & (2) não & (9) não sabe \\
\hline Q16 cardiopatia & & & \\
\hline Q17 hipertensão arterial & & & \\
\hline Q18 diabetes & & & \\
\hline Q19 endocrinopatias & & & \\
\hline Q20 infecção urinária e pielonefrite & & & \\
\hline Q21 luberculose & & & \\
\hline Q22 rubéola & & & \\
\hline Q23 m.Chagas & & & \\
\hline Q24 cervicite, vaginite(corrimento) & & & \\
\hline Q25 csquistossomose & & & \\
\hline Q26 hepatite & & & \\
\hline Q27 AlDS & & & \\
\hline Q28 outros $\left(^{*}\right)$ & & & \\
& & & \\
& & & \\
& & & \\
\end{tabular}

$\left.{ }^{\star}\right)$ incluir infeções genitais cspecificadas nos antecedentes ginecológicos da Ficha Clinica 
Q1. Você trabalhou desde o inicio da gravidez?
(1) $\mathrm{Sim}$
(2) Nào $\curvearrowleft($ signa Q3)

Q2. Ha quanto tempo? meses $\Rightarrow$ (siga Q5)

( ) antes da gravidez

( ) inicio da gravidez

mescs após

Q3. Por que não está trabalhando?

(1) nunca trabalhou fora de casa

(2) esıá descmpregada

(3) é aposentada/pensionista

(4) cstá de licença/afastada

(5) outros motivos $\rightarrow$

Quais?
Apenas para quem trabalha/ou na gravidez atual (Q5 a Q8)

Q5. O que faz no trabalho? (ou o que fazia quando estava trabalhando)

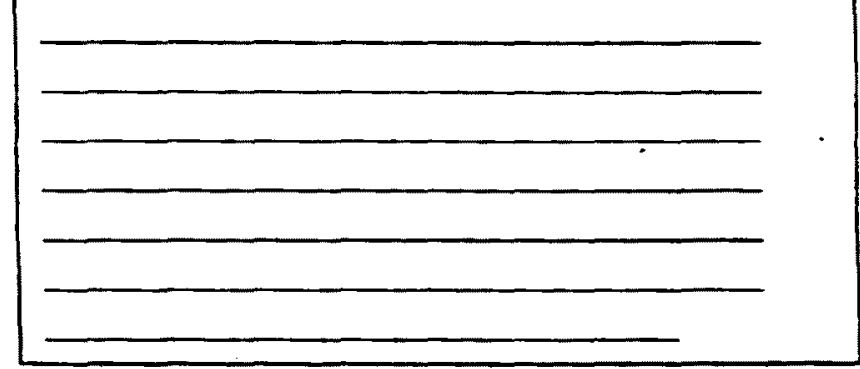

Q6. Quantos dias trabalha (trabalhava) na scmana? dias

Q7. Quantas horas trabalha ( trabalhava) por dia? horas

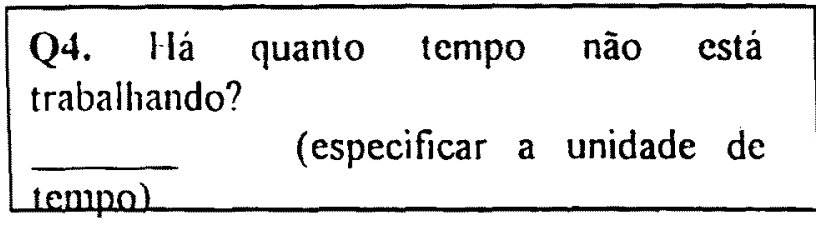

Q8. O local em que você trabalha oferece: ( marque mais de um " $x$ "se necessário)

(0 1 ) cesta básica

(02) vale refeição

(04) vale alimentação

(08) refeitório no local de trabalho

(16) refeições (casa de familia)

(32) nenhuma das anteriores 
PARTE 7: A ATIVIDADE FÍSICA

nome

código

Q1. Vocè acha que modificou suas atividades fisicas depois que ficou sabendo que estava grávida?

(1) sim, diminui

(2) sim, aumentei

( 3 ) não modifiquei

(9) não sabe referir

Q2. Nas suas atividades de casa (laval, passar, larrer, limpar, ełc.) você tem alguém que a ajude regularmente?
(1) $\mathrm{sim}$
(2) กล̃o

Q3. Con que frequência, na última semana, realizou as seguintes atividades (incluir o tempo e as atividades de trabalho fora quando este estiver relacionado com atividades domésticas como: faxincira, empregada doméstica, babá e ctc.)?

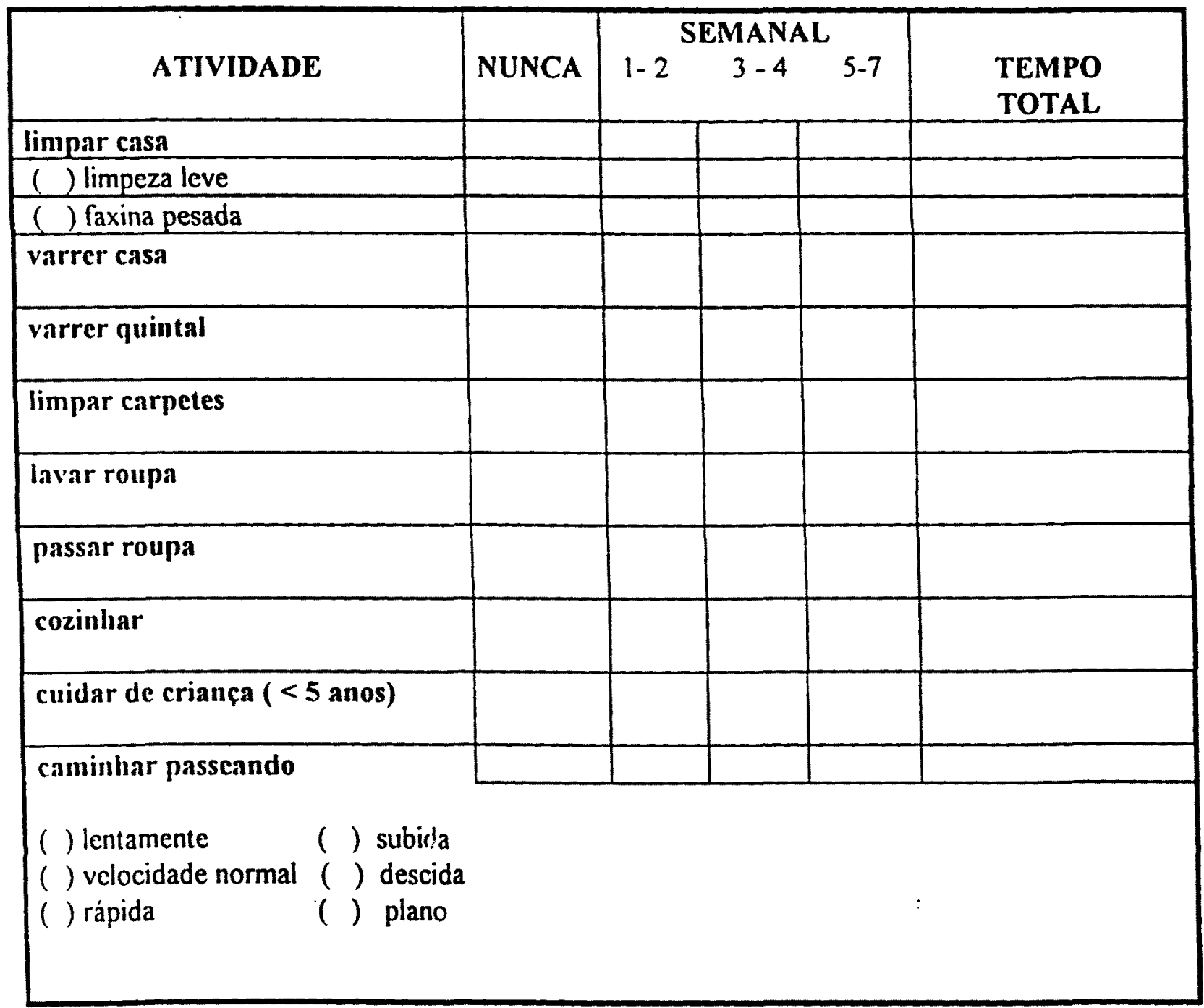




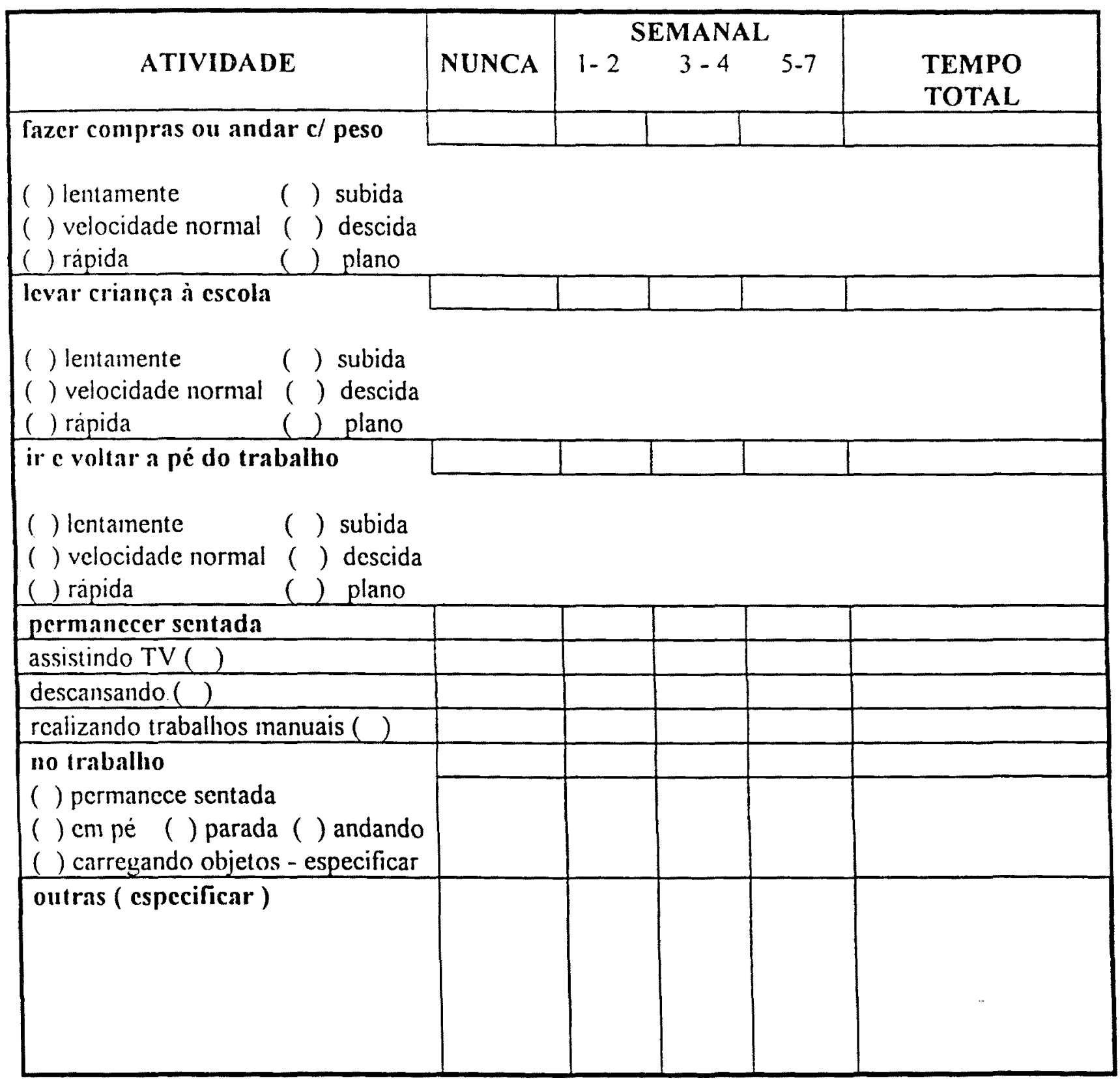

Q4.Quantas horas, por dia, dormiu na última semana? ( incluir horas de sono durante o dia) total de horas 
PARTE 7 : ATIVIDADE FISICA (B) nome código

Q1. Desde o mês ( mês em que foi aplicado o questinario anterior de

$\mathrm{AF}$ ) você está trabalhando fora de casa?

(1) $\sin$

(2) กล̃o

Q2. Quantos meses você trabalhou? meses

Q3. O que faz no trabalho?

Q4. Quantos dias trabalha na semana? dias

Q5. Quantas horas trabalha por dia? horas

\section{DATA}


PARTE 10: O CIGARRO

E OUTRAS DROGAS nome

\section{código}

Q1. Vocè fuma?
(1) $\mathrm{Sim}$
(2) Não
$\Rightarrow$ (siga questão 5)
(3) Fumava antes de ficar grávida
$\Rightarrow$ (siga questão 3 )

Q2. Quantos cigarros você fuma, em média, por dia? cigarros $\Rightarrow$ (siga questão 5)

Q3. Há quanto tempo você parou de fumar?

(especificar tempo)

näo preencher

Q4. Quantos cigarros você fumava, em média, por dia? cigarros

Você já fez uso de algumas dessas drogas?

E desde o início da gravidez até agora, você já fez uso de algum deles?

\begin{tabular}{|l|l|l|}
\hline Droga & Sim & Não \\
\hline Q5. remédio para emagrecer & & \\
\hline Q6. remédio para dormir & & \\
\hline Q7. calmantes & & \\
\hline Q8. maconha & & \\
\hline Q9. crack & & \\
\hline Q10. cocaina & & \\
\hline Q11. LSD & & \\
\hline Q12. heroina & & \\
\hline Q13. nutros & & \\
\hline Quais? & & \\
\hline
\end{tabular}




\section{PARTE 8: A ALIMENTAÇÃO}

nome

código

\section{data :}

Q1. Você acha que modificou a sua dieta (forma de comer, preferências, imlolèrancias e éc) desde que ficou sabendo que estava grávida?
(1) $\operatorname{Sim}$
(2) Não
$\Rightarrow$ (siga questão 5)
(3) Não sabe referir
$\Rightarrow$

Q2. De que forma você alterou a sua alimentação?
(1) Aumentou as quantidades
(2) Diminui as quantidades
(3) Mudou as preferências
Especificar:

Q3. Você recebeu alguma orientação para modificar a sua alimentação neste periodo?
(1) $\mathrm{Sim}$
(2) Não $\Rightarrow$ (siga questão 5)

Q4. Quem orientou esta modificação?
(1) Médico
(2) Enfermeira
(3) Nutricionista
(4) Outro profissional de saude
(5) Familiares
(6) Amigos
(7) Outros
Espccificar:. 
Quais as rcfeições que você costuma fazer?

\begin{tabular}{|l|l|l|}
\hline refeicões & (1) sim & (2) não \\
\hline Q5. cafö da manhã & & \\
\hline Q6. lanche da manhã & & \\
\hline Q7. almoço & & \\
\hline Q8. lanche da tarde & & \\
\hline Q9 jantar & & \\
\hline Q10. lanche da noite & & \\
\hline Outras rcfciçōes? & & \\
\hline
\end{tabular}

Q11. Quantas pessoas (adultos c crianças) normalmente tomam refeção em sua casa?

Númcro de adultos

Número de crianças $(>=18$ anos $)$

Atencior Q12. Ver follas anexas:

Qual n tipo de ólen ou gordura que é utilizado no preparo de sua alimentacão?

\begin{tabular}{|l|l|l|l|}
\hline & TIPO* & FREQ. DA COMPRA** & QUANTIDADE*** \\
\hline ólen vegetal & Q13. & Q13A & Q13B \\
\hline gordura vegetal & Q14. & Q14A. & Q14B. \\
\hline gordura animal & Q15 & Q15A & Q15B \\
\hline
\end{tabular}

(*) Especificar: ólco vegetal - soja. algodão. amendoin c cle. gorlura vegetal - margarina. gordura hidrogenada $\mathrm{c}$ ctc. gordura animal - mantciga. banha de porco c ctc

(**) Escrerer se a frequéncia dı compra ć scmanal. quinzenal. mensal. bimcstral. clc. Caso não compre ou não utili/c. ou não saiba. csercver não compra. não usa ou não sabc.

(***) Especificar a quantidadc, por ocasião da compra. cm litros ou quilos. Caso não saiba. cscrcver não sabc.

Q16. Qual a quantidade de açucar que sua familia gasta por semana? 
Q12. Na última semana com que frequência comeu os seguintes alimentos?

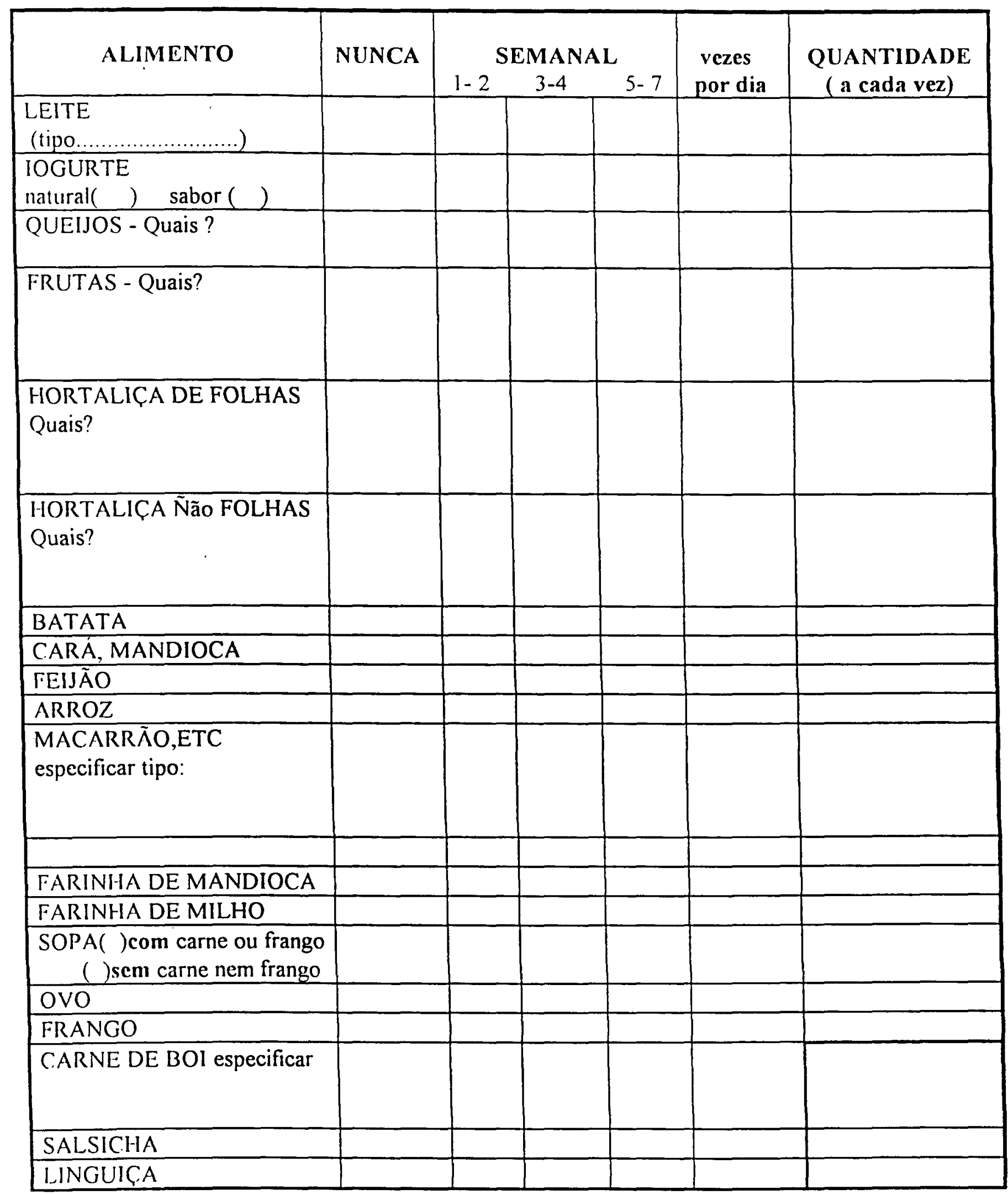




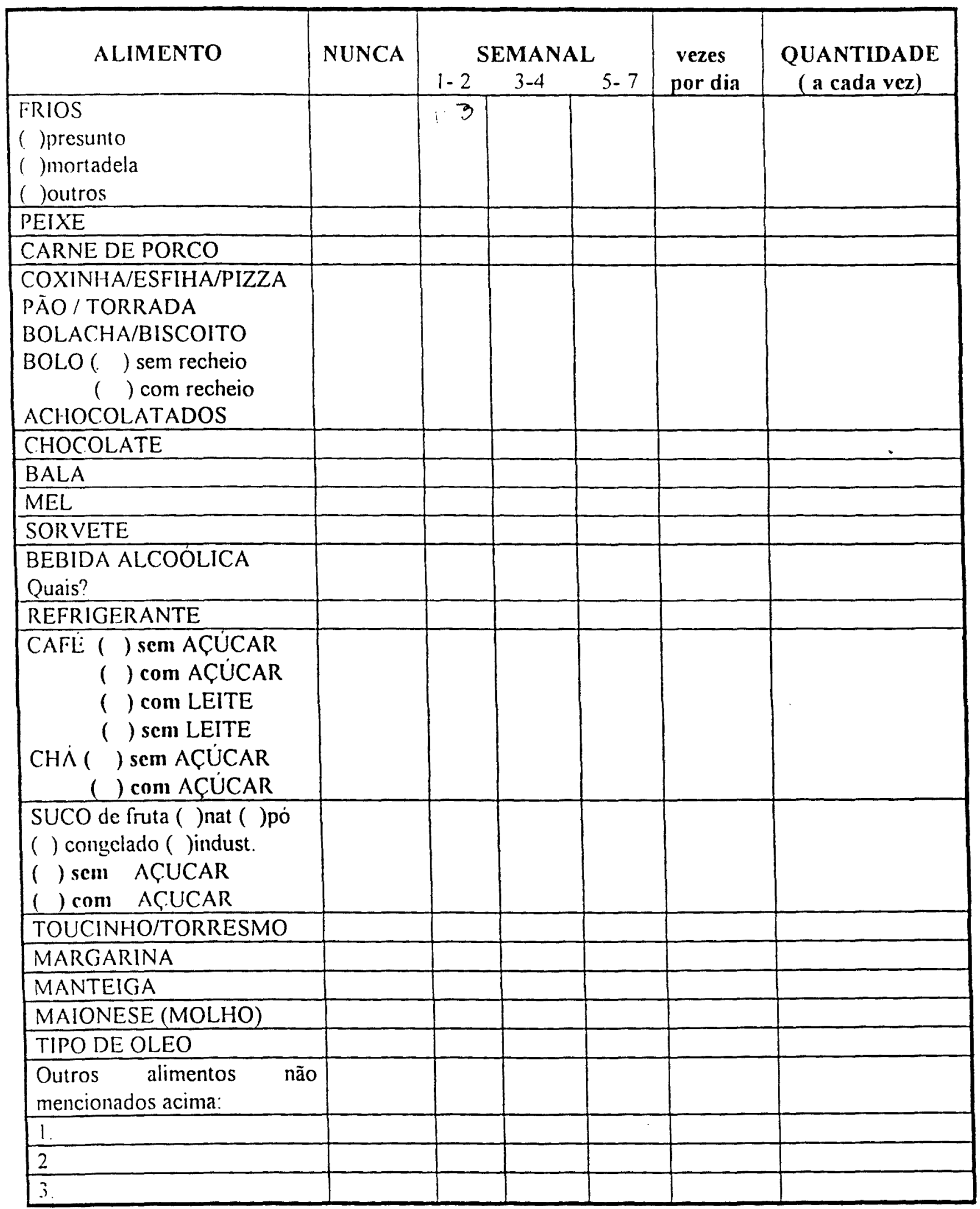




\begin{tabular}{|c|c|c|c|c|c|c|}
\hline \multirow{2}{*}{$\begin{array}{l}\text { Outros alimentos não } \\
\text { mencionados acima: }\end{array}$} & \multirow[t]{2}{*}{ NUNCA } & \multicolumn{3}{|c|}{ SEMANAL } & \multirow{2}{*}{$\begin{array}{l}\text { vezes } \\
\text { por dia }\end{array}$} & \multirow{2}{*}{$\begin{array}{l}\text { QUANTIDADE } \\
\text { ( a cada vez) }\end{array}$} \\
\hline & & $1-2$ & $3-4$ & $5-7$ & & \\
\hline \multicolumn{7}{|l|}{4.} \\
\hline \multicolumn{7}{|l|}{5.} \\
\hline 6. & & & & & & \\
\hline
\end{tabular}

Classificar o grau de dificuldade, utilizando o seguinte código:

(1) sem dificuldade.

(2) com dificuldade,realizou o inquérito.

(3) com dificuldade, não foi possivel realizar o inquérito.

obs:

data 


\section{ANEXO 8}

Gasto energético (múltiplos da TMB) para realização de determinas atividades físicas para o sexo feminino (OMS,1985)

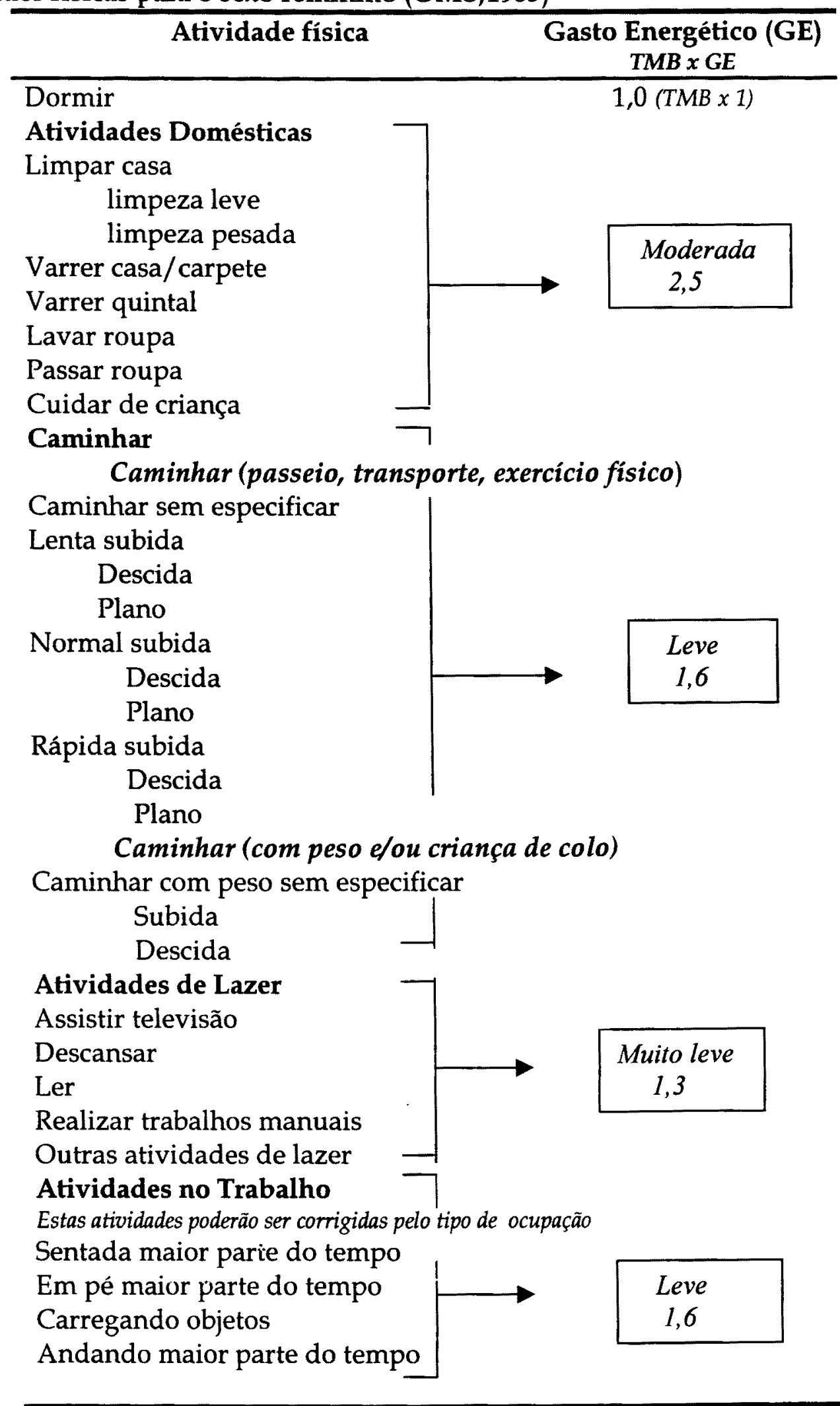




\section{ANEXO 9}

Média e desvio-padrão dos índices antropométricos das gestantes da coorte e das perdas de seguimento por abandono.

\begin{tabular}{|c|c|c|c|c|}
\hline Índices & Coorte & Perdas & $\mathbf{F}^{*}$ & $\mathbf{p}$ \\
\hline antropométricos & Média DP & Média DP & & \\
\hline Estatura (cm) & $158,5 \quad 5,70$ & $159,27 \quad 6,50$ & 0,55 & 0,458687 \\
\hline Peso pré-gestacional (kg) & $57,7 \quad 9,1$ & $61,7 \quad 14,7$ & 4,43 & 0,036396 \\
\hline Peso inicial (kg) & $58,6 \quad 9,8$ & $64,1 \quad 14,1$ & 7,59 & 0,006371 \\
\hline $\operatorname{IMC} C_{P G}\left(\mathrm{~kg} / \mathrm{m}^{2}\right)$ & $22,0 \quad 3,5$ & $24,2 \quad 4,6$ & 2,79 & 0,096161 \\
\hline $\operatorname{IMC}$ inicial $\left(\mathrm{kg} / \mathrm{m}^{2}\right)$ & $23,3 \quad 3,7$ & $24,9 \quad 4,5$ & 4,84 & 0,028831 \\
\hline \multicolumn{5}{|l|}{${ }^{*}$ Teste $t$ de Student } \\
\hline Idade gestacional (sem.) & $11,4 \quad 2,8$ & $24,9 \quad 4,5$ & - & - \\
\hline
\end{tabular}


ANEXO 10

Grau de dificuldade na aplicação do inquérito de freqüência de consumo de alimentos nos três periodos da gestação $(n=149)$

\begin{tabular}{cccc}
\hline & \multicolumn{3}{c}{ Período } \\
\cline { 2 - 4 } Grau de dificuldade & Primeiro & Segundo & Terceiro \\
& $n(\%)$ & $n \cdot(\%)$ & $n(\%)$ \\
\hline Sem dificuldade & $110(73,8)$ & $130(87,2)$ & $134(89,9)$ \\
Com dificuldade & $20(13,4)$ & $10(6,7)$ & $9(6,0)$ \\
Sem informação & $19(12,8)$ & $9(6,0)$ & $6(4,0)$ \\
\hline $\mathrm{N}$ & 149 & 149 & 149 \\
\hline
\end{tabular}




\section{ANEXO 11}

Lista dos alimentos consumidos por 13 gestantes a partir do registro alimentar de 3 dias. 


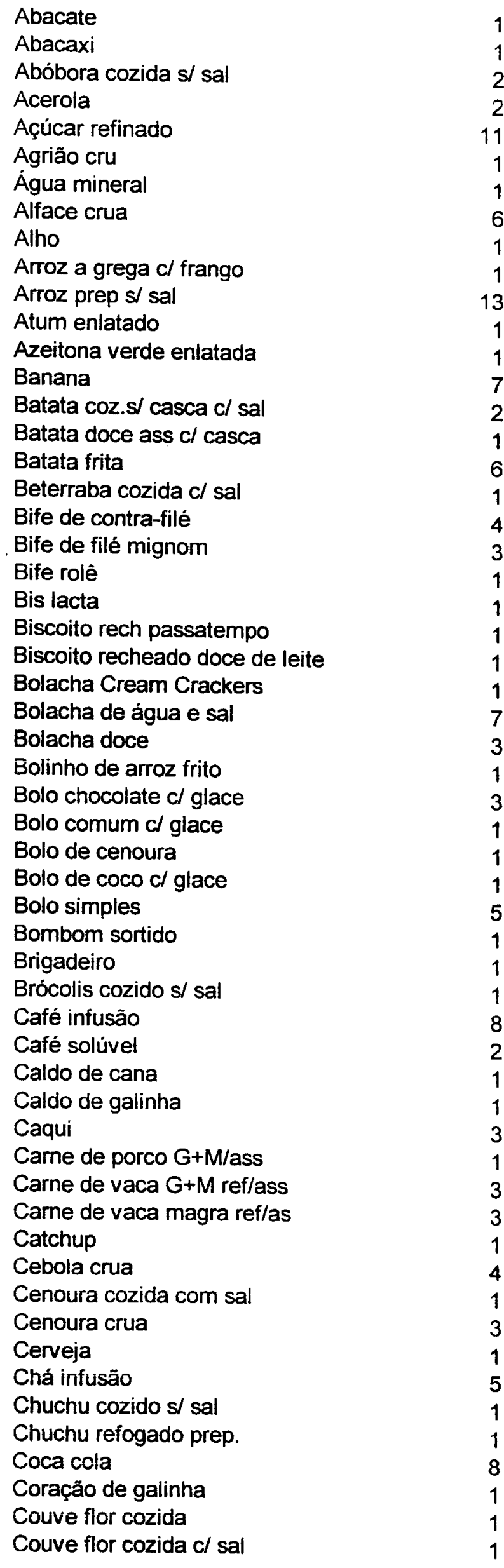


Couve refogada prep

Coxinha de galinha

Cremogema

Cuscuz de milho

Doce de leite

Ervilha verde enlatada

Escarola cozida

Escarola/ chicória crua

Fango asa ens.s/ pele

Farinha de mandioca

Farofa preparação

Feijão preparação

Frango asa ass cl pele

Frango cozido

Frango cozido o/ pele

Frango $c x$ ass cr pele

Frango cx ensop s/ pele

Frango peito assado s/ pele

Frango peito ens. $s /$ pele

Frango peito frito s/ pele

Frango sobcx fta s/ pele

Frango sobrecoxa frita cl pele

Fruta do conde

Gelatina pronta

Goiaba

Hamburger ol $10 \%$ gord

Hamburger de vaca

Hamburguer Mac Donaids

logurte dan"up morango

logurte natural danone

logurte polpa morango

logurte Sabor frutas

Kiwi

Laranja

Leite B

Leite C

Leite em pó integral

Lentilha cozida

Linguiça vaca/porco

Maça ci casca

Macarrão a bolonhesa

Macarrão ao sugo

Macarrão $\mathrm{c} /$ molho simples

Macarrão cozido

Maionese

Maionese salada

Mamão papaia

Mandioca cozida

Mandioquinha cozida

Manteiga c.' sal

Manteiga s/ sal

Margarina cremosa $\mathrm{c} / \mathrm{sal}$

Margarina cremosa s/ sal

Melancia

Melão

Moela crua 
Molho de tomate para macarrão

Molho $\mathrm{p} /$ carne ass/grelh 1

Mortadela 5

Mosiarda 1

Mucilon milho 1

Nescau pó 3

Óleo de oliva 2

Óleo de soja

Omelete simples 1

Ovo cozido 3

Ovo frito 4

Pão de forma 7

Pão de milho caseiro 1

Păo de queijo 4

Pão doce recheado caseiro 1

Pão doce s/ recheio 1

Pão frânces 13

Pão integral caseiro 3

Pastel de came 1

Peito de peru defumado 1

Peixe a milanesa 2

Peixe ensopado 1

Pepino cru 2

Pera 2

Pimentão cozido 2

Pimentão recheado 1

Pizza de calabreza 1

Pizza de mussarela 2

Presunto 5

Pudim de leite condensado 1

Pure de batata leite/marg 2

Queijo minas fresco 1

Queijo mussarela 5

Queijo prato 1

Quiabo cozido s/ sal $\quad 1$

Refrigerante diet 1

Repolho cru 1

Requeijã cremoso 1

Sagu 1

Sal 1

Salada de batata 1

Salada de frutas 1

Salame cozido 1

Salsicha 3

Sardinha eniatada no óleo 2

Sopa came c/ legumes s/ mac 2

Sopa de carne $\mathrm{c} / \operatorname{leg} \mathrm{c} / \mathrm{mac} \quad 1$

Sopa de feijāo com macarrão 1

Sopa de legumes s/ camc ol mac 1

Sopa leg s/ carne c/ mac 1

Sorv creme 1

Sorv napolitano 1

Suco de abacaxi enlatado 1

Suco de caju 2

Suco de frutas 1

Suco de goiaba diluido $\quad 1$ 
Suco de laranja enlatado

Suco de laranja fresca

Suco de limão fresco

Suco de maracujá

3

Suco tang laranja

2

Tangerina

3

Tomate cru

6

Torta de frango caseira 1

Torta de limão 1

Torta de palmito e ervilha 1

Uva comum 2

Uva tipo itália 2

Vagem cozida $c /$ sal $\quad 1$

Vinagre 4

Vitamina frutas/leite 3

Yakult 1 